\title{
Uncertainties in global aerosol simulations: Assessment using three meteorological data sets
}

\author{
Xiaohong Liu, ${ }^{1,2}$ Joyce E. Penner, ${ }^{1}$ Bigyani Das, ${ }^{3}$ Dan Bergmann, ${ }^{4}$ Jose M. Rodriguez, ${ }^{3,5}$ \\ Susan Strahan, ${ }^{3}$ Minghuai Wang, ${ }^{1}$ and Yan Feng ${ }^{1,6}$ \\ Received 2 November 2006; revised 1 February 2007; accepted 13 March 2007; published 13 June 2007.
}

[1] Current global aerosol models use different physical and chemical schemes and parameters, different meteorological fields, and often different emission sources.

Since the physical and chemical parameterization schemes are often tuned to obtain results that are consistent with observations, it is difficult to assess the true uncertainty due to meteorology alone. Under the framework of the NASA global modeling initiative (GMI), the differences and uncertainties in aerosol simulations (for sulfate, organic carbon, black carbon, dust, and sea salt) solely due to different meteorological fields are analyzed and quantified. Three meteorological data sets available from the NASA Goddard Data Assimilation Office (DAO) general circulation model (GCM), the Goddard Institute for Space Studies (GISS) GCM, version II' and the NASA Goddard Global Modeling and Assimilation Office (GMAO), finite-volume GCM (FVGCM) are used to drive the same aerosol model. The global sulfate and mineral dust burdens with FVGCM fields are $40 \%$ and $20 \%$ less than those with DAO and GISS fields, respectively, due to its larger precipitation. Meanwhile, the sea salt burden predicted with FVGCM fields is $56 \%$ and $43 \%$ higher than those with DAO and GISS, respectively, due to its stronger convection especially over the Southern Hemispheric Ocean. Sulfate concentrations at the surface in the Northern Hemisphere extratropics and in the middle to upper troposphere differ by a factor of 3 between the three meteorological data sets. The agreement between model calculated and observed aerosol concentrations in the surface source regions is similar for all three meteorological data sets. Away from the source regions, however, the comparisons with observations differ greatly for DAO, FVGCM, and GISS, and the performance of the model using different meteorological data sets varies depending on the site and the compared species. Sensitivity simulations with the NASA GEOS-4 assimilated fields show that the interannual variability of aerosol concentrations can be higher than a factor of 2 depending on the location and season, which is generally, however,

smaller than the differences due to using different meteorological data sets. Global annual average aerosol optical depth at $550 \mathrm{~nm}$ is $0.120-0.131$ for the three meteorological data sets. However, the contributions from different aerosol components to this total optical depth differ significantly, which reflects differences in the aerosol spatial distributions. The global annual average anthropogenic and all-sky aerosol direct forcing at the top-of-the atmosphere is estimated to be $-0.75,-0.35$, and $-0.40 \mathrm{~W} \mathrm{~m}^{-2}$ for DAO, FVGCM, and GISS fields, respectively. Regional differences can be much larger (by a factor of 4-5) in the tropics over the ocean and in the polar regions.

Citation: Liu, X., J. E. Penner, B. Das, D. Bergmann, J. M. Rodriguez, S. Strahan, M. Wang, and Y. Feng (2007), Uncertainties in global aerosol simulations: Assessment using three meteorological data sets, J. Geophys. Res., 112, D11212, doi:10.1029/2006JD008216.

\footnotetext{
${ }^{1}$ Department of Atmospheric, Oceanic and Space Sciences, University of Michigan, Ann Arbor, Michigan, USA.

${ }^{2}$ Now at the Pacific Northwest National Laboratory, Richland, Washington, USA

${ }^{3}$ Goddard Earth Science and Technology Center (GEST), University of Maryland Baltimore County, NASA Goddard Space Flight Center, Greenbelt, Maryland, USA.
${ }^{4}$ Lawrence Livermore National Laboratory, Livermore, California, USA.
${ }^{5}$ Rosenstiel School of Marine and Atmospheric Science, University of Miami, Miami, Florida, USA.
${ }^{6}$ Now at Scripps Institution of Oceanography, University of California,

Copyright 2007 by the American Geophysical Union. 0148-0227/07/2006JD008216
} 


\section{Introduction}

[2] Aerosols are one of the most important anthropogenic agents that perturb the radiation balance of Earth and perturb global climate. Increasing concentrations of anthropogenic aerosols may be partially counteracting the warming effects of greenhouse gases by an uncertain, but potentially large, amount. This in turn leads to large uncertainties in the sensitivity of climate to human perturbations and therefore also in the projections of future climate change [Penner, 2004; Andreae et al., 2005]. Various aerosol types (sulfate, carbonaceous aerosol, mineral dust, and sea salt) contribute to this effect on climate. These aerosols scatter and absorb incoming solar radiation increasing the planetary albedo (the direct effect) and they also enhance the albedo and extent of clouds by increasing the number of cloud droplets (the first indirect effect or Twomey effect) and by changing the precipitation efficiency of clouds (the second indirect effect or Albrecht effect) [e.g., Intergovernmental Panel on Climate Change (IPCC), 2001; Twomey, 1977; Twomey, 1991; Charlson et al., 1992; Lohmann et al., 1999a; Rotstayn and Penner, 2001].

[3] Multicomponent aerosol modules in global models have been developed and thus provide a much needed seasonal and global characterization of aerosol. However, differences in model complexity, physical and chemical schemes, meteorology, and the source strengths used in different models result in large differences in simulated aerosol concentrations [Textor et al., 2006]. This together with differing assumed or predicted aerosol size distributions, hydroscopic and optical properties, mixing status (internal versus external) between aerosols, and response of aerosols to relative humidities lead to large uncertainties in aerosol direct forcing estimations. The uncertainties in aerosol indirect forcing can be even larger due to the parameterizations used in models to describe the interactions between aerosol and clouds [Chen and Penner, 2005]. Current confidence in the estimates of aerosol radiative forcing is "low" for the sulfate direct effect and "very low" for both the direct effects of carbonaceous aerosols and the indirect effect [IPCC, 2001]. Thus a rigorous validation with observations and detailed model intercomparisons are needed.

[4] Early model intercomparisons [Barrie et al., 2001; Lohmann et al., 2001; Roelofs et al., 2001; Rasch et al., 2000a] mainly focused on sulfur related species, and the 2001 IPCC intercomparison included all aerosol components [Penner et al., 2002]. Comparisons with observations in these studies were based on surface or aircraft measurements. These studies indicated the large variance of model results arising from differences in parameterization schemes and meteorology. Satellite-retrieved total aerosol optical depth provides global coverage of the aerosol spatial distribution and can be used as a measure of aerosol column burden. Penner et al. [2002] presented a comparison of three different analysis of satellite-retrieved aerosol optical depth based on the Advanced Very High Resolution Radiometer (AVHRR)measured radiance with optical depths derived from six different models. The model-derived clear-sky reflected shortwave radiation was also compared with satellitemeasured reflectivities derived from the Earth Radiation Budget Experiment (ERBE) satellite. Kinne et al. [2003] intercompared the aerosol optical depth of seven global models and compared the model aerosol optical depth with the Aerosol Robotic Network (AERONET), Total Ozone mapping Spectrometer (TOMS), and the Moderate Resolution Imaging Spectroradiometer (MODIS) observations, although they did not specify similar source strengths for the aerosols.

[5] The ongoing AeroCom initiative was created to provide a platform for detailed evaluation of aerosol simulations in global models. This analysis permits an understanding of model differences, allows modelers to eliminate weak components, and to improve the simulated aerosol properties. Textor et al. [2006] analyzed the life cycles of aerosols as simulated by 16 global aerosol models, and quantified the differences among the models for the sources and sinks, burdens, particle sizes, water uptake, and spatial distributions. The different emissions used in this study, and the contrasting particle sizes for dust and sea salt generally lead to higher differences in these species than those of aerosols in the fine particle range such as sulfate, organic matter $(\mathrm{OM})$, and black carbon (BC). Large differences in the removal rates and relative importance of the dry versus wet deposition pathways were found for dust and sea salt. Kinne et al. [2006] compared satellite observations of aerosol optical depth (AOD) with the aerosol optical depths calculated in the models participating in the AeroCom project, and found large model differences for the relative contributions of different aerosol components to the total AOD. There were also significant differences in the amount of radiation absorbed by dust and carbonaceous aerosol.

[6] In all of the above studies, the aerosol dry and wet deposition schemes and the sulfur chemistry schemes (e.g., using prescribed versus predicted $\mathrm{H}_{2} \mathrm{O}_{2}$ fields) may differ among the models. Therefore one is not able to disentangle whether differences are solely due to differences in meteorology or to differences in these parameterizations. In this study, under the framework of the NASA global modeling initiative (GMI), the differences and uncertainties of aerosol simulations (for sulfate, organic carbon, black carbon, dust and sea salt) solely due to meteorology are analyzed and quantified. The GMI aerosol model was driven by three sets of meteorological fields using the same chemical scheme and physical treatments (e.g., for dry and wet deposition, for convective transport of trace species, and for sulfur chemistry), and the same emission fluxes to calculate the aerosol life cycles. Two additional meteorological fields were used to examine the interannual variability in aerosol concentrations. In addition, the aerosol optical depth and direct radiative forcing are calculated with the same aerosol optical properties (including the hydroscopic growth). Thus the modelestimated direct forcing differences are solely due to the meteorology (i.e., winds, convective mass fluxes, precipitation fields, and relative humidities) used in the calculations. The model is described in section 2. Model calculated aerosol spatial distributions, budgets, and comparisons with observations are presented in section 3. Section 4 discusses the calculations for aerosol optical depth and aerosol direct forcing. Section 5 presents our conclusions.

\section{Model Description}

\subsection{Model Framework}

[7] The GMI model [Rotman et al., 2004] was developed as a modular code intended to run on different computing 
platforms, including massively parallel computer architectures. The GMI calculations presented here utilize meteorological fields calculated off-line by both free-running General Circulation Models and Data Assimilation systems. The meteorological fields provide the input necessary to calculate the advective and convective transport of species, transformation through chemical reactions, and removal by wet and dry deposition. Three sets of meteorological fields are available: the NASA Goddard Data Assimilation Office (DAO) general circulation model (GCM), the Goddard Institute for Space Studies (GISS) GCM, version II' and the NASA/Goddard Global Modeling and Assimilation Office (GMAO), finite-volume GCM (FVGCM). These meteorological fields have been archived every 3-6 hours, and are interpolated to 1-hour time steps. Specific details of the individual meteorological fields are as follows.

[8] The DAO fields were obtained from the former NASA/Goddard Data Assimilation Office, utilizing the GEOS-STRAT simulation. The fields represent the period from March 1997 through February 1998. The meteorological fields were degraded from an original horizontal resolution of $2^{\circ} \times 2.5^{\circ}$ to $4^{\circ} \times 5^{\circ}$, and have 46 vertical levels which extend from the surface to $0.15 \mathrm{mb}$. The fields are archived as 6-hour averages. Since the GCM used in this assimilation system adopts the relaxed Arakawa-Schubert (RAS) convective parameterization [Moorthi and Suarez, 1992], only one set of cloud convective mass fluxes and cloud detrainment rates is included.

[9] The GISS fields represent a 1-year realization from the GISS GCM, version II' [Rind and Lerner, 1996; Koch and Rind, 1998] which also includes a slab ocean model. Six-hour averaged fields were obtained on 23 vertical levels from the surface to $0.02 \mathrm{mb}$ with a horizontal resolution of $4^{\circ} \times 5^{\circ}$. These meteorological fields separate convective transport into shallow and deep convection and specify convective mass fluxes as well as detrainment rates.

[10] The FVGCM fields were obtained from the finitevolume GCM used by the NASA/GMAO. This GCM is used as part of the GEOS-4 data assimilation system [Bloom et al., 2005], but the fields we obtained were from a 1-year realization of the GCM in free-running mode, forced by the year 1994 sea surface temperature (SST). The sea surface temperature is derived from the weekly $1^{\circ} \times 1^{\circ}$ Reynolds' optimum interpolation sea surface temperature (OISST) version 2 [Reynolds et al., 2002] and updated every time step using a linear interpolation in time. The FVGCM fields are obtained as 3-hour averages and degraded from an original grid with $2^{\circ} \times 2.5^{\circ} \times 55$ vertical levels to one with $4^{\circ} \times 5^{\circ} \times 42$ vertical levels, extending from the surface to $0.01 \mathrm{mb}$. The GEOS-4 system adopted physics from the National Center for Atmospheric Research Community Climate Model, version 3 (CCM3), and thus includes the parameterizations by Hack [1994] for shallow and Zhang and McFarlane [1995] for deep convection.

[11] The GMI model uses a flux-form semi-Lagrangian (FFSL) advection scheme [Lin and Rood, 1996]. Vertical convective transport includes transport in updrafts and downdrafts, as well as entrainment and detrainment. Cumulus transport is implemented in the GMI model using the CONVTRANS algorithm [Rasch et al., 1997]. Whenever separate fields exist for shallow and deep convection, these two processes are treated sequentially in a split-operator fashion. Vertical diffusion is based on an implicit scheme [Walton et al., 1988] with the three-dimensional fields of time-varying vertical diffusion coefficients supplied by both the DAO and FVGCM fields used to determine mixing within the planetary boundary layer (PBL). No vertical diffusion coefficients existed in the GISS-II' fields; in this case, the diurnally varying height of the PBL was used to estimate species concentrations in the PBL, assuming relaxation to a well-mixed distribution with a time constant of 3 hours.

[12] An aerosol module was added to the GMI model framework. It includes prognostic variables for sulfur and related species: dimethylsulfide (DMS), sulfur dioxide $\left(\mathrm{SO}_{2}\right)$, sulfate aerosol $\left(\mathrm{SO}_{4}^{2-}\right)$, and hydrogen peroxide $\left(\mathrm{H}_{2} \mathrm{O}_{2}\right)$; biomass burning $\mathrm{BC}$ and $\mathrm{OM}$, fossil fuel $\mathrm{BC}$ and OM, natural OM, mineral dust, and sea salt. Sulfate aerosol is divided into three size bins with radii varying from 0.01 to $0.05 \mu \mathrm{m}, 0.05$ to $0.63 \mu \mathrm{m}$, and 0.63 to $1.26 \mu \mathrm{m}$, while mineral dust and sea salt are predicted in four bins with radii varying from 0.05 to $0.63 \mu \mathrm{m}, 0.63$ to $1.26 \mu \mathrm{m}, 1.26$ to $2.5 \mu \mathrm{m}$, and 2.5 to $10 \mu \mathrm{m}$. Carbonaceous aerosol (OM and $\mathrm{BC}$ ) is currently represented by a single submicron size bin. These size cuts are based on consideration of the mass size distribution and thermodynamics of these aerosols as well as the CCN activation spectrum under typical supersaturations. The mass-weighted average radius in each bin for each aerosol component can be calculated from the size distribution in each bin. In the current version of the GMI model, aerosol dynamics has not been included, thus the aerosol size distributions are assumed to follow those derived from measurements. Sulfate aerosol was assumed to follow the size distribution given by Chuang et al. [1997] within each size bin. Following Penner et al. [1998], the particle size distributions for fossil fuel $\mathrm{BC} / \mathrm{OM}$ and for biomass burning $\mathrm{BC} / \mathrm{OM}$ and natural $\mathrm{OM}$ were based on measurements by Radke et al. [1988] and by Anderson et al. [1996], respectively. Mineral dust particles are assumed to follow the size distribution of d'Almeida et al. [1991] within each size bin while sea salt follows that of Quinn and Coffman [1998].

\subsection{Sulfur Chemistry}

[13] The sulfur chemistry included in the model was described by Liu et al. [2005]. In the gas phase, DMS is oxidized by $\mathrm{OH}$ radical to form $\mathrm{SO}_{2}$, and $\mathrm{SO}_{2}$ oxidized by $\mathrm{OH}$ radical to form sulfate. The chemical source of $\mathrm{SO}_{2}$ from the reaction of DMS with $\mathrm{NO}_{3}$ is neglected, as this contribution to $\mathrm{SO}_{2}$ is generally small $(10-15 \%)$ compared to that from DMS + OH [e.g., Feichter et al., 1996; Chin et al., 2000a]. Within cloudy regions of the atmosphere, the aqueous phase oxidation of $\mathrm{SO}_{2}$ with $\mathrm{H}_{2} \mathrm{O}_{2}$ and $\mathrm{O}_{3}$ to produce $\mathrm{SO}_{4}^{2-}$ is considered. Within a cloud the partitioning of $\mathrm{SO}_{2}, \mathrm{H}_{2} \mathrm{O}_{2}$ and $\mathrm{O}_{3}$ is given by aqueous phase equilibria based on Henry's Law (aqueous phase dissociations are included for $\mathrm{SO}_{2}$ ). Gas-phase produced sulfate is distributed to sulfate aerosol in the 3 size bins with the proportion in each bin calculated from the assumed sulfate size distribution mentioned above. The sulfate produced in-cloud is added to the second size bin for sulfate aerosol (0.05 to $0.63 \mu \mathrm{m})$ consistent with the study by Kreidenweis et al. [2003]. 
(a) DAO
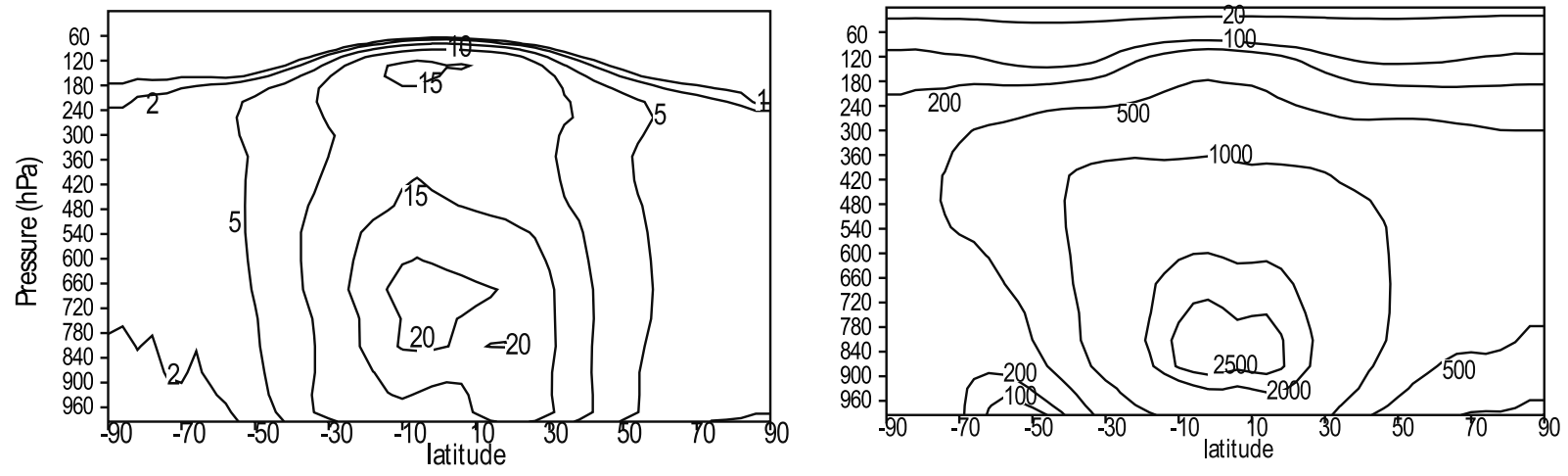

(b) FVGCM
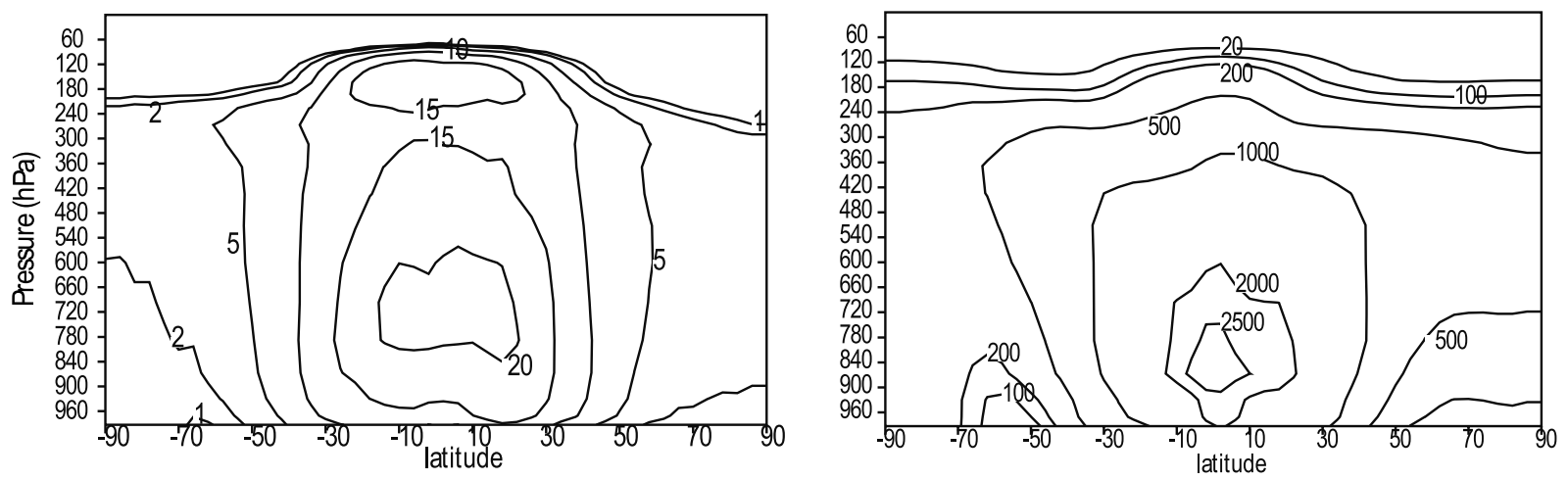

(c) GISS
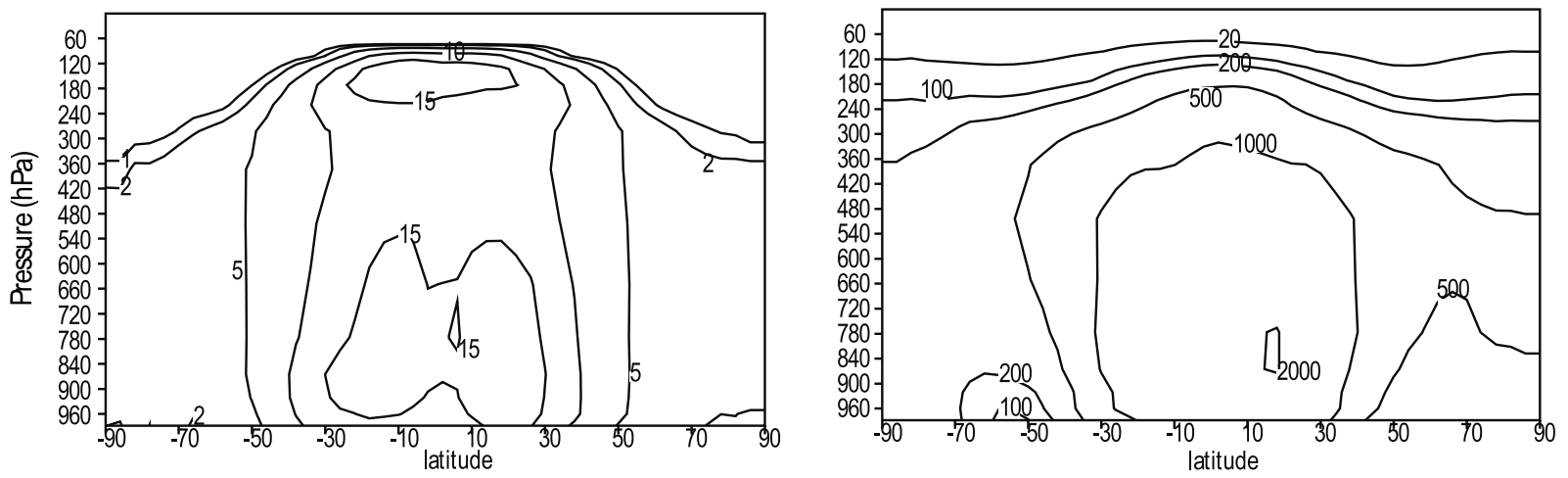

x 1E5 molecules/cm3

pptv

Figure 1. Annual averaged zonal mean distributions of (left) $\mathrm{OH}$ in $10^{5}$ molecules $\mathrm{cm}^{-3}$ and (right) $\mathrm{H}_{2} \mathrm{O}_{2}$ in pptv with the three meteorological data sets.

[14] The gas phase species involved in the sulfur chemistry, $\mathrm{OH}, \mathrm{HO}_{2}$, and $\mathrm{O}_{3}$, have prescribed concentrations taken from monthly averages in a simulation of photochemically active compounds by the GMI tropospheric chemistry model [Rodriguez et al., 2003; Stevenson et al., 2006], with the DAO, FVGCM and GISS fields, respectively. The $\mathrm{H}_{2} \mathrm{O}_{2}$ concentration is predicted from prescribed $\mathrm{HO}_{2}$ concentrations with losses from reactions by $\mathrm{OH}$ and by photolysis [Liu et al., 2005]. The photolysis rate of $\mathrm{H}_{2} \mathrm{O}_{2}$ is determined via a look-up table method where the photolysis rate depends on the latitude and the height of the grid box and the month of year. Diurnal variations of $\mathrm{OH}$ and $\mathrm{HO}_{2}$ concentrations and $\mathrm{H}_{2} \mathrm{O}_{2}$ photolysis rates are imposed by scaling the average fields to the cosine of solar zenith angle. Figure 1 compares the $\mathrm{OH}$ and $\mathrm{H}_{2} \mathrm{O}_{2}$ concentrations for the three meteorological data sets. The distribution patterns of both $\mathrm{OH}$ and $\mathrm{H}_{2} \mathrm{O}_{2}$ are similar among the three data sets. However, the maximum in the tropical lower to middle troposphere is lower with the GISS data by $10 \%$ and $30 \%$ for $\mathrm{OH}$ and $\mathrm{H}_{2} \mathrm{O}_{2}$, respectively, while the GISS $\mathrm{OH}$ has the 
highest concentration in the $\mathrm{SH}$ extratropical regions in the lower troposphere. There is no single factor one can point to for these differences with different meteorological fields. It is a combination of different water vapor, cloud optical depths, and distributions of chemical species (e.g., carbon monoxide and nitrogen oxides).

[15] Cloud water content which is required for calculating the aqueous fractions of chemical species $\left(\mathrm{SO}_{2}, \mathrm{H}_{2} \mathrm{O}_{2}\right.$, and $\mathrm{O}_{3}$ ) in clouds is not available from the three meteorological data sets and we found that the DAO cloud fractions are unrealistically too small [Feng et al., 2004]. Thus we diagnosed the cloud water content and cloud fraction using the same parameterizations in all three meteorological data sets. Cloud water content was calculated from the parameterization used in the NCAR CCM2 [Hack, 1998]. Largescale stratiform cloud fraction is parameterized according to Sundqvist et al. [1989] based on the relative humidity (RH). For convective cloud fraction, a parameterization which uses the convective mass flux [Xu and Krueger, 1991] was adopted. The calculated cloud fractions for all three data sets generally reflect the geographical patterns of the International Satellite Cloud Climatology Project (ISCCP) cloud fraction observations. The calculated liquid water path for the three meteorological data sets will be compared with the special sensor microwave/image (SSM/I) observations [Greenwald et al., 1993; Weng and Grody, 1994] and with the MODIS observations in section 3.1 (see Figure 6 below).

\subsection{Emissions}

[16] The emissions specified for the model simulations reported here were as follows. Fossil fuel sulfur emission used the draft IPCC-specified 2000 scenario [Nakicenovic et al., 2000] and totaled $69 \mathrm{Tg}_{-} \mathrm{S} \mathrm{yr}{ }^{-1}$. Volcanic $\mathrm{SO}_{2}$ sources were from Andres and Kasgnoc [1998]. These include sporadic and continuously emitting volcanoes but they are averages over a 25 -year time period, so the total (4.8 $\left.\mathrm{Tg}_{-} \mathrm{S} \mathrm{yr}^{-1}\right)$ includes only $1 \%$ from sporadic emissions. Marine DMS fluxes with a total of $26.1 \mathrm{Tg}_{-} \mathrm{S} \mathrm{yr}^{-1}$ were based on Kettle and Andreae [2000] using the ocean DMS field compiled by Kettle et al. [1999]. We used the average of the fluxes that they calculate based on the Liss and Merlivat [1986] parameterization (low estimate) and the Wanninkhof [1992] parameterization (high estimate). Natural OM fluxes were derived by assuming that $9 \%$ of the terpene emissions developed by Guenther et al. [1995] were rapidly converted to OM and totaled 14.4 $\mathrm{Tg}_{\mathrm{yr}}{ }^{-1}$. OM and BC from fossil fuels were developed from the inventories of Penner et al. [1993] and Liousse et al. [1996] for a calendar year representative of the mid-1980s. The biomass burning sources were taken from the inverse model study of Zhang et al. [2005] who compared the modeled aerosol index (AI) with that measured by the EP TOMS instrument. The annual global source of biomass aerosols for the year 1997 is about 13\% larger than that reported by Liousse et al. [1996] and has a factor of 8-10 increase for emissions from Indonesia due to the Indonesia fires in 1997. The total fossil fuel and biomass burning emissions for $\mathrm{OM}$ and $\mathrm{BC}$ are $96.8 \mathrm{Tg} \mathrm{yr}^{-1}$ and $13.5 \mathrm{Tg} \mathrm{yr}^{-1}$, respectively. Dust aerosol fluxes at every $6 \mathrm{hrs}$ were provided by Ginoux et al [2001] in four size bins (0.1$1 \mu \mathrm{m}, 1-1.8 \mu \mathrm{m}, 1.8-3 \mu \mathrm{m}$, and 3-6 $\mu \mathrm{m})$. Mass fluxes in our size bins were derived as described by Liu et al. [2005]

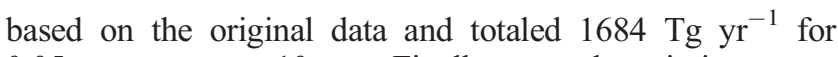
$0.05 \mu \mathrm{m}<r<10 \mu \mathrm{m}$. Finally, sea salt emissions were provided from Gong et al. [1997]. An interpolation based on the algorithm of Monahan et al. [1986] was used to derive mass fluxes for our four size bins which totaled $3768 \mathrm{Tg} \mathrm{yr}^{-1}$. We note that mineral dust and sea salt emissions can differ by as much as a factor of 8 in the literature (see Tables 3 and 4 below). In this study we prescribed these emissions, a procedure that is common to other model intercomparison (e.g., AeroCom Phase-B). Thus any differences in dust and sea salt concentrations in this study are related to transport and deposition processes in the atmosphere. Fossil fuel emissions of $\mathrm{SO}_{2}$, carbonaceous aerosol, natural emissions of DMS, OM, and sea salt emissions are injected into the lowest model layer, while mineral dust and biomass burning emissions of carbonaceous aerosol are uniformly injected in the boundary layer.

\subsection{Deposition}

[17] Dry deposition rates for gaseous species are calculated using a package developed at Harvard University based on the work of Jacob and Wofsy [1990], Wesely [1989], and Walcek et al. [1986]. For aerosols a surface resistance scheme based on Zhang et al. [2001] was used. Gravitational settling is also included for aerosols. The settling velocity and the slip correction factor for Stokes law are calculated from Seinfeld and Pandis [1998] using the mass-weighted average radius in each bin for each aerosol component based on the assumed size distribution in each bin. Hygroscopic growth using the Gerber [1991] scheme increases the sizes of sulfate, sea salt, and carbonaceous aerosols.

[18] GMI uses the Harvard wet scavenging model [Mari et al., 2000; Liu et al., 2001]. Two types of scavenging are implemented: (1) scavenging in subgrid wet convective updrafts, and (2) first-order rainout (in-cloud scavenging) and washout (below-cloud scavenging) in precipitating columns. In the convective updrafts, the fraction of tracer scavenged is calculated based on the rate constant for conversion of cloud condensate (including liquid and ice) to precipitation (assumed to be $0.005 \mathrm{~s}^{-1}$ ) and the fraction of tracer present in the cloud condensate $f_{i}$ (scavenging efficiency). Highly soluble gas species such as $\mathrm{HNO}_{3}(\mathrm{~g})$ are assumed to be $100 \%$ in the cloud condensate phase. For less soluble gas species scavenging efficiencies depend on their Henry's law coefficients. Aerosol scavenging efficiencies are generally prescribed to be constants for different aerosol components. For this study, we set $f_{i}=1$ for sulfate, mineral dust in size bins 1 and 2 and sea salt; $f_{i}=0.3$ for dust particles in size bins 3 and 4 based on the study of Liu et al. [2005]; and $f_{i}=0.4$ for BC/OM.

[19] The GMI model also applies the Harvard first-order wet scavenging scheme to treat the rainout and washout in stratiform and convective precipitation. In this scheme, incloud scavenging follows Giorgi and Chameides [1986], while below-cloud scavenging follows Balkanski et al. [1993]. One difference between the GMI and Harvard schemes is the assumed stratiform cloud condensate water content. This has been reduced in the GMI scheme from $1.5 \mathrm{~g} \mathrm{~m}^{-3}$ to $0.5 \mathrm{~g} \mathrm{~m}^{-3}$ to be consistent with measurements [Considine et al., 2005]. Resuspension is calculated in any 

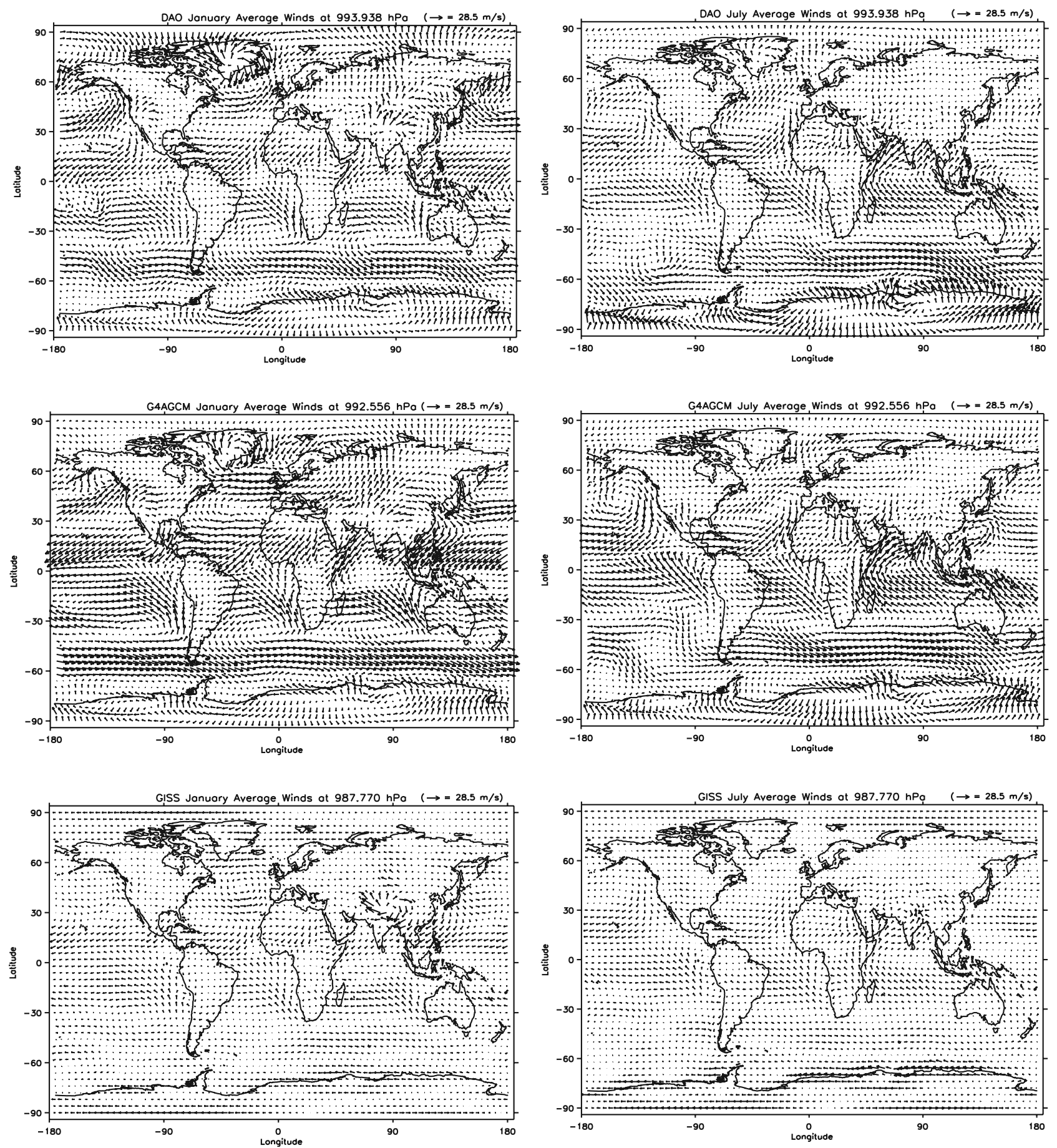

Figure 2. Vectors of horizontal winds at the surface from the three meteorological data sets in January (left) and July (right), with a maximum magnitude of $28.5 \mathrm{~m} \mathrm{~s}^{-1}$.

grid box where there is net evaporation of precipitation. A fraction (assumed to be half) or all of the tracer precipitating from above is released in the grid box to reflect the partial or total evaporation of precipitation, respectively. Evaporation of scavenged aerosol species in precipitation therefore increases the concentrations of aerosol particles in the lower atmosphere. It is noted that the Harvard/GMI wet scavenging schemes have been evaluated against the radionuclide $\left({ }^{210} \mathrm{~Pb}\right.$ and $\left.{ }^{7} \mathrm{Be}\right)$ observations at the surface and in the upper troposphere/lower stratosphere [Liu et al., 2001; Considine et al., 2005].

\section{Model Results}

\subsection{Comparison of Wind, Cloud, and Precipitation Fields Between DAO, FVGCM, and GISS Meteorological Data Sets}

[20] Wind fields determine the transport by advection of chemical species on the regional and global scale, and play 

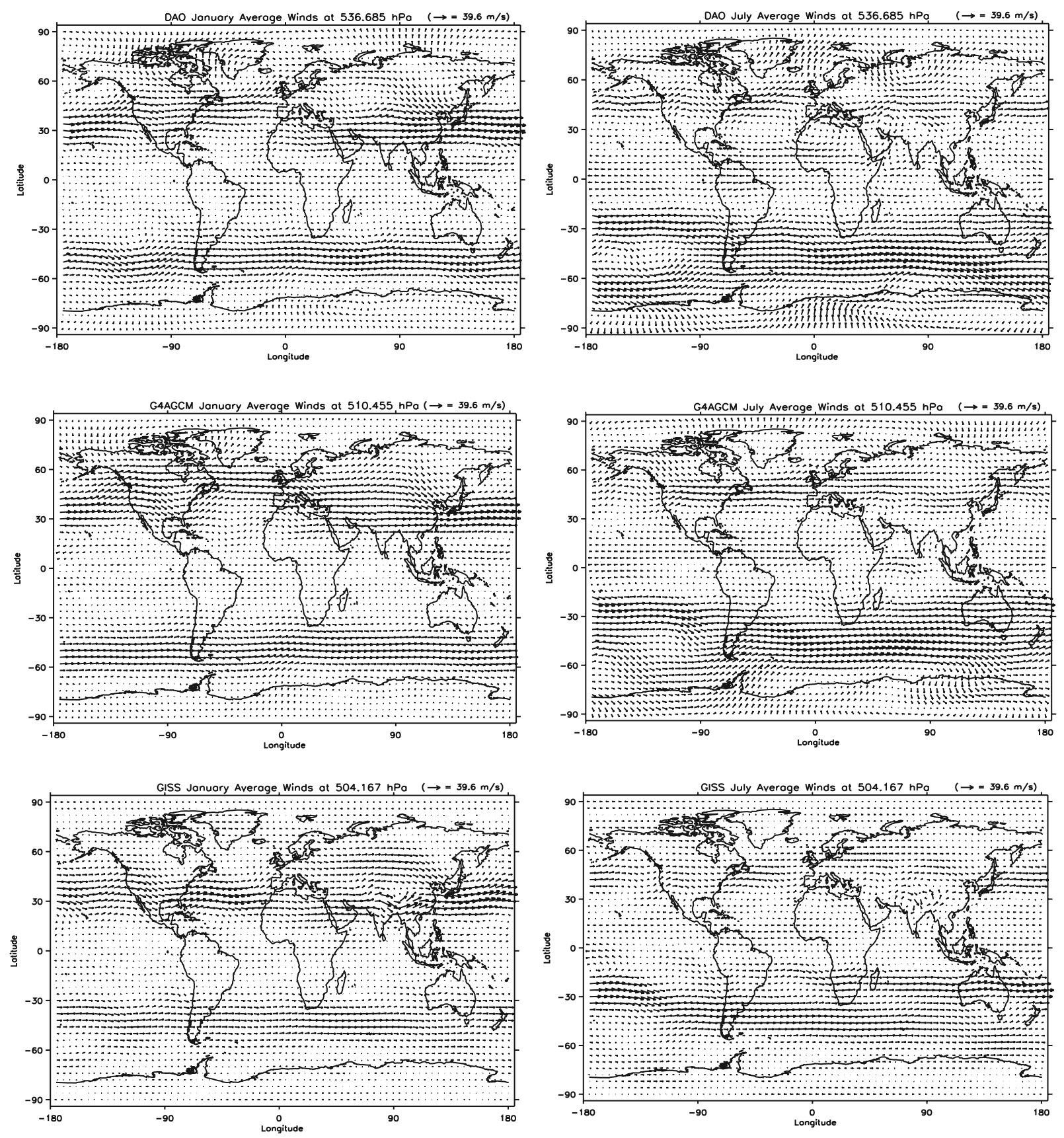

Figure 3. Vectors of horizontal winds at about $500 \mathrm{hPa}$ from the three meteorological data sets in (left) January and (right) July, with a maximum magnitude of $39.6 \mathrm{~m} \mathrm{~s}^{-1}$.

an important role in determining the extent of chemical species exporting from the polluted continents to the remote and ocean areas. Figures 2 and 3 compare the horizontal winds from the three meteorological data sets at the surface and at $\sim 500 \mathrm{hPa}$, respectively. The FVGCM has generally the strongest winds, and GISS has the weakest on the global scale at the lower levels (Figure 2). DAO has the largest wind speeds over the North Pole for the air coming from Europe and Asia in January. The strong polar vortex in the DAO and FVGCM data sets isolates the air around South Pole, especially during the austral winter. This feature is, however, much weaker in GISS. The winds at upper levels $(\sim 500 \mathrm{hPa})$ are more zonally distributed and are quite similar between the three meteorological data sets in both January and July (Figure 3).

[21] Clouds and precipitation play a key role in the sulfur chemistry and wet scavenging of species and largely determine the burdens, lifetimes, and spatial distributions of submicron aerosol particles. In order to understand the differences in the aerosol concentrations calculated with the different meteorological fields, annual mean surface precipitation (large-scale plus convective), and convective mass fluxes from the three meteorological fields are shown in Figures 4 and 5, respectively. Also included in Figure 4 is the satellite observed surface precipitation from the Global Precipitation Climatology Project (GPCP) climatology data 
(a) DAO

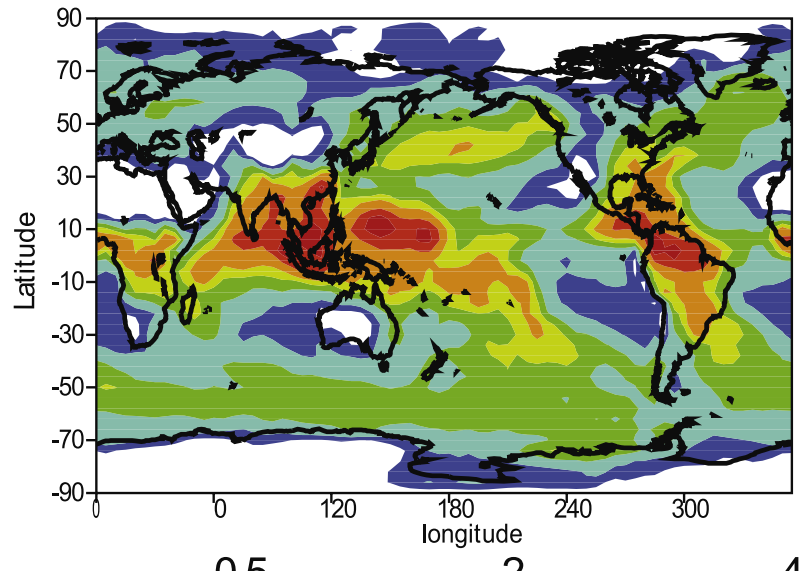

0.5 (b) FVGCM

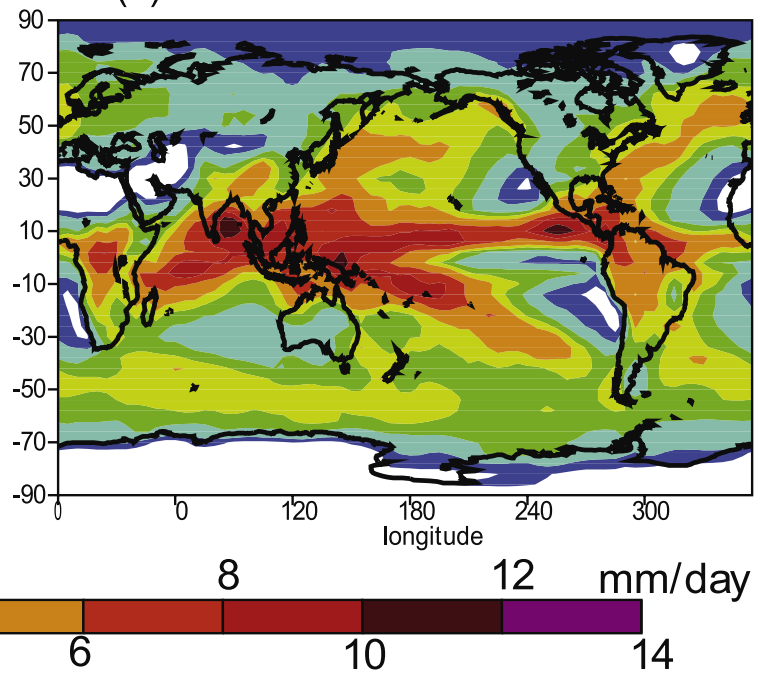

(d) GPCP

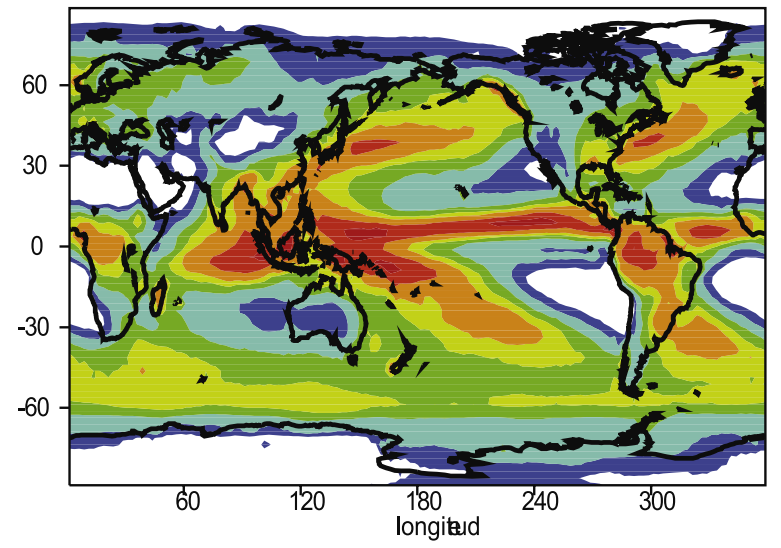

(e) Precip - annual average

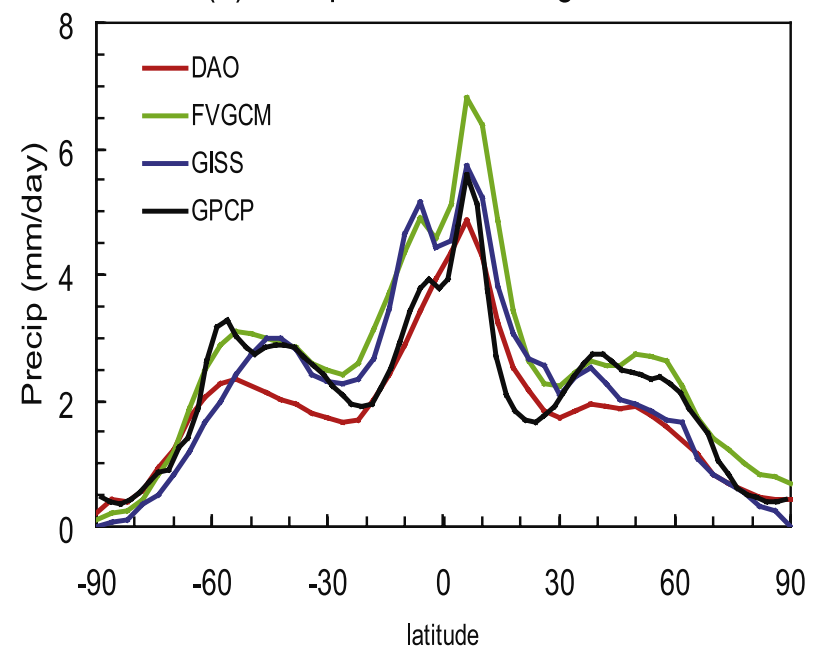

Figure 4. Annual average surface total precipitation $\left(\mathrm{mm} \mathrm{day}^{-1}\right)$ with the three meteorological data sets (a) DAO, (b) FVGCM, and (c) GISS; (d) observed annual average surface precipitation ( $\mathrm{mm} \mathrm{day}^{-1}$ ) from the Global Precipitation Climatology Project (GPCP), and also (e) the annual zonal average surface precipitation $\left(\mathrm{mm}\right.$ day $\left.^{-1}\right)$. 
DAO

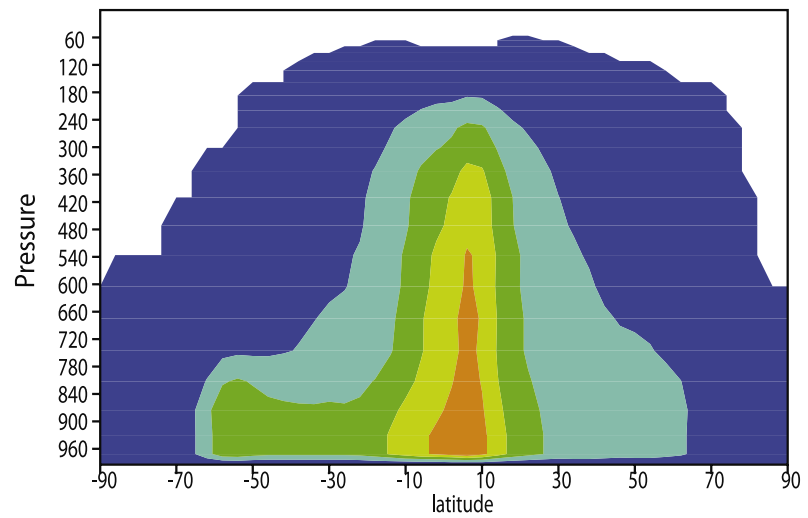

FVGCM

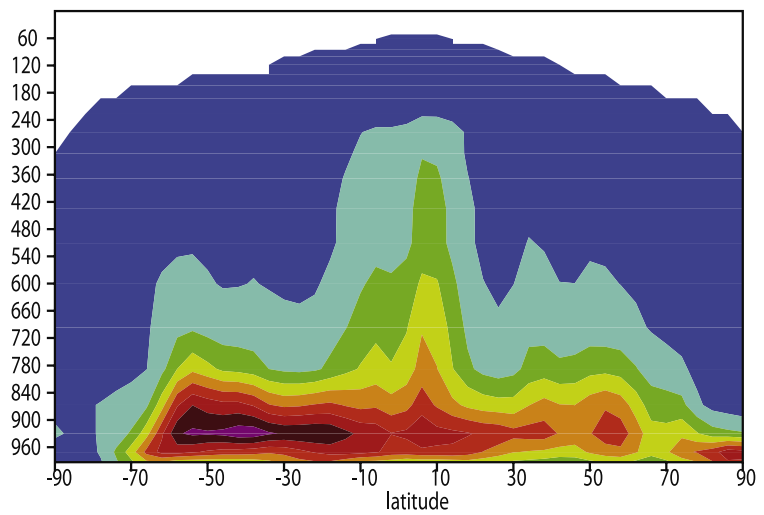

0.012

$0.016 \mathrm{~kg} / \mathrm{m} 2 / \mathrm{s}$
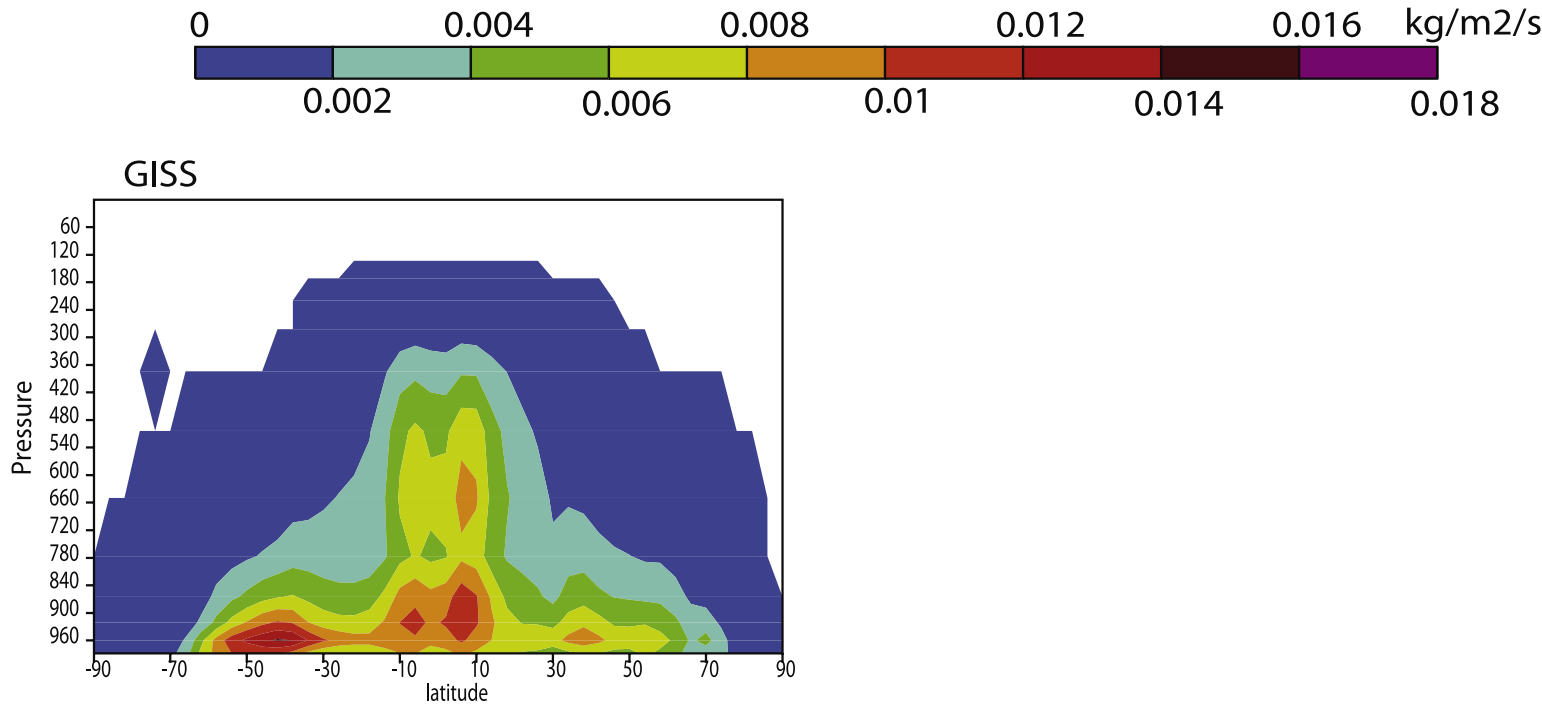

Figure 5. Annual averaged zonal mean distributions of convective mass flux $\left(\mathrm{kg} \mathrm{m}^{-2} \mathrm{~s}^{-1}\right)$ from the three meteorological data sets.

set from the period of 1979-2002 [Adler et al., 2003]. From Figure 4, precipitation is heaviest with FVGCM throughout most of the globe (the global mean is 2.3, 3.2, 2.8, and $2.6 \mathrm{~mm} \mathrm{day}{ }^{-1}$ for DAO, FVGCM, GISS, and GPCP, respectively). Light precipitation $\left(<0.5 \mathrm{~mm} \mathrm{day}^{-1}\right)$ in the generally subsiding regions in the subtropics, e.g, in the Sahara Desert in Northern Africa, is more widely spread in DAO and GISS than in FVGCM. The precipitation devoid region in the Gobi desert extends further east in DAO, which can affect the wet scavenging of anthropogenic pollutants in the Eastern Asia. The distribution patterns with high precipitation $\left(>4 \mathrm{~mm} \mathrm{day}^{-1}\right)$ between $40^{\circ} \mathrm{S}$ and $40^{\circ} \mathrm{N}$ are similar between FVGCM and GISS over oceans, especially in the Intertropical convergence zone (ITCZ). In the extratropics, however, the GISS precipitation rate reduces much faster toward the poles than that in FVGCM (see Figure 4e). Compared to the GPCP data, the DAO precipitation is underestimated in the tropical Pacific and North Atlantic, and the precipitation in both the $\mathrm{SH}$ and $\mathrm{NH}$ storm track regions at $40-60^{\circ}$ is also underpredicted. FVGCM overpredicts the precipitation in the tropical Pacific. Consistent with the precipitation field, the convective mass flux in the boundary layer is strongest with FVGCM, especially between $40^{\circ} \mathrm{S}$ and $60^{\circ} \mathrm{S}$ while that in the DAO is the weakest except in the tropical middle to upper troposphere.

[22] Radionuclide simulations of $\mathrm{Rn}-222 / \mathrm{Pb}-210$ with the GMI model have been compared within the three meteorological fields and with the observations [Considine et al., 2005]. While the Rn-222 simulation with FVGCM fields shows good agreement with observations at the surface, concentrations are lower than those with the DAO fields and are also lower than observations in the mid to upper troposphere. $\mathrm{Pb}-210$ concentrations with FVGCM are lower than other simulations and observations in both the $\mathrm{NH}$ middle to high latitudes at the surface and in the upper troposphere and lower stratosphere. These results are consistent with the higher precipitation rates in the FVGCM data and also suggest a weaker vertical transport of tracer with FVGCM especially in the summer.

[23] The annual mean liquid water path calculated from the model with the three meteorological data sets is compared with SSM/I observations [Weng and Grody, 1994; Greenwald et al., 1993] and with MODIS observations for the year 2000 in Figure 6. The geographic pattern is reproduced well by the parameterizations in the model. The observed maximum in liquid water path associated with tropical convection is captured as well as the $\mathrm{NH}$ 
(a) DAO

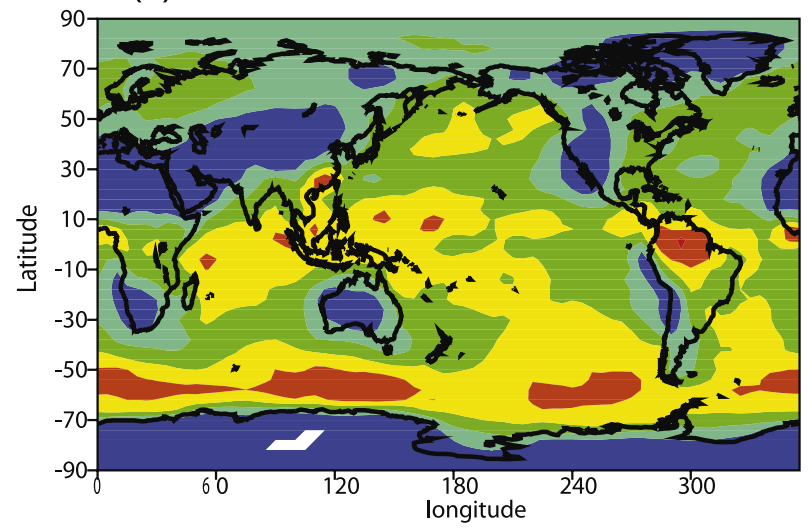

(c) GISS

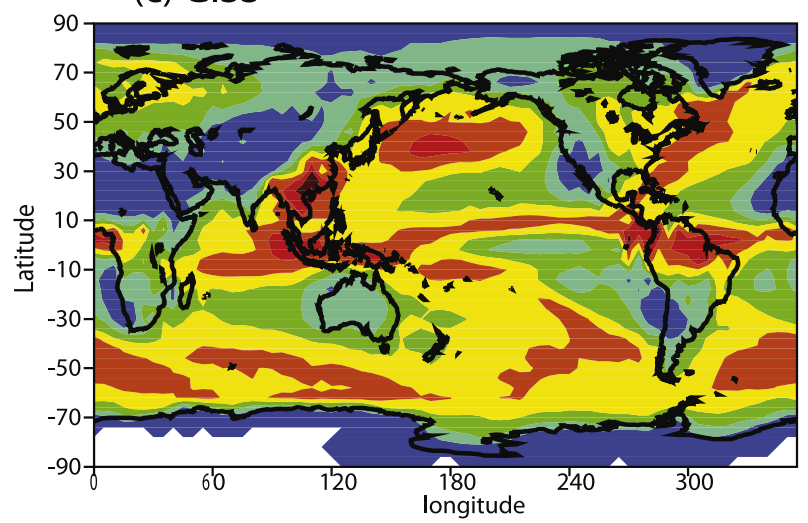

(e) SSM/I [Greenwald]

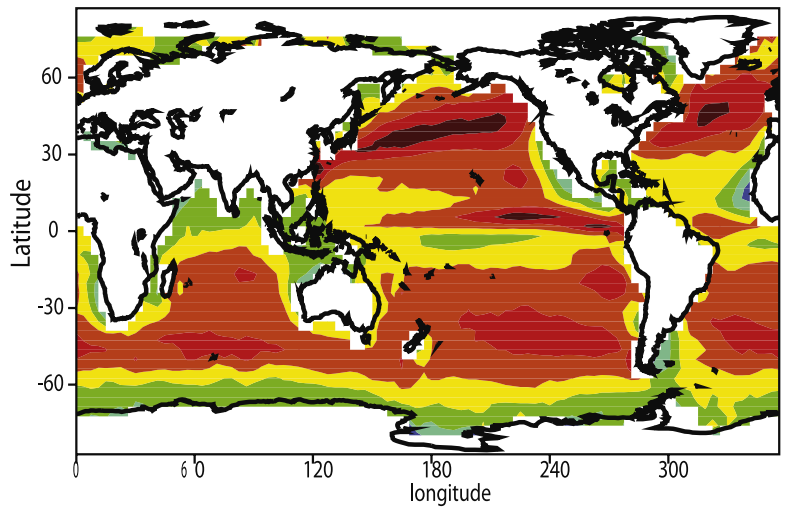

0

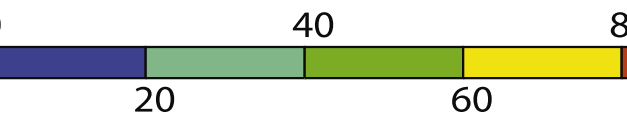

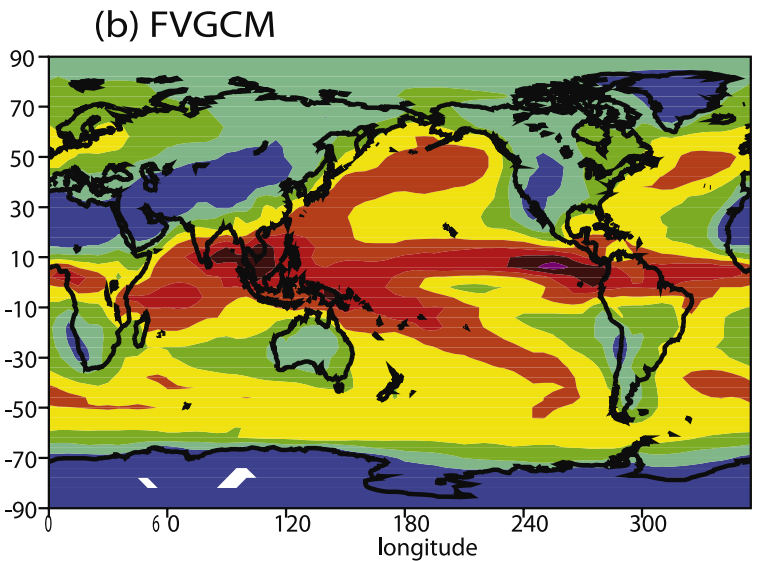

(d) SSM/I [Weng \& Grody]

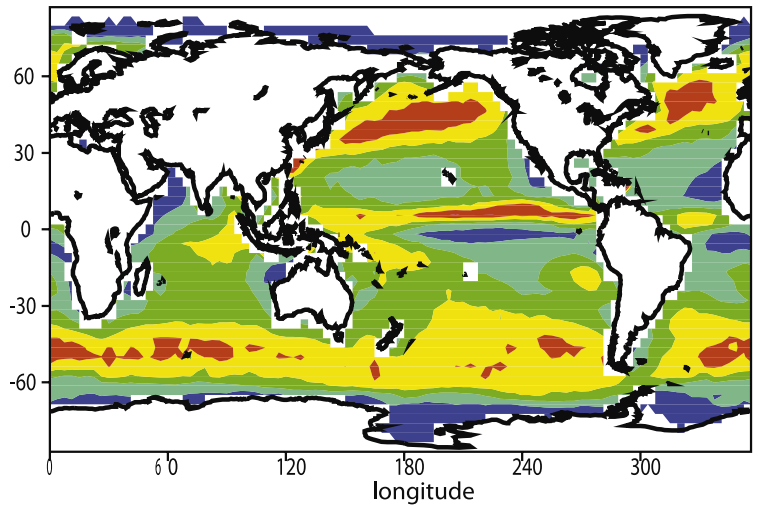

(f) MODIS

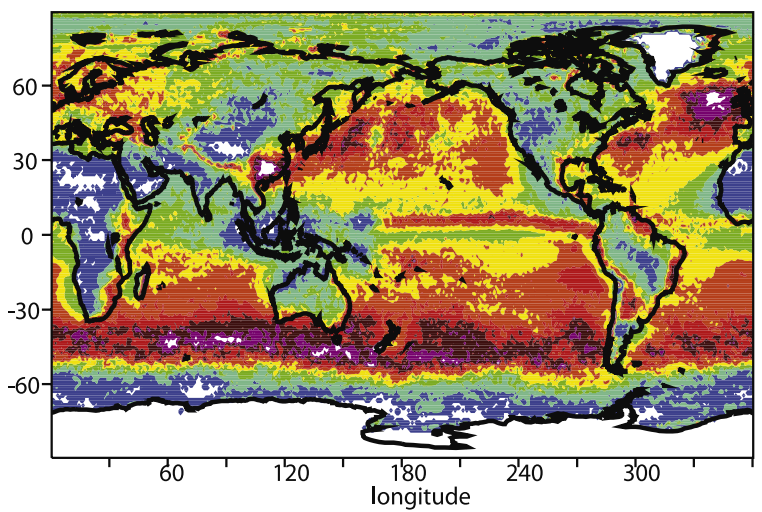

80

120

Figure 6. Geographic distribution of annual average liquid water path in $\mathrm{g} \mathrm{m}^{-2}$. (a) Model calculations over the whole domain with the DAO, (b) FVGCM, and (c) GISS meteorological fields, (d) SSM/I observations over the oceans from Weng and Grody [1994], (e) SSM/I observations over the oceans from Greenwald et al. [1993], and (f) MODIS observations for the year 2000.

extratropical cyclones and SH marine stratiform clouds near $50^{\circ} \mathrm{S}$. The order of magnitude of the liquid water path is generally in good agreement with the observations over the oceans. DAO underpredicts the liquid water path in the $\mathrm{NH}$ extratropical regions. The annual and global mean liquid water path is 48,62 , and $56 \mathrm{~g} \mathrm{~m}^{-2}$, respectively for DAO,
FVGCM and GISS compared to the observations of $48 \mathrm{~g}$ $\mathrm{m}^{-2}$ from Weng and Grody [1994], of $79 \mathrm{~g} \mathrm{~m}^{-2}$ from Greenwald et al. [1993], and of $64 \mathrm{~g} \mathrm{~m}^{-2}$ from MODIS.

[24] We compared the RH fields from the three meteorological data sets. RH in the boundary layer is important for aerosol hygroscopic growth (and thus also for dry deposi- 
(a) DAO
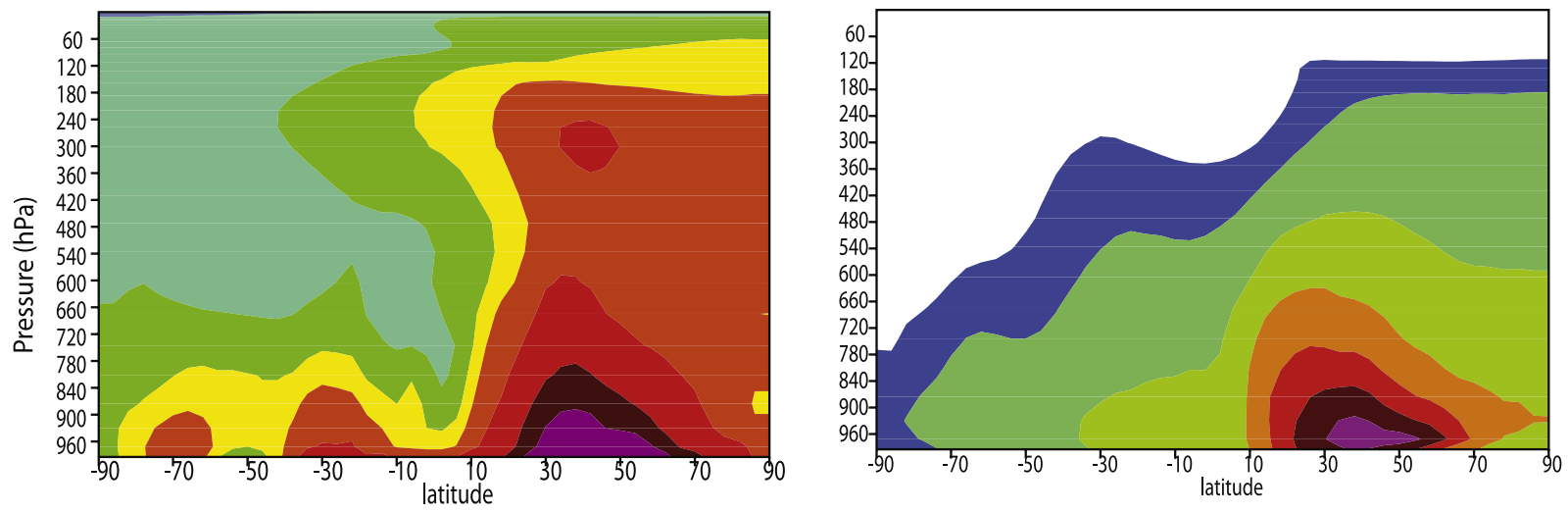

(b) FVGCM
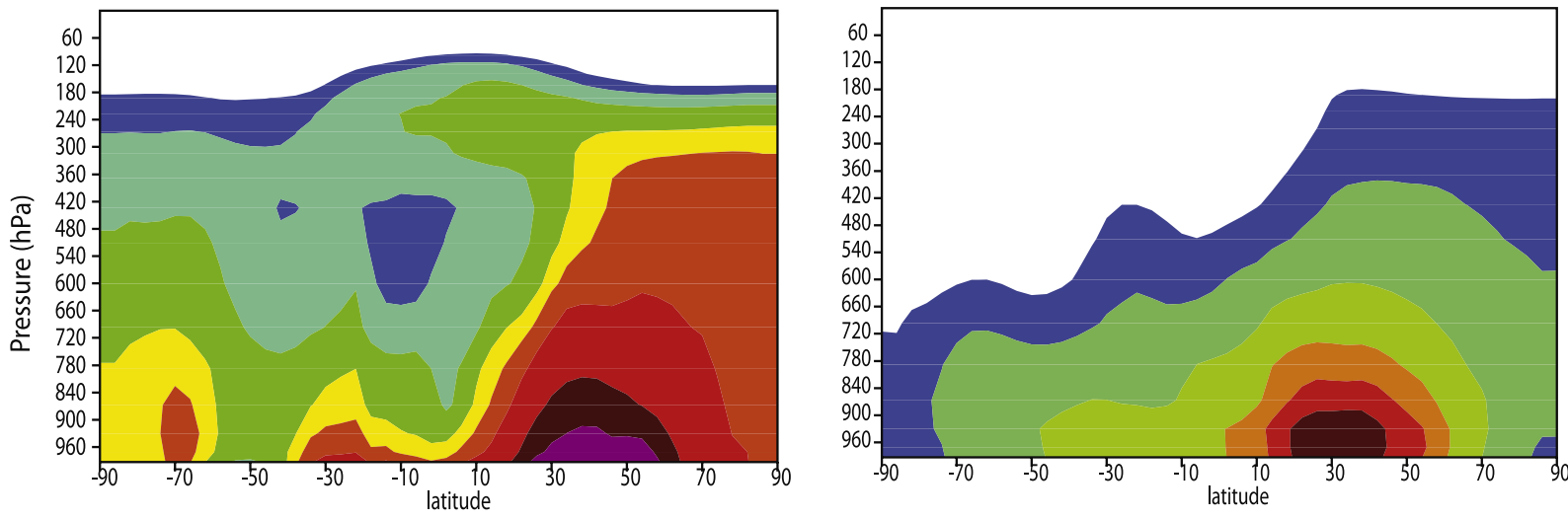

(c) GISS
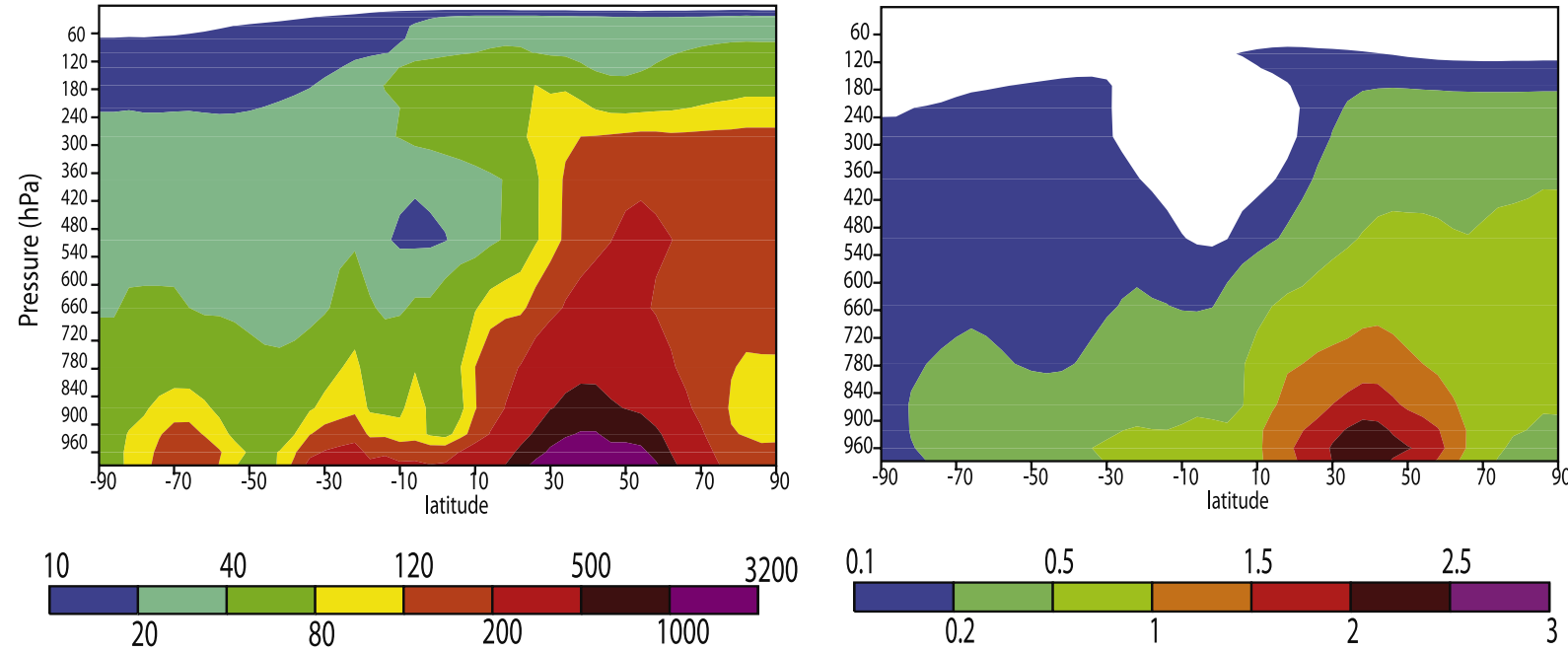

Figure 7. Annual and zonal mean (left) $\mathrm{SO}_{2}$ (in pptv) and (right) sulfate (in $\mu \mathrm{g} \mathrm{m}^{-3}$ ) concentrations with the three meteorological fields.

tion and gravitational settling and the aerosol mass extinction coefficient) and has a similar distribution pattern among the three meteorological data sets: higher RH over the oceans (generally $>80 \%$ ), and lower $\mathrm{RH}$ in the generally subsiding regions in the subtropics, e.g, in the Sahara Desert in Northern Africa. This geographic pattern resembles those of precipitation (Figure 4) and liquid water path (Figure 6).
However, regional differences exist as shown in the liquid water path distribution: $\mathrm{RH}$ from the DAO data is lowest in the NH storm track regions and in the tropical ITCZ regions. GISS has the lowest $\mathrm{RH}$ in the polar regions, consistent with having the lowest precipitation and liquid water path fields. 
(a) DAO
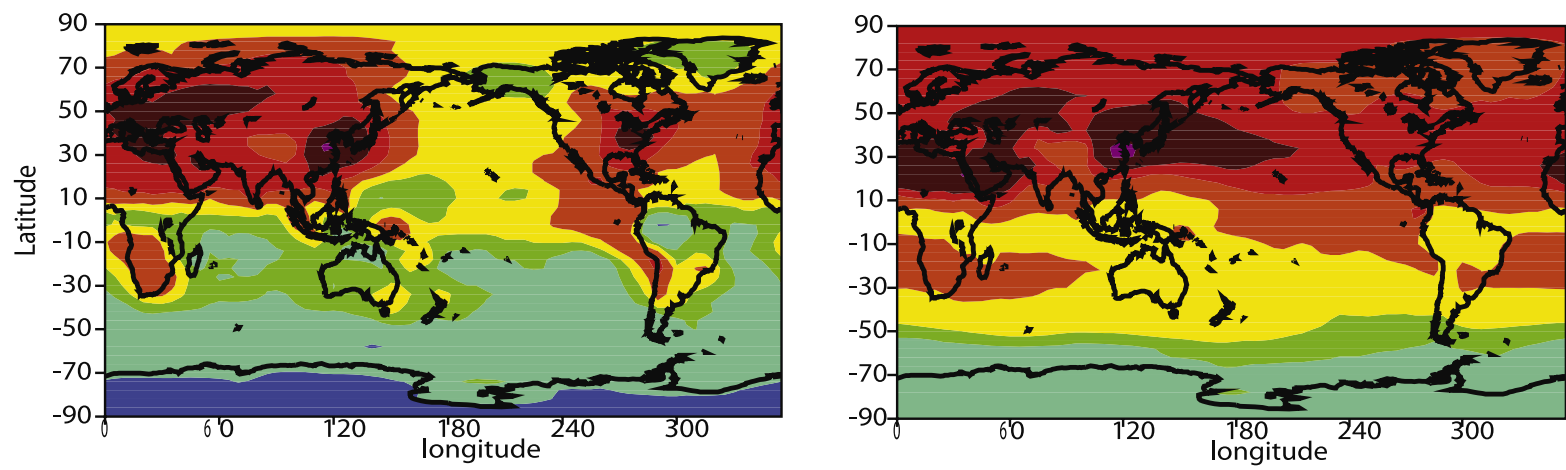

(b) FVGCM
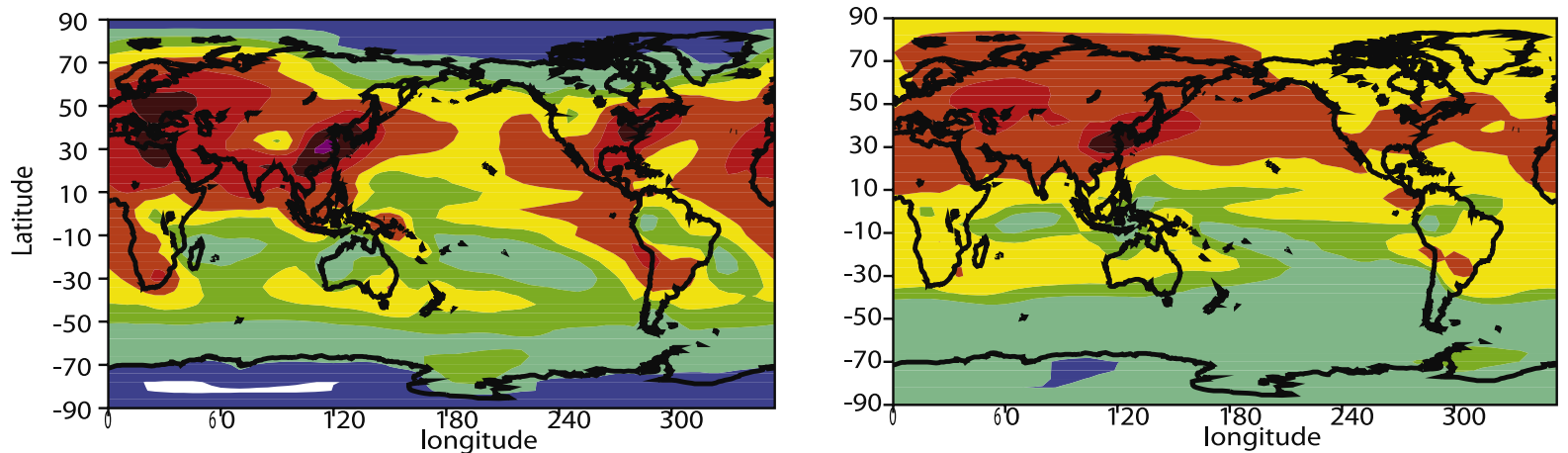

(c) GISS
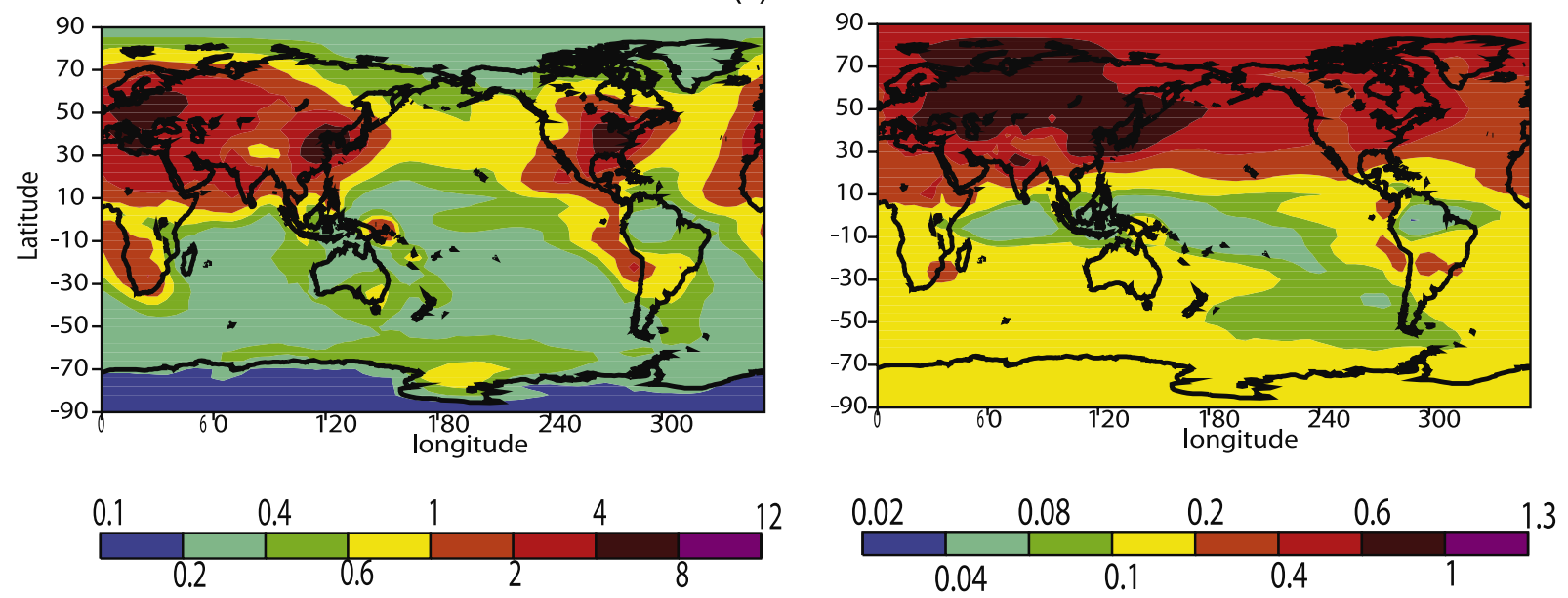

Figure 8. Annual averaged sulfate concentrations (in $\mu \mathrm{g} \mathrm{m}^{-3}$ ) (left) at the surface and at (right) $500 \mathrm{hPa}$ predicted by the model with the three meteorological data sets.

\subsection{Species Concentration Distributions}

[25] Figure 7 shows model-predicted zonal mean $\mathrm{SO}_{2}$ and sulfate concentrations with the DAO, FVGCM and GISS meteorological fields, respectively. The NH vertical transport for $\mathrm{SO}_{2}$ is strongest with DAO, followed by GISS, and then the FVGCM, consistent with the Rn-222 simulations. Correspondingly, FVGCM has the least interhemispheric exchange of $\mathrm{SO}_{2}$ from the $\mathrm{NH}$ to the $\mathrm{SH}$ in the upper troposphere. The $\mathrm{SO}_{2}$ distribution patterns for the three meteorological fields in the $\mathrm{NH}$ lower troposphere look similar. In the $\mathrm{SH}$ at $70^{\circ} \mathrm{S}$ south where DMS emissions are high, the FVGCM has the strongest vertical and poleward transport. Similar to the transport of $\mathrm{SO}_{2}$, the vertical transport of sulfate in the NH is weakest with the FVGCM. $\mathrm{DAO}$ has the highest sulfate concentrations in the $\mathrm{NH}$ midlatitudes because it has the least wet scavenging among the three meteorological data sets. DAO has strong low level transport at $\sim 900 \mathrm{hPa}$ toward the North Pole due to winter extratropical cyclones, while the poleward transport in GISS occurs at higher levels. FVGCM has minimal transport toward the North Pole at all levels due to the strongest wet removal. GISS has the highest sulfate concentrations in the middle troposphere at $40^{\circ} \mathrm{S}$ south.

[26] Figure 8 compares the annual average sulfate mass concentrations at the surface and at $500 \mathrm{hPa}$ predicted from the three meteorological fields. As expected, sulfate surface 
DAO

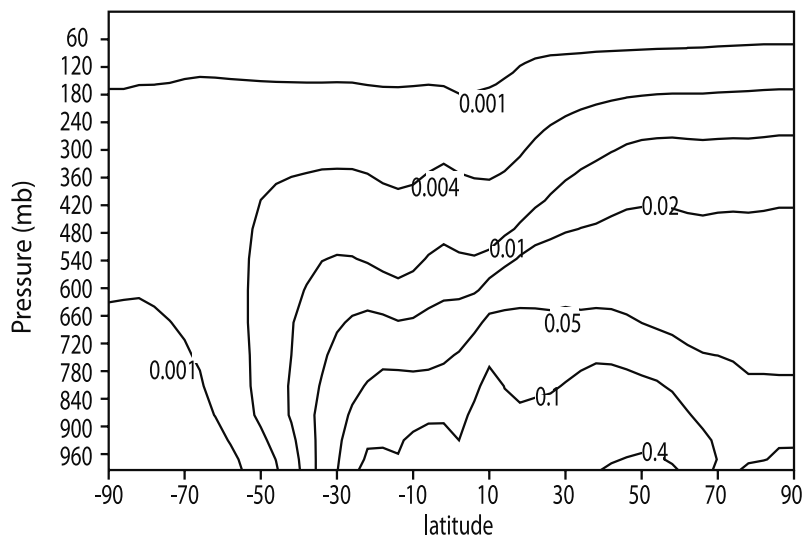

GISS

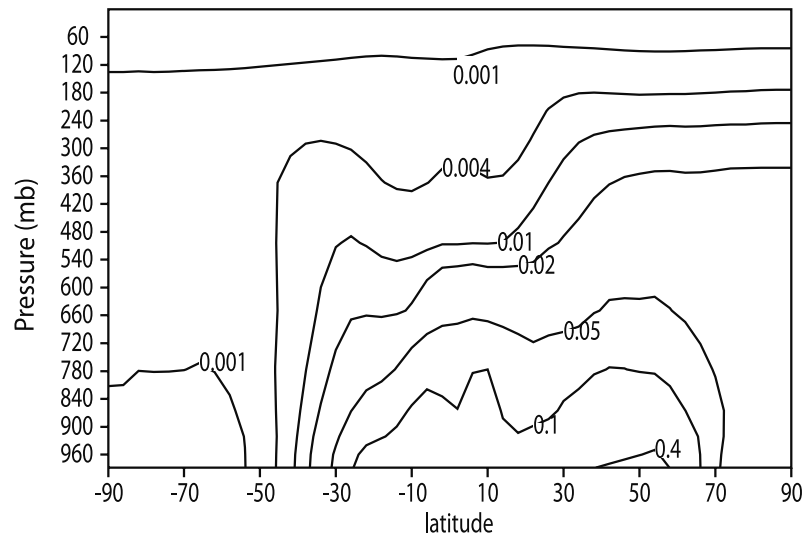

FVGCM

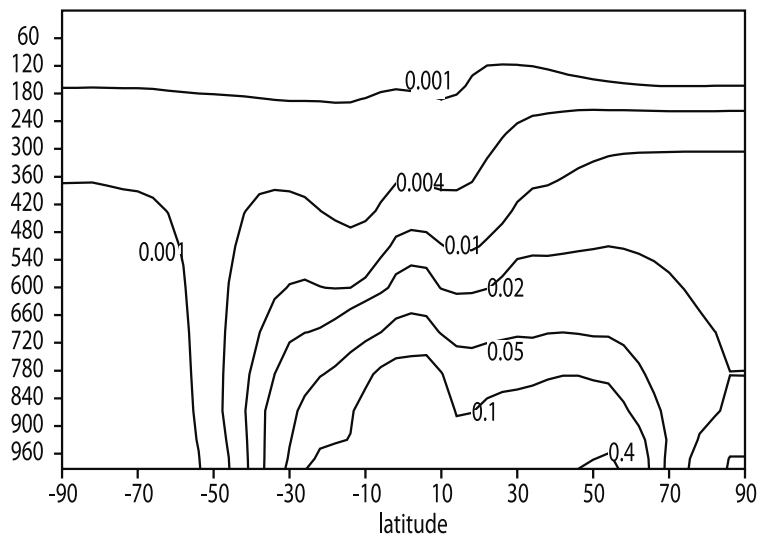

Figure 9. Annual averaged zonal mean $\mathrm{BC}$ concentrations $\left(\mu \mathrm{g} \mathrm{m}^{-3}\right)$ of predicted by the model with the three meteorological data sets.

concentrations over the industrial regions are generally quite similar among the three meteorological fields as they are dominated by anthropogenic sources. In the remote regions, the differences are significant. Over the North Pole, sulfate concentrations at surface are a factor of 3 higher with the DAO fields than those with the FVGCM due to the strong poleward transport in the DAO data and the strong wet scavenging in the FVGCM. On the other hand, the FVGCM has the strongest intercontinental transport from the industrialized regions toward the oceans, e.g, over the Atlantic, and over most of the Pacific, whereas GISS has the weakest transport. Since the FVGCM generally has the largest precipitation removal, this reflects the even higher advection fluxes from continents with FVGCM (see Figure 2). Sulfate mass at $500 \mathrm{hPa}$ is better mixed zonally and the concentrations are almost one order of magnitude lower than those at the surface. Large discrepancies still exist among the three meteorological data sets: sulfate concentrations in most of the $\mathrm{NH}$ are considerably lower with FVGCM than those with DAO and GISS due to the stronger wet removal of species from the surface. Between $10^{\circ} \mathrm{N}$ and $30^{\circ} \mathrm{S}$ sulfate concentrations and distribution patterns between FVGCM and GISS are similar, both concentrations are less than those with DAO, especially over Pacific and Indian Ocean where concentrations differ by a factor of $2-4$. At $50^{\circ} \mathrm{S}$ south, GISS predicts the highest sulfate concentrations in the free troposphere, a factor of 3 larger than those with DAO and FVGCM.

[27] Even though the FVGCM has the strongest convective mass flux, the vertical transport of sulfate into the free troposphere at the NH midlatitudes is minimal due to the efficient scavenging of sulfate by heavy rainfall. The same is true for $\mathrm{SO}_{2}$ in the $\mathrm{NH}$ which is also oxidized in clouds to form sulfate. The strong convection in the marine boundary layer at $40^{\circ}-70^{\circ} \mathrm{S}$ with $\mathrm{FVGCM}$ explains the higher $\mathrm{SO}_{2}$ concentrations transported to the free troposphere compared to those with DAO and GISS (see Figure 7). This is also confirmed by sea salt concentrations at upper levels which are higher with FVGCM than DAO and GISS (see Figure 11 below).

[28] Figure 9 shows annual mean zonal average concentrations of BC predicted by the model. Similar to the sulfate distributions, there is stronger vertical transport of $\mathrm{BC}$ in the $\mathrm{NH}$ with DAO and GISS than with FVGCM (e.g., comparing the contour line of $0.02 \mu \mathrm{g} \mathrm{m}^{-3}$ in the $\mathrm{NH}$ ). The meridional transport toward the North Pole is evident with DAO being the strongest and FVGCM the weakest. The deep gradient at $50^{\circ}-60^{\circ} \mathrm{S}$ is produced by the polar vortex, precluding the meridional transport of biomass burning $\mathrm{BC}$ to the South Pole. However, upper level transport can be seen in all the three meteorological fields with GISS being the strongest. GISS also gives the highest $\mathrm{BC}$ concentra- 
DAO
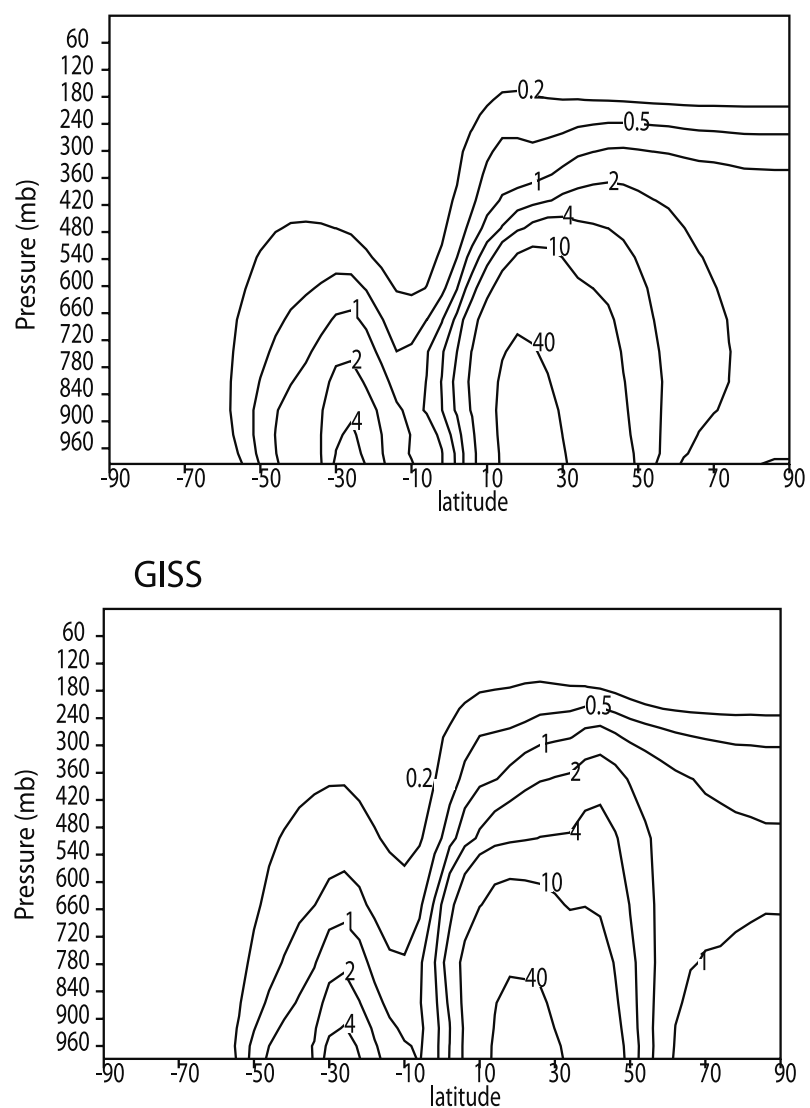

FVGCM

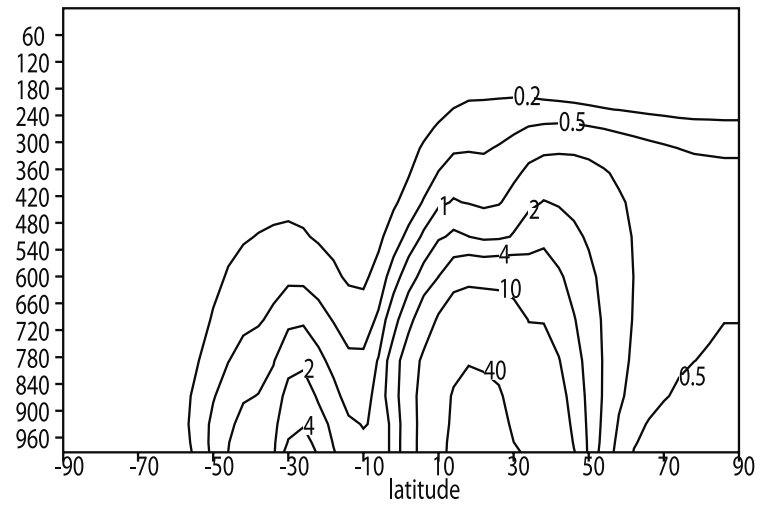

Figure 10. Same as Figure 9, but for mineral dust.

tions near the surface at the South Pole. Differences in the vertically integrated $\mathrm{BC}$ concentrations demonstrate that FVGCM produces less transport of $\mathrm{BC}$ to the NH extratropics than DAO and GISS (by a factor of 2-3) and has generally lower $\mathrm{BC}$ burdens in remote regions (figure not shown). However, in the biomass source regions, e.g., in Southern Africa and South America, the lowest BC burdens are produced with DAO fields.

[29] Figure 10 shows the annual mean zonal average concentrations of dust predicted by the model. Dust particles are strongly transported vertically. The reason may be partly due to the uniform injection of dust flux in the boundary layer and less wet scavenging of dust due to the lower rainfall over the dust source regions. As for BC, DAO predicts a stronger meridional transport toward the North Pole than does FVGCM and GISS, but at lower altitudes. Figure 11 is the same as Figure 10 but for sea salt. Sea salt particles are mostly constrained to the lower atmosphere having a stronger decay rate with altitude due to their large settling velocity (because of the hygroscopic growth of sea salt) and effective wet removal. Among the three meteorological data sets, FVGCM predicts the strongest vertical transport of sea salt by the convection and has the highest vertically integrated concentrations over the main source regions. This is because the stronger convection in the FVGCM takes sea salt away from the wet deposition "sink" regions. Higher sea salt concentrations in the marine bound- ary layer in the storm track regions at $40^{\circ}-60^{\circ} \mathrm{S}$ are also produced with FVGCM than those with DAO and GISS.

\subsection{Budgets}

[30] The global sulfur budgets for DMS, $\mathrm{SO}_{2}$, and sulfate are summarized in Table 1, together with a range of results from other models. Our global emission of DMS (26.1 Tg $\mathrm{S} \mathrm{yr}^{-1}$ ) is well within the range of 15 to $33 \mathrm{Tg} \mathrm{S} \mathrm{yr}^{-1}$ suggested by Kettle and Andreae [2000] but is at the high end of the values used in other global models. DMS is lost in the atmosphere almost completely by oxidation with the $\mathrm{OH}$ radical. The budgets for DMS are quite similar among the three meteorological data sets. While the sources for $\mathrm{SO}_{2}$ are very close, the sink terms are quite different among the DAO, FVGCM, and GISS fields. FVGCM predicts a higher aqueous phase $(79 \%)$ versus gas phase $\mathrm{SO}_{2}$ oxidation, compared with $70 \%$ and $75 \%$ for DAO and GISS, respectively. These ratios are similar to the values given by Koch et al. [1999] who also used a prognostic prediction of $\mathrm{H}_{2} \mathrm{O}_{2}$ in their model. $\mathrm{SO}_{2}$ aqueous phase oxidation would be faster using a prescribed $\mathrm{H}_{2} \mathrm{O}_{2}$ field if the same cloud fields (liquid water content, cloud fraction) were used. Our global and annual average $\mathrm{SO}_{2}$ burdens $(0.55-0.75 \mathrm{Tg})$ are high compared to most previous models, which is partly due to our higher DMS emissions. Our model has an efficient wet removal with $\sim 94 \%$ of total sulfate lost by wet deposition, whereas $\sim 6 \%$ is lost by dry deposition. Not surprisingly, FVGCM has the lowest burdens and shortest lifetimes for $\mathrm{SO}_{2}$ and sulfate, and the burdens for $\mathrm{SO}_{2}$ and 

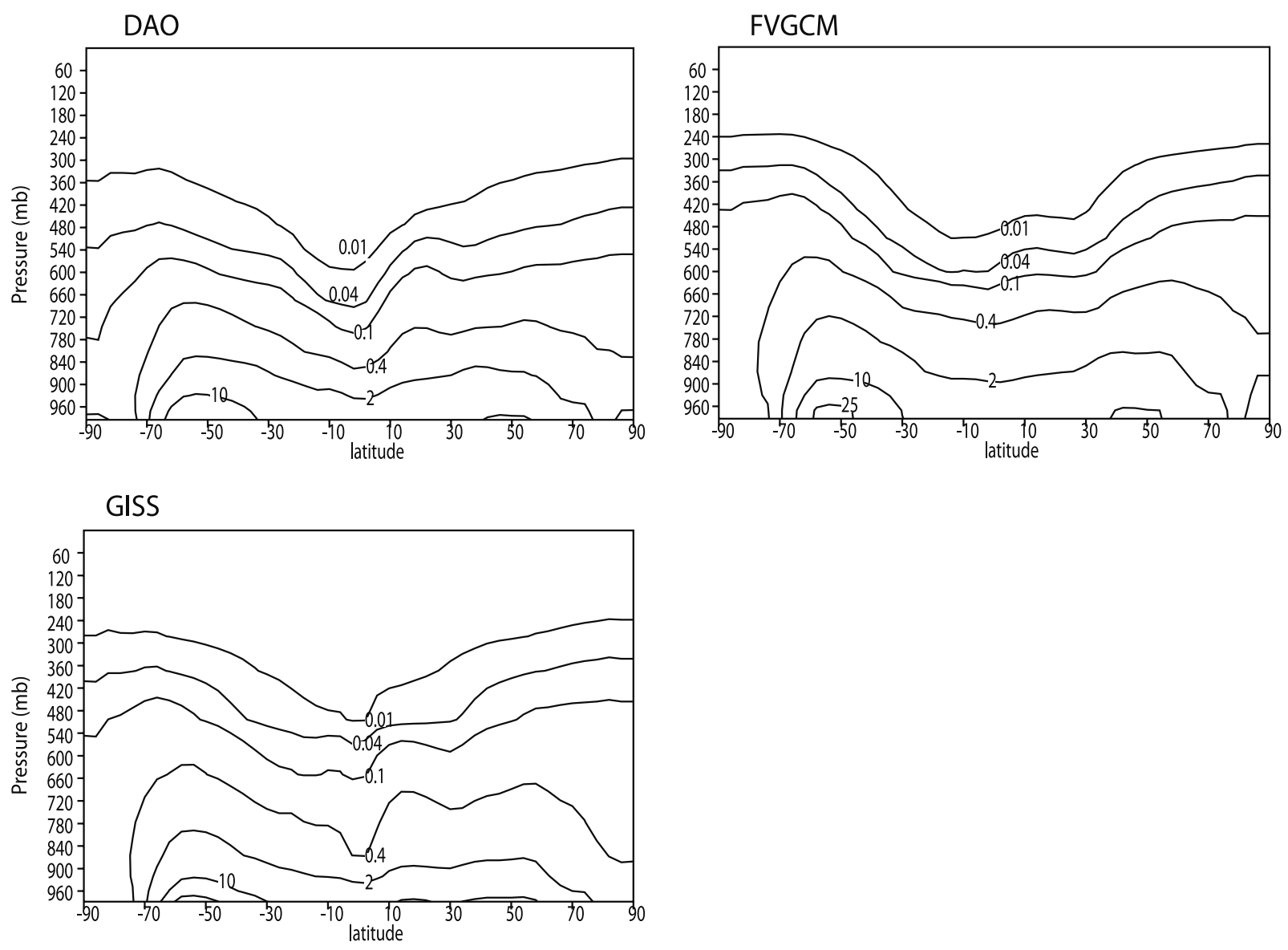

Figure 11. Same as Figure 9, but for sea salt.

sulfate are $\sim 40 \%$ and $\sim 20 \%$ lower than those with DAO and GISS, respectively. The slightly smaller wet deposition of sulfate with FVGCM compared to that with DAO can be explained by the much lower sulfate concentrations with FVGCM (the absolute wet deposition amount depends on species concentrations).

[31] Table 2 presents the annual budgets for $\mathrm{OM}$ and $\mathrm{BC}$ predicted with the three meteorological fields along with the results from other global aerosol models. Wet deposition dominates the sinks for OM and BC by $86-90 \%$. FVGCM predicts the lowest $\mathrm{OM}$ and $\mathrm{BC}$ burdens. However, the difference is not as large as that for $\mathrm{SO}_{2}$ and sulfate because of the smaller scavenging efficiency of carbonaceous aerosols in the model. A slightly higher ratio of wet versus dry deposition for both $\mathrm{OM}$ and $\mathrm{BC}$ is predicted by $\mathrm{DAO}$, due to stronger wet removal in the biomass burning source regions, e.g., in South America with the DAO fields (see the precipitation fields in Figure 4).

[32] Table 3 gives the annual budgets for dust in each size class along with a range of estimates from other models. Dust emissions and burdens vary by a factor of 8 in different models. Our budget for total dust $(0.05-10 \mu \mathrm{m})$ is in the middle of the range from different models. Dust particles in the first three bins are mainly scavenged by wet removal compared to the dominant effect of dry over wet scavenging in the largest size bin $(2.5-10 \mu \mathrm{m})$. Our model predicts the highest loading $(11.0-15.0 \mathrm{Tg})$ in the size range from 1.25 to $2.5 \mu \mathrm{m}$, which is similar to that found by Ginoux et al. [2001] (14.5 Tg in the size range from 1 to
$2 \mu \mathrm{m})$. Mass loadings are 4.3-5.9 $\mathrm{Tg}(0.05-1.25 \mu \mathrm{m})$ and $4.2-6.5 \mathrm{Tg}(2.5-10 \mu \mathrm{m})$ compared to $14.7 \mathrm{Tg}(0.1-1 \mu \mathrm{m})$ and 7.4 Tg $(2-6 \mu \mathrm{m})$ from Ginoux et al. [2001]. Our model predicts fairly similar lifetimes for the first three bins. The lifetimes range from 6.5 to 9.3 days (for $0.05-1.25 \mu \mathrm{m}$ ) and are less than that of 14 days $(0.1-1 \mu \mathrm{m})$ from Ginoux et al. [2001]. Therefore we predict a much lower dust loading and a shorter lifetime for submicrometer dust particles compared to Ginoux et al. [2001]. The lifetimes from our model for other size bins are 7.2-9.7 days $(1.25-2.5 \mu \mathrm{m})$ and 1.7-2.7 days $(2.5-10 \mu \mathrm{m})$ and are comparable to those of 9 days $(1-2 \mu \mathrm{m})$ and 2.9 days $(2-6 \mu \mathrm{m})$ from Ginoux et al. [2001]. Within the three meteorological data sets, FVGCM predicts the lowest dust burden and the shortest lifetime which are $30 \%$ less than those with the DAO fields.

[33] Table 4 presents our budget for sea salt for each size class along with a range of estimates from other models. There are only a few global model estimates of sea salt budgets. Our model has very high emissions and dry deposition in the largest size bin $(2.5-10 \mu \mathrm{m})$ compared to those in the other three bins, whereas the wet deposition and mass loading are less variable for different bins. Our model predicted burden and lifetime for total sea salt $(0.05-$ $10 \mu \mathrm{m})$ are less than the results from some other models [e.g., Tegen et al., 1997; Chin et al., 2002; Chuang et al., 2002], but are close to Easter et al.'s [2004] results. Sea salt burden $(0.05-10 \mu \mathrm{m})$ with the FVGCM fields is $56 \%$ and $43 \%$ higher than that with DAO and GISS, respectively, due 
Table 1. Global Budgets for DMS, $\mathrm{SO}_{2}$, and Sulfate ${ }^{\mathrm{a}}$

\begin{tabular}{|c|c|c|c|c|}
\hline & $\mathrm{DAO}$ & FVGCM & GISS & Other Models $^{\mathrm{b}}$ \\
\hline \multicolumn{5}{|c|}{$D M S$} \\
\hline Sources (emission) & 26.1 & 26.1 & 26.1 & $10.7-23.7$ \\
\hline Sinks & 25.9 & 25.9 & 26.0 & \\
\hline Dry deposition & 0.43 & 0.34 & 0.32 & \\
\hline Oxidation & 25.5 & 25.6 & 25.7 & $10.0-24.7$ \\
\hline Burden & 0.17 & 0.17 & 0.15 & $0.02-0.15$ \\
\hline Lifetime & 2.4 & 2.4 & 2.1 & $0.5-3.0$ \\
\hline \multicolumn{5}{|c|}{$\mathrm{SO}_{2}$} \\
\hline Sources & 99.3 & 99.4 & 99.5 & \\
\hline Anthropogenic emission & 69.0 & 69.0 & 69.0 & $61.2-92.0$ \\
\hline Volcanic emission & 4.8 & 4.8 & 4.8 & $3.4-9.2$ \\
\hline DMS oxidation & 25.5 & 25.6 & 25.7 & $10.0-24.7$ \\
\hline Sinks & 99.0 & 99.0 & 99.3 & \\
\hline Dry deposition & 27.2 & 27.6 & 30.1 & $16.0-55.0$ \\
\hline Wet deposition & 4.4 & 5.2 & 5.2 & $0.0-19.9$ \\
\hline Gas-phase oxidation & 19.8 & 14.1 & 15.7 & $6.1-16.8$ \\
\hline Aqueous-phase oxidation & 47.6 & 52.0 & 48.2 & $24.5-57.8$ \\
\hline Burden & 0.75 & 0.55 & 0.64 & $0.20-0.61$ \\
\hline Lifetime & 2.8 & 2.0 & 2.4 & $0.6-2.6$ \\
\hline \multicolumn{5}{|c|}{ Sulfate } \\
\hline Sources & 67.4 & 66.1 & 64.0 & \\
\hline Gas-phase $\mathrm{SO}_{2}$ oxidation & 19.8 & 14.1 & 15.7 & $6.1-16.8$ \\
\hline Aqueous-phase $\mathrm{SO}_{2}$ oxidation & 47.6 & 52.0 & 48.2 & $24.5-57.8$ \\
\hline Sinks & 67.3 & 66.0 & 64.0 & \\
\hline Dry deposition & 3.2 & 4.2 & 3.4 & $3.9-18.0$ \\
\hline Wet deposition & 64.1 & 61.8 & 60.6 & $34.7-61.0$ \\
\hline Burden & 0.93 & 0.65 & 0.78 & $0.53-1.07$ \\
\hline Lifetime & 5.0 & 3.6 & 4.4 & $3.9-6.8$ \\
\hline \multicolumn{5}{|c|}{$\begin{array}{l}{ }^{\mathrm{a} U n i t s} \text { are sources and sinks, } \mathrm{Tg} \mathrm{S} \mathrm{yr}{ }^{-1} ; \text { burden, Tg S; lifetime, days. } \\
\text { b Including Langner and Rodhe [1991], Pham et al. [1995], Chin and } \\
\text { Jacob [1996]; Feichter et al. [1996], Lohmann and Feichter [1997], } \\
\text { Chuang et al. [1997], Roelofs et al. [1998], Koch et al. [1999], Lohmann et } \\
\text { al. [1999b], Rasch et al. [2000b], Chin et al. [2000a], Chuang et al. [2002], } \\
\text { Rotstayn and Lohmann [2002], and Easter et al. [2004]. }\end{array}$} \\
\hline
\end{tabular}

Table 2. Global Budgets for Carbonaceous Aerosol ${ }^{\mathrm{a}}$

\begin{tabular}{|c|c|c|c|c|}
\hline & DAO & FVGCM & GISS & $\begin{array}{c}\text { Other } \\
\text { Models }\end{array}$ \\
\hline & $O M$ & & & \\
\hline Sources & 111.2 & 111.2 & 111.2 & \\
\hline Fossil fuel emission & 30.6 & 30.6 & 30.6 & $9.8-36.5$ \\
\hline Biomass burning emission & 66.2 & 66.2 & 66.2 & $44.6-107.8$ \\
\hline Photochemistry from terpenes & 14.4 & 14.4 & 14.4 & $7.8-17.8$ \\
\hline Sinks & 111.2 & 111.1 & 111.2 & \\
\hline Dry deposition & 11.4 & 15.2 & 15.5 & $19.0-29.8$ \\
\hline Wet deposition & 99.7 & 95.9 & 95.7 & $60.1-113.3$ \\
\hline Burden & 1.43 & 1.41 & 1.50 & $0.95-1.8$ \\
\hline \multirow[t]{2}{*}{ Lifetime } & 4.7 & 4.6 & 4.9 & $3.9-6.4$ \\
\hline & $B C$ & & & \\
\hline Sources & 13.5 & 13.5 & 13.5 & \\
\hline Fossil fuel emission & 6.7 & 6.7 & 6.7 & $5.1-8.0$ \\
\hline Biomass burning emission & 6.8 & 6.8 & 6.8 & $5.6-11.0$ \\
\hline Sinks & 13.5 & 13.5 & 13.5 & \\
\hline Dry deposition & 1.6 & 2.0 & 2.1 & $2.7-4.6$ \\
\hline Wet deposition & 11.8 & 11.5 & 11.4 & $7.8-13.7$ \\
\hline Burden & 0.18 & 0.17 & 0.18 & $0.13-0.29$ \\
\hline Lifetime & 4.8 & 4.5 & 4.9 & $3.9-8.4$ \\
\hline
\end{tabular}

${ }^{\mathrm{a}}$ Units are sources and sinks, $\mathrm{Tg} \mathrm{yr}^{-1}$; burden, $\mathrm{Tg}$; lifetime, days.

${ }^{\mathrm{b}}$ Range of OM/BC results from Cooke and Wilson [1996], Liousse et al. [1996], Cooke et al. [1999], Koch [2001], Chin et al. [2002], Chuang et al. [2002], Chung and Seinfeld [2002], Cooke et al. [2002], Easter et al. [2004], and Wang [2004].
Table 3. Global Budgets for Dust ${ }^{\mathrm{a}}$

\begin{tabular}{|c|c|c|c|c|}
\hline Size, $\mu \mathrm{m}$ & $\mathrm{DAO}$ & EVGCM & GISS & Other Models ${ }^{b}$ \\
\hline $\begin{array}{l}\text { Emission } \\
\quad(\text { total } 0.5-10 \mu \mathrm{m})\end{array}$ & 1684 & 1684 & 1684 & $820-5102$ \\
\hline $0.05-0.63$ & 46 & 46 & 46 & \\
\hline $0.63-1.25$ & 191 & 191 & 191 & \\
\hline $1.25-2.5$ & 561 & 561 & 561 & \\
\hline $2.5-10$ & 886 & 886 & 886 & \\
\hline $\begin{array}{l}\text { Dry deposition } \\
\quad \text { (total } 0.05-10 \mu \mathrm{m})\end{array}$ & 939 & 1001 & 992 & $486-4080$ \\
\hline $0.05-0.63$ & 5.0 & 6.5 & 6.3 & \\
\hline $0.63-1.25$ & 23.9 & 29.9 & 28.4 & \\
\hline $1.25-2.5$ & 174.8 & 199.0 & 191.8 & \\
\hline $2.5-10$ & 734.9 & 766.1 & 765.4 & \\
\hline $\begin{array}{l}\text { Wet deposition } \\
\quad(\text { total } 0.05-10 \mu \mathrm{m})\end{array}$ & 743 & 680 & 690 & $183-1027$ \\
\hline $0.05-0.63$ & 41.3 & 39.8 & 40.0 & \\
\hline $0.63-1.25$ & 167.2 & 161.2 & 162.8 & \\
\hline $1.25-2.5$ & 385.0 & 360.9 & 368.3 & \\
\hline $2.5-10$ & 149.5 & 118.3 & 119.2 & \\
\hline $\begin{array}{l}\text { Burden } \\
\quad(\text { total } 0.05-10 \mu \mathrm{m})\end{array}$ & 27.3 & 19.4 & 22.1 & $4.3-35.9$ \\
\hline $0.05-0.63$ & 1.2 & 0.85 & 0.94 & \\
\hline $0.63-1.25$ & 4.7 & 3.4 & 3.8 & \\
\hline $1.25-2.5$ & 14.9 & 11.0 & 12.7 & \\
\hline $2.5-10$ & 6.5 & 4.2 & 4.8 & \\
\hline $\begin{array}{l}\text { Lifetime } \\
\qquad(\text { total } 0.05-10 \mu \mathrm{m})\end{array}$ & 5.9 & 4.2 & 4.8 & $1.9-7.1$ \\
\hline $0.05-0.63$ & 9.3 & 6.7 & 7.4 & \\
\hline $0.63-1.25$ & 9.0 & 6.5 & 7.3 & \\
\hline $1.25-2.5$ & 9.7 & 7.2 & 8.3 & \\
\hline $2.5-10$ & 2.7 & 1.7 & 20. & \\
\hline
\end{tabular}

${ }^{\mathrm{a}}$ Units are sources and sinks, $\mathrm{Tg} \mathrm{yr}^{-1}$; burden, $\mathrm{Tg}$; lifetime, days.

${ }^{\mathrm{b}}$ Range of dust results from Tegen and Fung [1994], Tegen and Lacis [1996], Ginoux et al. [2001], Chin et al. [2002], Chuang et al. [2002], Tegen et al. [2002], Werner et al. [2002], Zender et al. [2003], Luo et al. [2003], and Easter et al. [2004].

to stronger vertical transport of sea salt over the source regions with the FVGCM fields.

\subsection{Comparison With Measurement Data}

[34] Direct comparison with point measurements is difficult because the model results are interpreted as the average of each GCM grid cell ( $4^{\circ}$ latitude by $5^{\circ}$ longitude for our model) and the simulated wind direction and wind speed resolved by the wind fields may not be consistent with those at the measurement site. In addition the measurement data that we are comparing with represent observations at a variety of time periods, some in the 1980s and others after 2000. However, these comparisons can serve as a reference to determine, in part, the accuracy of our simulated aerosol concentrations. Our modeled seasonal cycles of sulfate, mineral dust, and sea salt are compared with aerosol concentrations measured at a number of locations that are part of an ocean network operated by a group at the University of Miami [Prospero et al., 1989; Arimoto et al., 1996; Savoie et al., 1989, 1993]. Figure 12 shows a comparison of observed and modeled monthly mean surface concentrations of sulfate at twelve sites in the SH. The model is broadly able to capture the observed seasonal cycles (a broad minimum during the austral winter) at middle to high latitude oceanic sites in the SH. Sulfate is too high at sites (e.g., Mawson Antarctica, Palmer Antarctica, Marsh King George Island) in the SH summer possibly because the DMS emissions that we used in the model are too high (global sum of $26.1 \mathrm{Tg}-\mathrm{S} \mathrm{yr}^{-1}$ ). This discrepancy 
Table 4. Global Budgets for Sea Salt ${ }^{\mathrm{a}}$

\begin{tabular}{|c|c|c|c|c|}
\hline Size, $\mu \mathrm{m}$ & $\mathrm{DAO}$ & EVGCM & GISS & Other Models ${ }^{\mathrm{b}}$ \\
\hline $\begin{array}{l}\text { Emission } \\
\quad(\text { total } 0.5-10 \mu \mathrm{m})\end{array}$ & 3770 & 3770 & 3770 & $1010-8076$ \\
\hline $0.05-0.63$ & 220 & 220 & 220 & \\
\hline $0.63-1.25$ & 254 & 254 & 254 & \\
\hline $1.25-2.5$ & 453 & 453 & 453 & \\
\hline $2.5-10$ & 2843 & 2843 & 2843 & \\
\hline $\begin{array}{l}\text { Dry deposition } \\
\quad \text { (total } 0.05-10 \mu \mathrm{m})\end{array}$ & 2715 & 2795 & 2860 & $940-7450$ \\
\hline $0.05-0.63$ & 18 & 25 & 22 & \\
\hline $0.63-1.25$ & 31 & 37 & 38 & \\
\hline $1.25-2.5$ & 137 & 153 & 164 & \\
\hline $2.5-10$ & 2529 & 2579 & 2636 & \\
\hline $\begin{array}{l}\text { Wet deposition } \\
\quad(\text { total } 0.05-10 \mu \mathrm{m})\end{array}$ & 1048 & 968 & 903 & $74-2436$ \\
\hline $0.05-0.63$ & 201 & 194 & 197 & \\
\hline $0.63-1.25$ & 222 & 216 & 215 & \\
\hline $1.25-2.5$ & 315 & 299 & 288 & \\
\hline $2.5-10$ & 309 & 260 & 203 & \\
\hline $\begin{array}{l}\text { Burden } \\
\quad(\text { total } 0.05-10 \mu \mathrm{m})\end{array}$ & 3.4 & 5.3 & 3.7 & $3.0-12.0$ \\
\hline $0.05-0.63$ & 0.71 & 1.10 & 0.84 & \\
\hline $0.63-1.25$ & 0.76 & 1.21 & 0.91 & \\
\hline $1.25-2.5$ & 1.04 & 1.67 & 1.19 & \\
\hline $2.5-10$ & 0.88 & 1.35 & 0.72 & \\
\hline $\begin{array}{l}\text { Lifetime } \\
\qquad(\text { total } 0.05-10 \mu \mathrm{m})\end{array}$ & 0.33 & 0.52 & 0.36 & $0.19-1.0$ \\
\hline $0.05-0.63$ & 1.17 & 1.83 & 1.40 & \\
\hline $0.63-1.25$ & 1.10 & 1.75 & 1.31 & \\
\hline $1.25-2.5$ & 0.84 & 1.35 & 0.96 & \\
\hline $2.5-10$ & 0.11 & 0.17 & 0.09 & \\
\hline
\end{tabular}

${ }^{\mathrm{a}}$ Units are sources and sinks, $\mathrm{Tg} \mathrm{yr}^{-1}$; burden, $\mathrm{Tg}$; lifetime, days

${ }^{\mathrm{b}}$ Range of sea salt results from Erickson and Duce [1988], Tegen et al. [1997], Chin et al. [2002], Chuang et al. [2002], Gong et al. [2002], and Easter et al. [2004].

was also present in the model results of Rotstayn and Lohmann [2002]. They have done a sensitivity test using the parameterization of Liss and Merlivat [1986] instead of that by Nightingale et al. [2000] for DMS emission. Their global DMS emission was reduced from 22.1 to $14.3 \mathrm{Tg}-\mathrm{S}$ $\mathrm{yr}^{-1}$, and the model results were remarkably improved at these SH sites. The model predicts too little sulfate in the SH winter at Marsh King George Island and Invercargill New Zealand and the seasonal cycle is too strong. The model with the DAO and GISS fields reproduces the seasonal variations at Chatham Island and Wellington New Zealand but overpredicts the SH summer peaks at midlatitude sites with the FVGCM fields due to the strong continental influence (see Figure $8 b$ ). The model reproduces the maxima in February or March at some sites (e.g., Norfolk Island, Yate New Caledonia), however, predicts another peak in November at some sites (e.g., Reunion Island and America Samoa) which is not present in observations. A contributing factor to this discrepancy appears to be the month-to-month variations in the climatological seawater DMS concentrations from Kettle et al. [1999].

[35] Sulfate concentrations at 11 oceanic sites in the $\mathrm{NH}$ are shown in Figure 13. Observations at marine sites in the $\mathrm{NH}$ show strong seasonal enhancements of sulfate concentrations due to transport from the main anthropogenic source regions [Andreae et al., 1988; Savoie and Prospero, 1989; Savoie et al., 1993]. The springtime maximum at Midway Island and the summer maximum at Tenerife are captured by the model but are too high with the FVGCM fields. The same is true for the summer maximum at
Barbados and Hawaii with the FVGCM. The model generally reproduces the seasonal cycles at Miami, Bermuda and Cheju Korea with the three meteorological data sets. The springtime peak observed at Mace Head is captured by the model. The concentrations at Mace Head and Heimaey Iceland are too high in the summer with the DAO fields, which can be due to both the weak wet scavenging in the storm track regions and the strong advection of continental air towards these high-latitude sites with the DAO.

[36] Figures 14 and 15 compare modeled $\mathrm{SO}_{2}$ and sulfate concentrations over North America and Europe where extensive monitoring networks exist. North America observations are from the Eulerian Model Field Study (EMEFS) network [McNaughton and Vet, 1996], and European observations are from the European Monitoring and Evaluation Program (EMEP) [Hjellbrekke and Hanssen, 1998]. We have computed annual average $\mathrm{SO}_{2}$ and sulfate concentrations for 75 EMEFS sites in 1989 and 69 EMEP sites in 1986. Figures 14 and 15 show that there are large discrepancies between the modeled and the observed $\mathrm{SO}_{2}$ which is also found in a number of global models [e.g., Barth et al., 2000; Chin et al., 2000b; Easter et al., 2004]. By contrast, the simulated sulfate concentrations agree better with the observations, especially for the North American sites. The gross bias and gross error in both absolute and percentage terms for the three meteorological data sets are listed in Table 5. Model results tend to have the highest overestimation of $\mathrm{SO}_{2}$ with the DAO fields and the highest underestimation of sulfate with the FVGCM fields at both North American and European sites.

[37] Figure 16 shows the observed and simulated surface concentrations of $\mathrm{OM}$ and $\mathrm{BC}$ at a number of locations compiled by Liousse et al. [1996] and Cooke et al. [1999]. Comparisons of carbonaceous aerosol to these observations are more difficult because the measured concentrations are only available on a campaign basis so that the measured values are subject to short-term variability. Such temporal variations may introduce a significant discrepancy between the observations and the monthly averaged predictions from the model. Despite these facts, $\sim 50 \%$ of simulated values are within a factor of 2 , and $\sim 90 \%$ within a factor of 10 of the $\mathrm{OC}$ and $\mathrm{BC}$ measurements, respectively, for all three meteorological data sets. The model does a reasonable job of predicting the OC data for Liousse et al.'s [1996] SH locations, for Cooke et al.'s [1999] Island and Rural locations, and the BC data for Liousse et al. [1996]'s NH Rural locations and Cooke et al.'s [1999] Rural locations. For the comparisons with data at other locations, while model predictions are good compared with some of the data, there are some locations which are underpredicted or overpredicted, which may imply a problem with the emissions used or may simply be due to the difficulty of comparing model results with these campaign-based measurement data. Table 6 gives the gross bias and gross error for the model predictions with these campaign-measured $\mathrm{OC}$ and $\mathrm{BC}$ values. Model results with the DAO and GISS fields tend to overpredict measured $\mathrm{OC}$ and $\mathrm{BC}$, while the FVGCM has the lowest gross bias and gross error in percentage due to its more efficient wet scavenging.

[38] Besides comparison with these campaign-based data, we compare the $\mathrm{OC}$ and $\mathrm{BC}$ simulation results to the Interagency Monitoring of Protected Visual Environments 

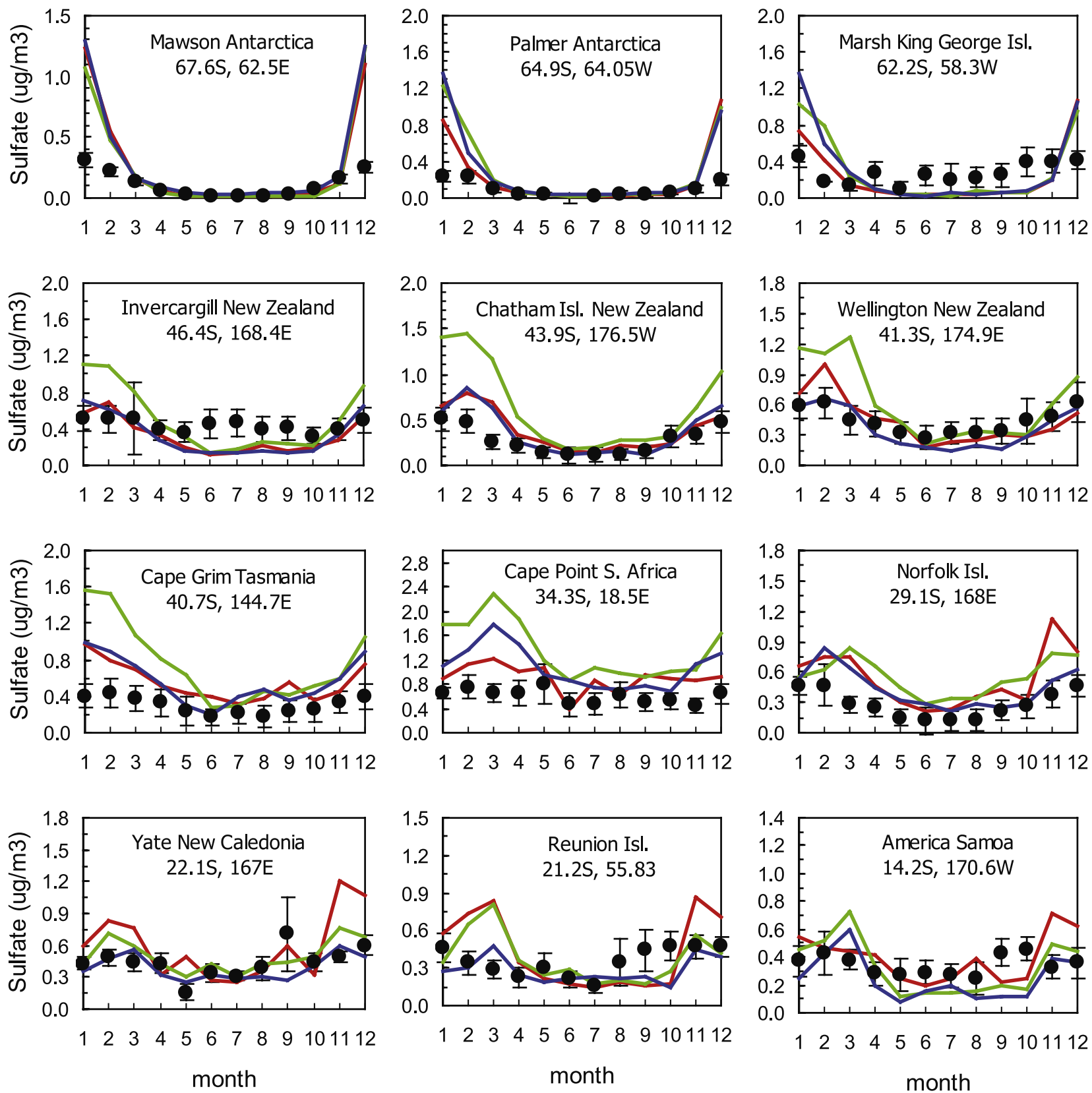

Figure 12. Comparison of modeled and observed monthly mean surface mass concentrations of sulfate at 12 sites in the SH. Model results are in solid lines (DAO: in red; FVGCM: in green; GISS: in blue), and observed data in dots with one standard deviation.

(IMPROVE) database [Malm et al., 2000]. The IMPROVE network consists of aerosol and optical measurements at approximately 140 rural sites in the United States. The observation data for $\mathrm{OC}$ and $\mathrm{BC}$ from 48 sites are averaged over 3 years from March 1996 to February 1999. The comparison is shown in Figure 17. The model underpredicts both $\mathrm{OC}$ and $\mathrm{BC}$ concentrations at this set of locations on average by about $40 \%$ for all the three meteorological data sets. The low biases have also been found in other model studies [Chung and Seinfeld, 2002; Easter et al., 2004]. This suggests a problem with local emissions or local complex terrain influences which a global model can not reproduce. The gross bias and gross error for the model predictions with this measurement data set are listed in Table 6. FVGCM tends to have the highest and GISS the lowest underestimations for both $\mathrm{OC}$ and $\mathrm{BC}$. But the differences with different meteorological data sets are smaller at these sites than at those from campaign-based measurements.

[39] Figure 18 compares the modeled and observed seasonal cycle of $\mathrm{BC}$ concentrations at several sites in the $\mathrm{NH}$ and $\mathrm{SH}$. While the simulation exhibits a small seasonal variation which is also reflected in the observations, the simulated peak concentrations in early spring are much 

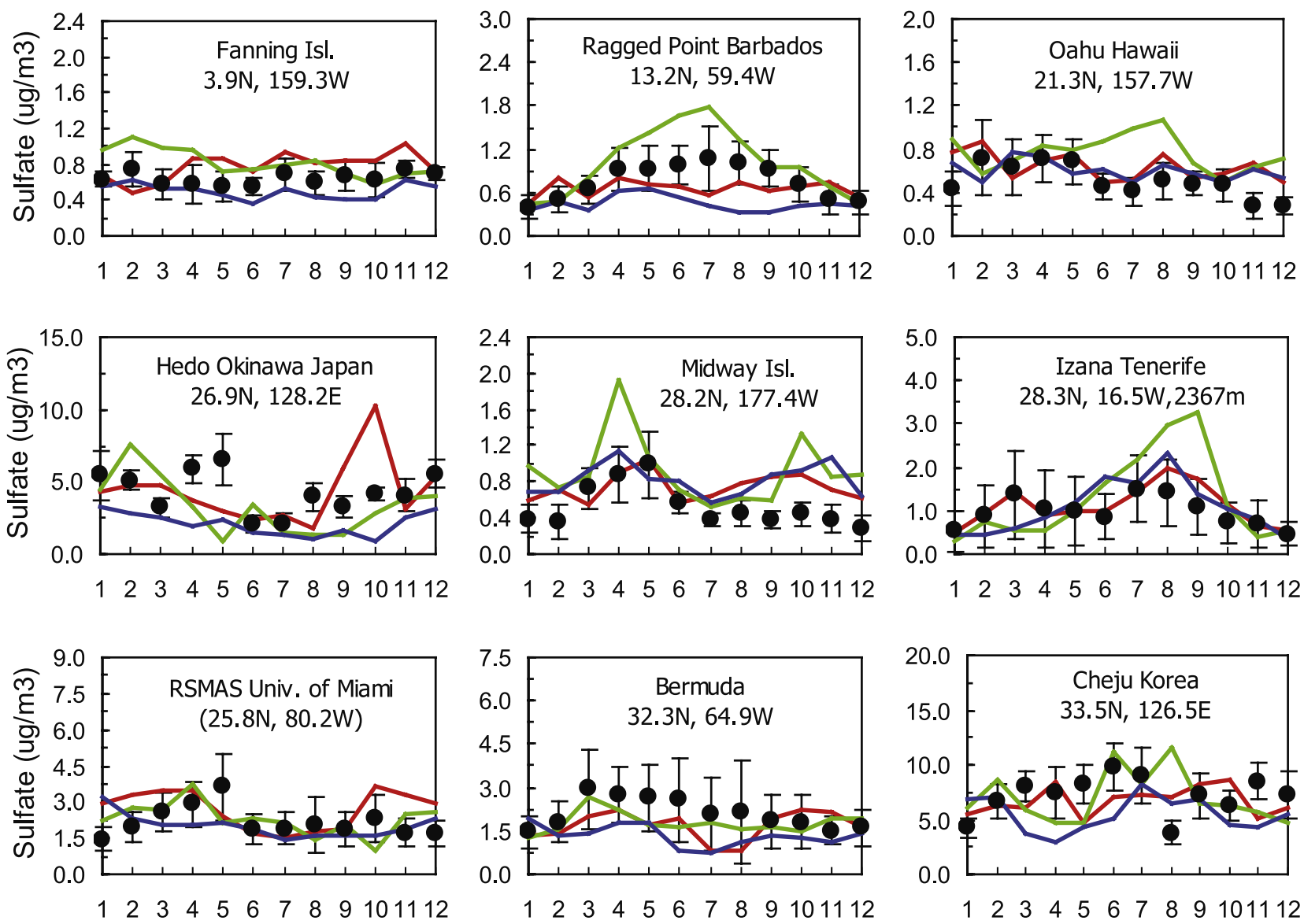

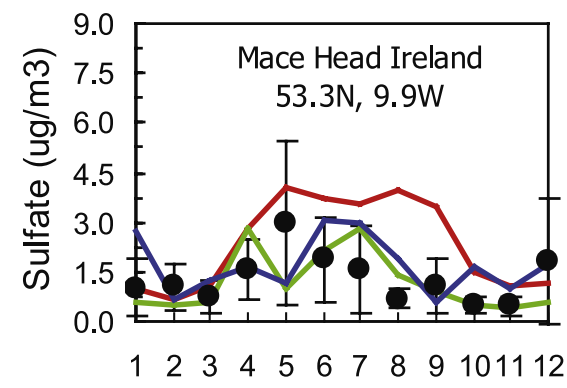

month

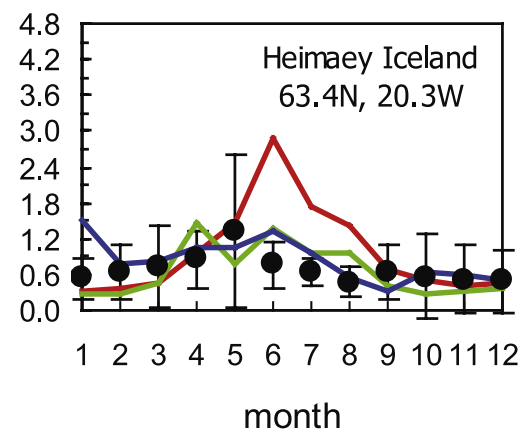

Figure 13. Same as Figure 12 but for 11 sites in the NH.

lower than the observed values at two Arctic sites (Alert and Barrow), even for the DAO data which has the strongest transport of pollutants toward the North Pole. FVGCM has the lowest concentrations due to its strong wet scavenging. A similar underestimation was obtained by Liousse et al. [1996] and Chung and Seinfeld [2002]. Possible explanations include the underestimation of local sources and overestimation of wet scavenging. The $\mathrm{BC}$ predictions are compared to the observations at Mace Head, Ireland (only observation data from the continental sector are shown here). The observed peaks in February and May are offset by 1 and 2 months with all the three meteorological data sets. FVGCM is the best in predicting the low summertime concentrations, while DAO and GISS predictions are too high. The model reproduces the seasonal cycle of BC concentrations at Jungfraujoch, Switzerland (a site in the free troposphere) with a minimum in the winter months. FVGCM does the best job in capturing the peaks in April and July. The peaks reproduced by DAO are offset by 1 month. Both DAO and GISS overpredict the BC concentrations in the summer.

[40] Figure 18e compares the modeled and observed BC concentrations at Mauna Loa, Hawaii. DAO predicts a peak in February, which is earlier than the observed one. FVGCM reproduces the March peak, but is lower and both FVGCM and GISS predict a peak in May which is not present in the observations. DAO overpredicts the $\mathrm{BC}$ concentrations in all the seasons except the spring. All three meteorological fields 

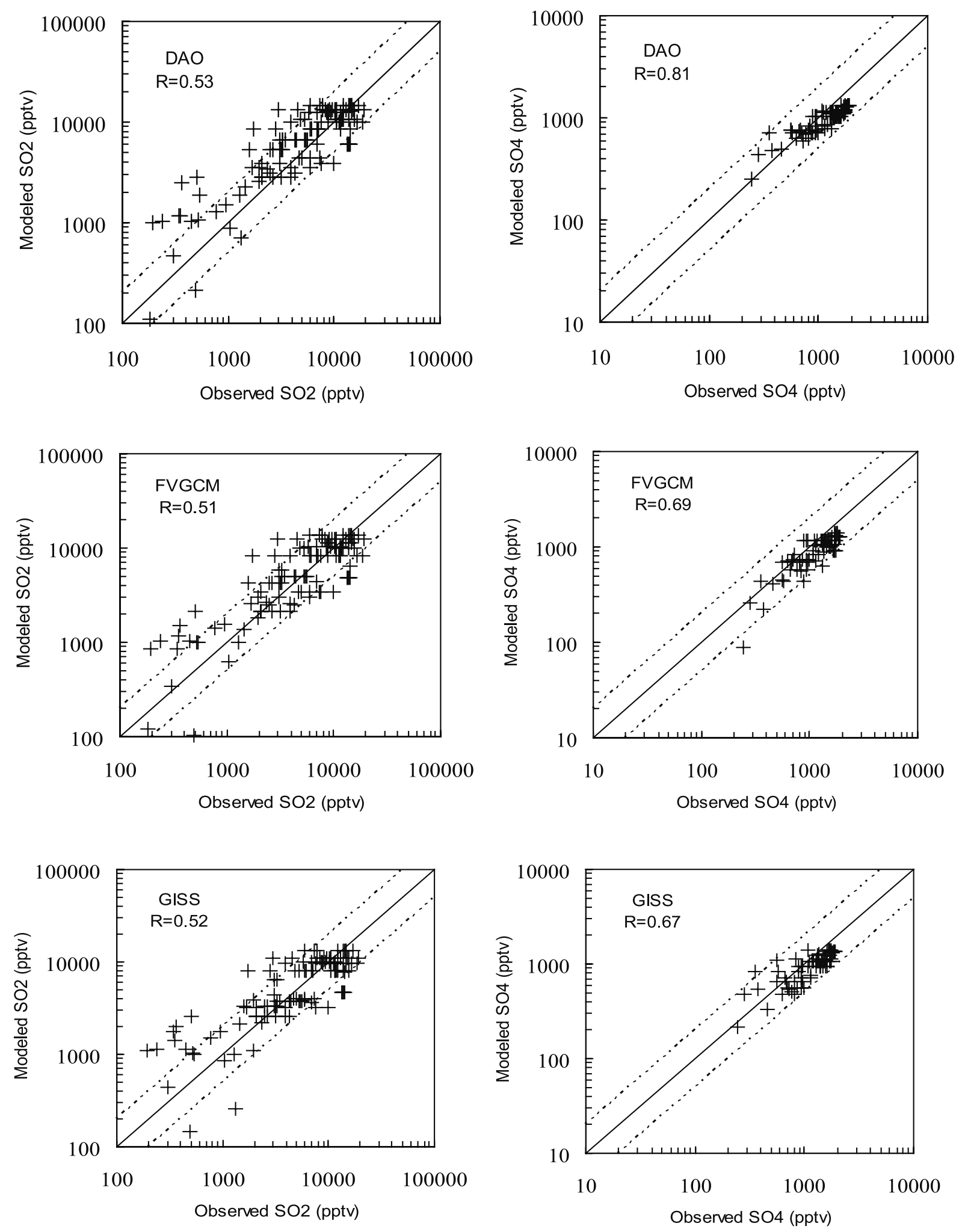

Figure 14. Comparison of annually averaged (left) $\mathrm{SO}_{2}$ and (right) sulfate mass concentrations at 75 North American (EMEFS) sites in 1989. The solid lines are 1:1, and the dashed lines are 2:1 or 1:2. Correlation coefficients $(R)$ are included in the figure. 

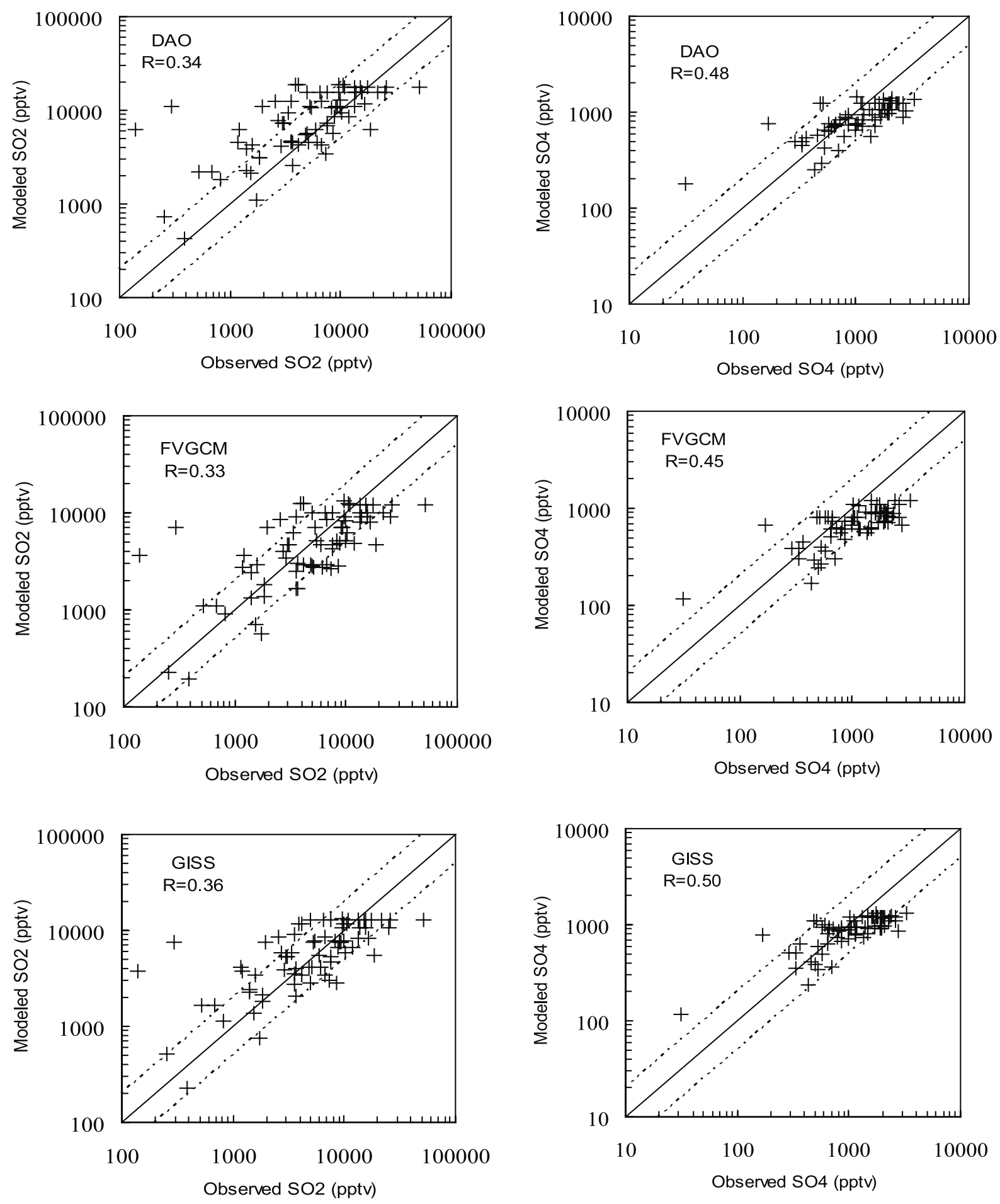

Figure 15. Same as Figure 14, but at 69 European (EMEP) sites in 1986.

capture the seasonal cycle of $\mathrm{BC}$ concentrations at Amsterdam Island with a maximum from June to September which results from biomass burning emissions, and FVGCM has the highest concentration. However the observed BC concentrations are underpredicted in other seasons. Figure $18 \mathrm{~g}$ shows a comparison of BC concentrations at Cape Grim, a remote site. The observation data include only the clean air sector [Heintzenberg and Bigg, 1990] and are severely overpredicted by the model. The simulation reflects the seasonal trend of observed $\mathrm{BC}$ at the two Antarctic sites shown in Figures $18 \mathrm{~h}$ and $18 \mathrm{i}$ with a peak in the austral spring. However the observations are underpredicted by DAO and FVGCM. The peak is correctly predicted by GISS, which has the weakest polar vortex and the lowest rainfall in the $\mathrm{SH}$ extratropical regions. 
Table 5. Modeled $\mathrm{SO}_{2}$ and $\mathrm{SO}_{4}$ Compared to Observations at North American and European Sites ${ }^{\mathrm{a}}$

\begin{tabular}{|c|c|c|c|c|c|c|c|c|c|c|c|c|}
\hline & \multicolumn{3}{|c|}{ Gross Bias (Absolute, pptv) } & \multicolumn{3}{|c|}{ Gross Error (Absolute, pptv) } & \multicolumn{3}{|c|}{ Gross Bias, \% } & \multicolumn{3}{|c|}{ Gross Error, \% } \\
\hline & DAO & FVGCM & GISS & $\mathrm{DAO}$ & FVGCM & GISS & $\mathrm{DAO}$ & FVGCM & GISS & DAO & FVGCM & GISS \\
\hline $\mathrm{SO}_{2}$ N. America & 797 & -129 & -523 & 2684 & 2543 & 2504 & 54 & 30 & 31 & 72 & 58 & 63 \\
\hline $\mathrm{SO}_{2}$ Europe & 1636 & -1757 & -876 & 4283 & 3998 & 3711 & 183 & 73 & 96 & 198 & 122 & 130 \\
\hline $\mathrm{SO}_{4}$ N. America & -264 & -282 & -258 & 310 & 315 & 323 & -15 & -20 & -15 & 24 & 25 & 28 \\
\hline $\mathrm{SO}_{4}$ Europe & -366 & -544 & -359 & 501 & 616 & 492 & -2 & -24 & -4 & 48 & 49 & 44 \\
\hline
\end{tabular}

${ }^{\text {a }}$ Gross bias in pptv is calculated as the sum of the difference between the model predictions and observations for each station, and averaged over all the locations while gross error in pptv is calculated as the absolute value of the difference between the model predictions and observations. Gross bias in percentage is calculated as the sum of the percentage difference between the model predictions and observations while gross error in percentage is calculated as the sum of the percentage of the absolute value of the difference between the model predictions and observations, both are averaged over all the stations. All calculations are based on the annual means for these sites.

[41] Figure 19 shows the modeled and observed seasonal variation of dust concentrations at eight ocean sites in the $\mathrm{SH}$ and ten sites in the $\mathrm{NH}$. In the remote region of the Antarctic (Mawson), the model reproduces the seasonal cycle of dust concentration, although the austral summer maximum is underpredicted (the measured standard deviation is particularly large during these months). None of the three meteorological data sets reproduce the peak in April at Marsh-King George Island, which is also not seen in the work of Ginoux et al. [2001] and Luo et al. [2003]. At Cape Grim, southeast of the Australian dust source, the model seems to reproduce the seasonal variation, however, its concentrations are too low in the austral summer. At Cape Point, near the Namibian dust source, the model simulates the increase of concentration from March to July, however, it overpredicts the concentration in all seasons. This overprediction also appeared in the work of Luo et al. [2003]. At Norfolk and New Caledonia, downwind of the Australian dust sources, all three data sets generally agree well with observations in both the concentrations and seasonal cycles except the concentrations are too high in September at New Caledonia for the DAO fields. The model underpredicts concentrations at Funafuti in the summer, and the same is true at Nauru in March and April especially with the GISS fields. In the $\mathrm{NH}$, the model generally reproduces the seasonal cycles at these sites. At Barbados, Izana Tenerife, and Miami, which are under the influence of the African dust source, FVGCM having the strongest advection of dust from the North African continent (see Figure 2), overpredicts the concentration during the summer at Barbados and Izana Tenerife but captures the summer maximum at Miami. However, the concentration in July and August at Bermuda is underpredicted by all three meteorological data sets. The model captures the seasonal cycles at Enewetak Atoll, Oahu Hawaii, Hedo, Midway Island, and Cheju Korea. However, the April maximum at Hedo and the spring maximum at Cheju are severely underpredicted, which was also evident in the results of Ginoux et al. [2001]. While DAO overpredicts the dust concentration at Mace Head, an extratropical site, FVGCM with the strongest wet scavenging underpredicts the concentration.

[42] The model-predicted sea salt surface concentrations are compared to observed data at nine $\mathrm{SH}$ sites and nine $\mathrm{NH}$ sites, in Figure 20. In the $\mathrm{SH}$, the observed seasonal variations are generally small. However, the model produces concentrations that are too high in the summer (e.g, Invercargill, Chatham Island, Wellington) or in February (e.g.,
Reunion Island). This may be caused by surface emissions that are too high. At the $\mathrm{NH}$ sites, the model predictions agree well with observations in terms of both concentrations and seasonal cycles for Oahu Hawaii, Midway, Miami, and Heimaey Iceland. While the model reproduces the seasonal variation (summer minimum and winter maximum) at Hedo Okinawa, Cheju, and Mace Head Ireland, the concentrations are too low in the NH winter months at Hedo, and too high from October to December at Mace Head. Generally, the differences in the sea salt concentrations simulated with the three meteorological data sets at these surface ocean sites are small.

\subsection{Interannual Variability in Aerosol Concentrations}

[43] We have performed two additional sets of simulations to examine the uncertainties associated with the interannual variability in aerosol concentrations. The first set of 5-year simulations (FVGCM 94-98) used FVGCM fields which were obtained every 3 hours from the NASA/ GMAO finite volume GCM forced by each respective year's (1994-1998) SST (the reference 1-year FVGCM fields are one of the 5 years of data set). The second set of 3-year simulations (GEOS-4) used the assimilated meteorological fields from the NASA GEOS-4 Data Assimilation System (DAS), representing 2001, 2004, and 2005. Year 2001 is a La Nina year with low North Atlantic Oscillation (NAO) Index, while year 2004 and 2005 are El Nino years with high NAO Index. The fields are obtained as 6-hour averages. GEOS-4 DAS uses the NASA/GMAO finite-volume GCM as part of its assimilation system, and thus GEOS-4 fields have the same horizontal and vertical resolution as the FVGCM fields.

[44] Table 7 lists the global averaged annual burden from simulations with the FVGCM 94-98, GEOS-4 data sets along with those using the DAO and the FVGCM data sets. The global burden difference between the FVGCM and FVGCM 94-98 data sets is negligibly small. The differences between the FVGCM and GEOS-4 data sets are larger but still within $15 \%$ on the global mean. Timmreck and Schulz [2004] obtained a larger difference for their dust simulation in the nudged and climatological mode of the ECHAM climate model. In their study they also included the difference in dust emissions due to changing surface winds. In Table 7 burdens with the DAO fields for year 1997 which is a GEOS-1 product with a different climate model are also listed for comparison. The GEOS-4 burden is in between the range derived by the DAO and FVGCM fields for $\mathrm{SO}_{2}$ and sulfate, very close to that with the 

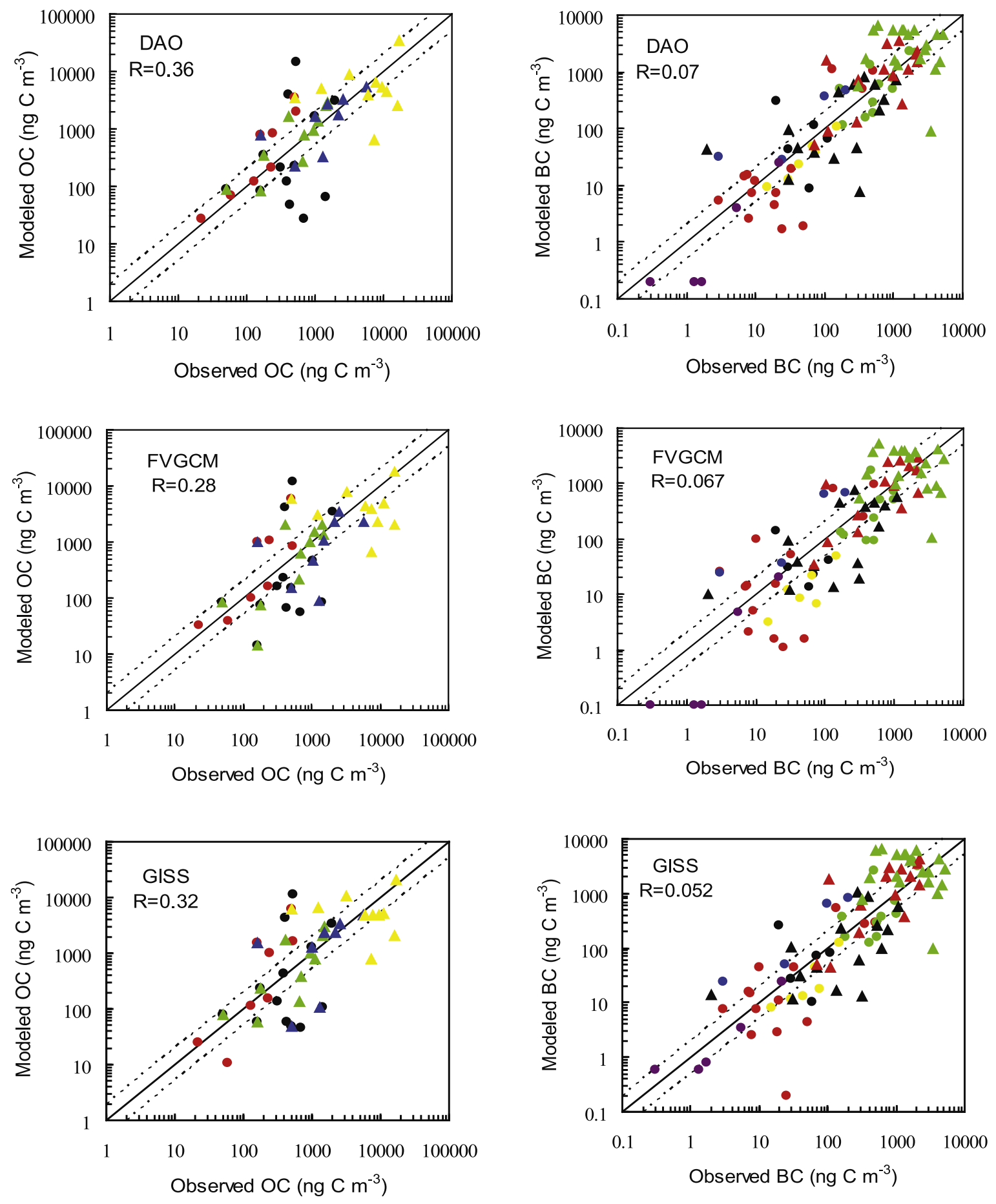

\begin{tabular}{lll}
$\bullet$ & Liousse NH \\
Cooke Island & $\bullet$ & Liousse SH \\
Cooke Urban & $\Delta$ & Cooke Rural \\
\hline
\end{tabular}

\begin{tabular}{|ll|}
\hline - Liousse Atlantic & $\bullet$ Liousse Pacific \\
L Liousse NH Rural & $\bullet$ Liousse SH Rural \\
Liousse NH Remote & $\bullet$ Liousse SH Remote \\
$\Delta$ Cooke Remote & $\Delta$ Cooke Rural \\
$\Delta$ Cooke Urban & \\
\hline
\end{tabular}

Figure 16. Comparison of observed and simulated mass concentrations of $\mathrm{OC}$ and $\mathrm{BC}$ at a number of locations. The solid lines are 1:1, and the dashed lines are 2:1 or 1:2. Correlation coefficients $(R)$ are included in the figure. Observations refer to those summarized by Liousse et al. [1996] and Cooke et al. [1999]. 
Table 6. Modeled OC and BC Compared to Observations ${ }^{\mathrm{a}}$

\begin{tabular}{|c|c|c|c|c|c|c|c|c|c|c|c|c|}
\hline & \multicolumn{3}{|c|}{ Gross Bias (Absolute, $\mu \mathrm{g} \mathrm{m}^{-3}$ ) } & \multicolumn{3}{|c|}{$\begin{array}{c}\text { Gross Error } \\
\left(\text { Absolute, } \mu \mathrm{g} \mathrm{m}^{-3}\right)\end{array}$} & \multicolumn{3}{|c|}{ Gross Bias, \% } & \multicolumn{3}{|c|}{ Gross Error, \% } \\
\hline & $\mathrm{DAO}$ & FVGCM & GISS & $\mathrm{DAO}$ & FVGCM & GISS & $\mathrm{DAO}$ & FVGCM & GISS & $\mathrm{DAO}$ & FVGCM & GISS \\
\hline Campaign OC & 0.53 & -0.44 & 0.74 & 1.82 & 1.70 & 2.11 & 157 & 85 & 208 & 192 & 155 & 254 \\
\hline Campaign $\mathrm{BC}$ & 0.06 & -0.17 & -0.09 & 0.91 & 0.84 & 1.02 & 113 & 70 & 105 & 168 & 138 & 163 \\
\hline IMPROVE OC & -0.70 & -0.71 & -0.60 & 0.74 & 0.75 & 0.63 & -42 & -43 & -33 & 44 & 45 & 35 \\
\hline IMPROVE BC & -0.09 & -0.10 & -0.08 & 0.11 & 0.12 & 0.10 & -31 & -38 & -27 & 39 & 44 & 35 \\
\hline
\end{tabular}

${ }^{\text {a }}$ The definitions for gross bias and error in absolute and percentage values are the same as those in the Table 5 caption, whereas the absolute values are in unit of $\mu \mathrm{g} \mathrm{m}^{-3}$. The calculations are based on the monthly mean for campaign-based OC and BC, and the annual mean for the IMPROVE data.

FVGCM fields for mineral dust and sea salt, and is $\sim 10 \%$ higher than those with both the DAO and FVGCM fields for $\mathrm{OM}$ and $\mathrm{BC}$.

[45] Figure 21 shows the annual averaged relative difference (maximum minus minimum divided by the mean in percent) of vertically integrated sulfate, BC, dust, and sea salt concentrations between the DAO, FVGCM, and GISS fields, between the 5 years of FVGCM 94-98 fields, and between the 3 years of GEOS-4 fields. The interannual variability in vertically integrated sulfate concentrations is smaller than the differences due to using the three meteorological data sets. It is larger (by a factor of 3 ) for $\mathrm{BC}$ and dust in the tropics and in the storm track regions over the Atlantic. Away from these regions, the interannual variability in BC and dust concentrations is generally smaller than the differences due to using different meteorological data sets. The interannual variability for sea salt is small (within $40 \%$ ) over the ocean but is larger over the land where its concentrations are very small. It is interesting to note that the largest differences in sulfate, $\mathrm{BC}$, and dust concentrations due to using different meteorological data sets and due to the interannual variability in meteorological fields occurs largely in the tropics (e.g., over Indonesia) and in the storm track regions (e.g., over the Atlantic). This suggests that cloud and precipitation processes may be responsible for the differences in simulated aerosol concentrations. It is also interesting to note that the interannual variability of sulfate, $\mathrm{BC}$, and dust concentrations in the FVGCM 94-98 fields is larger than the interannual variability in the GEOS-4 fields in these same regions. In addition large differences in sulfate, BC, and dust concentrations among the three meteorological data sets also occur in the polar regions.

[46] Figures 22 and 23 are the same as Figures 12 and 13, respectively, but for model results with 3-year GEOS-4 fields. Comparing with the results with the FVGCM fields shown in Figures 12 and 13, the assimilated GEOS-4 fields perform better at many sites (e.g., in SH: Palmer Antarctica, Marsh King George Island, and America Samoa; in NH: Barbados, Hedo Okinawa Japan, and Izana Tenerife). However, at several sites (e.g., Norfolk, Reunion Island, Fanning Island, and Oahu Hawaii) the overestimation of sulfate concentration is worse. Differences between 3-year simulations can be large (a factor of 2) in these oceanic sites depending on the region and season. However, these differences are generally smaller than the differences due to the use of different meteorological data sets (see Figures 12 and 13). The interannual variability in dust concentrations can be larger than that of sulfate (shown in Figure 24) in these oceanic sites; however, it is generally within the range of the differences due to using different meteorological data sets (see Figure 19). The interannual variability in sea salt concentration near the surface is small (less than 40\%) except in some continental regions where the concentrations are very low. We also examined the variations in aerosol concentrations in the free troposphere (e.g., $500 \mathrm{hPa}$ ) and found similar differences due to the interannual variability as that near the surface for sulfate, BC, and dust (figure not shown). Differences in sea salt concentration at $500 \mathrm{hPa}$ are larger than those near the surface; however, they are generally smaller than the uncertainty with different meteorological data sets. We note that the interannual variability in dust and sea salt concentrations can be much larger when the emission uncertainties due to source parameterization and surface wind speeds are considered [Luo et al., 2003; Timmreck and Schulz, 2004], which is, however, not included in this study.

\section{Aerosol Optical Depth and Direct Radiative Forcing}

[47] The aerosol optical depth (AOD) at $550 \mathrm{~nm}$ was calculated off-line based on the present-day monthly average aerosol concentrations calculated with DAO, FVGCM, and GISS fields. Temperature, surface pressure, and specific humidity from the three meteorological data sets were read in every 6 hours to reflect the effect of diurnal variation of these meteorological fields (especially relative humidity) on the aerosol optical properties (for the hygroscopic growth of soluble aerosol species). The aerosol optical properties at $550 \mathrm{~nm}$ (specific extinction, single scattering albedo, and asymmetry factor) are first calculated based on the Mie theory (see Table 8). Fossil fuel sulfate, OM, and BC are assumed to be internally mixed and also hydrophilic. The same is true for biomass burning $\mathrm{OM} / \mathrm{BC}$. Natural sulfate and sea salt are soluble and thus experience hygroscopic growth. Lookup tables for the optical property changes with RH were derived for the hydrophilic or soluble aerosols with wet sizes calculated from the Köhler theory. Also for dust and sea salt, the optical properties are calculated separately for the four size bins $(0.05-0.63 \mu \mathrm{m}, 0.63-$ $1.26 \mu \mathrm{m}, 1.26-2.5 \mu \mathrm{m}$, and 2.5-10 $\mu \mathrm{m})$. Aerosol optical parameters in twelve wavelength bands ranging from 0.175 to $3.846 \mu \mathrm{m}$ were derived by weighting the optical properties at each wavelength by the solar flux. A radiative transfer model for shortwave radiation from Grant et al. [1997, 1999] is used to calculate the aerosol direct solar forcing for both clear sky and all-sky cases. For the all-sky calculations the maximum random cloud overlap scheme is 

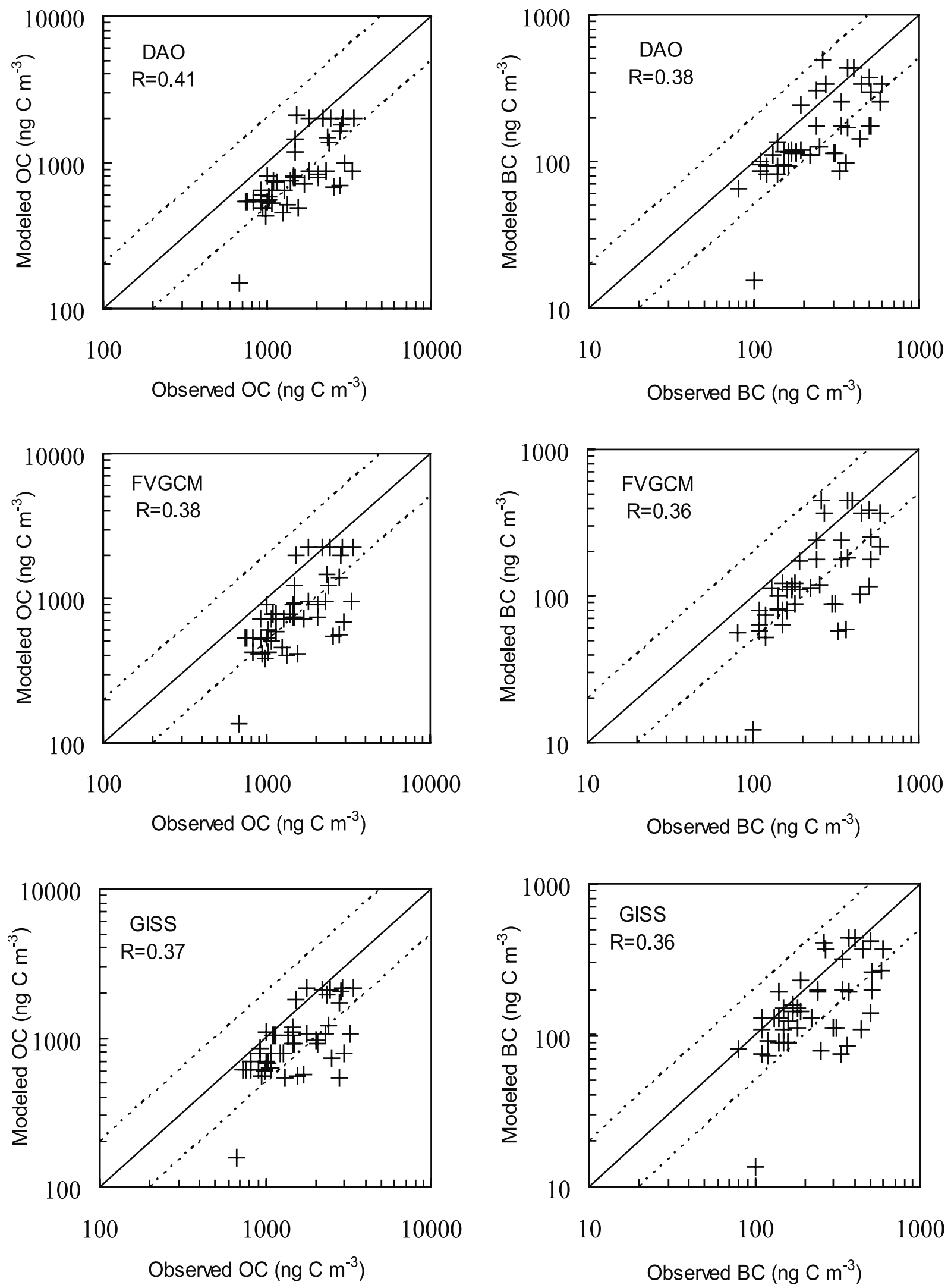

Figure 17. Simulated (left) $\mathrm{OC}$ and (right) $\mathrm{BC}$ concentrations versus observations from the IMPROVE network. The solid lines are 1:1, and the dashed lines are $2: 1$ or $1: 2$. Correlation coefficients $(R)$ are included in the figure. 
(a) Alert, Canada

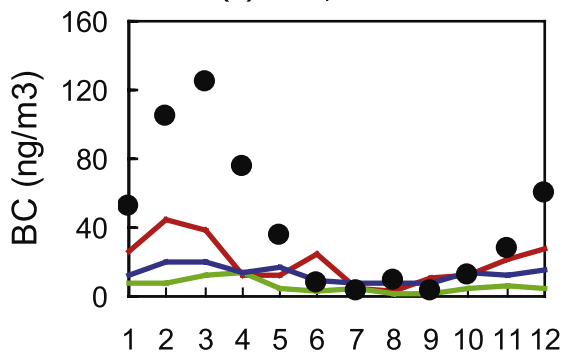

(d) Jungfraujoch, Switzerland

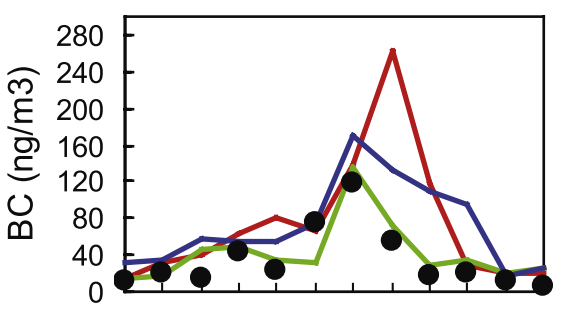

$\begin{array}{lllllllllll}1 & 2 & 3 & 4 & 5 & 6 & 7 & 8 & 9 & 10 & 1112\end{array}$

(g) Cape Grim, Tasmania

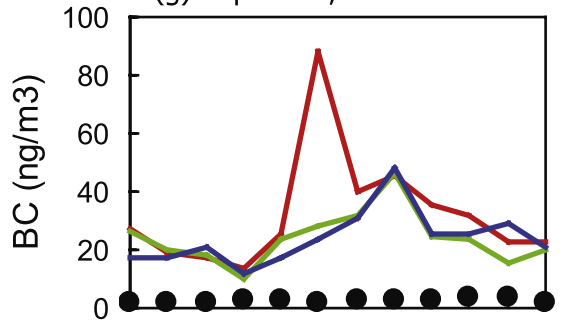

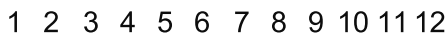
month (b) Barrow, Alaska

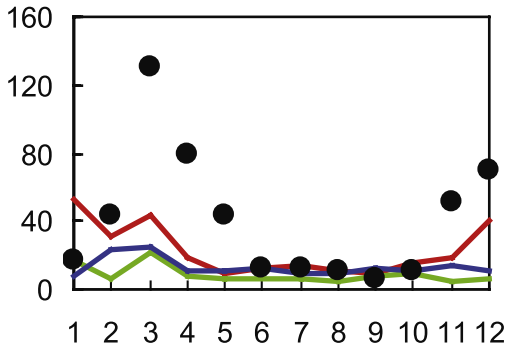

(e) Mauna Loa, Hawaii

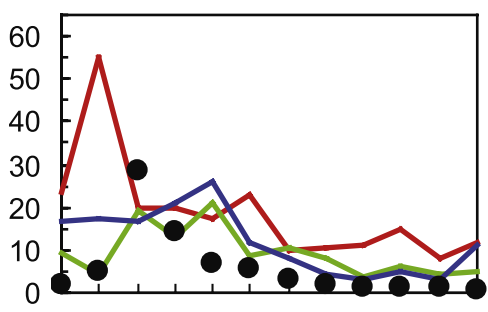

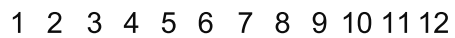

(h) Halley, Antarctica

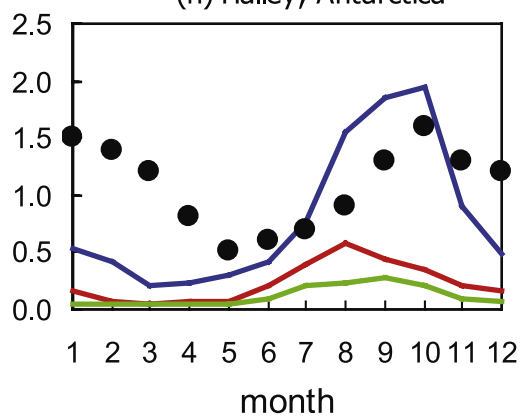

(c) Mace Head, Ireland

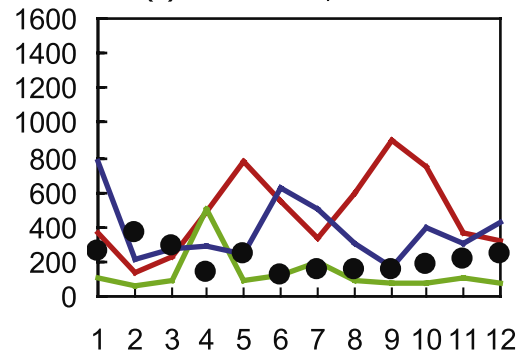

(f) Amsterdam Island

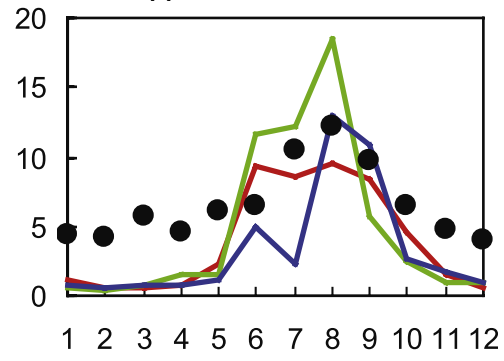

(i) Amundsen-Scott, S. Pole

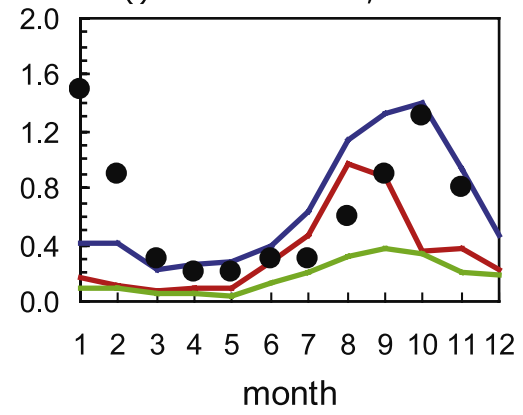

Figure 18. Comparison of modeled and observed seasonal variation of $\mathrm{BC}$ concentrations at various sites: (a) Alert, Canada $\left(82.5^{\circ} \mathrm{N}, 62.3^{\circ} \mathrm{W}\right)$ [Hopper et al., 1994], (b) Barrow, Alaska $\left(71.2^{\circ} \mathrm{N}, 156.3^{\circ} \mathrm{W}\right)[$ Bodhaine, 1995], (c) Mace Head, Ireland $\left(53.3^{\circ} \mathrm{N}, 9.9^{\circ} \mathrm{W}\right)$ [Cooke et al., 1997], (d) Jungfraujoch, Switzerland $\left(46.5^{\circ} \mathrm{N}, 9^{\circ} \mathrm{E}, 3.5 \mathrm{~km}\right.$ asl) [Nyeki et al., 1998], (e) Mauna Loa, Hawaii $\left(19.3^{\circ} \mathrm{N}, 155.4^{\circ} \mathrm{W}, 3.4 \mathrm{~km}\right.$ asl) [Bodhaine, 1995], (f) Amsterdam Island, France $\left(38^{\circ} \mathrm{S}, 77^{\circ} \mathrm{E}\right)$ [Wolff and Cachier, 1998], (g) Cape Grim, Tasmania $\left(40.7^{\circ} \mathrm{S}, 144.7^{\circ} \mathrm{E}\right)$ [Heintzenberg and Bigg, 1990], (h) Halley, Antarctica $\left(75.6^{\circ} \mathrm{S}, 26.2^{\circ} \mathrm{W}\right)$ [Wolff and Cachier, 1998], and (i) Amundsen-Scott, South Pole (89 ${ }^{\circ} \mathrm{S}, 102^{\circ} \mathrm{W}, 2.8$ asl) [Bodhaine, 1995 ]. Model results are in solid lines (DAO: in red; FVGCM: in green; GISS: in blue), and observed data in dots.

used [Feng et al., 2004]. Common surface albedo field (from the DAO data set) is used in the aerosol radiative effect calculations for all three meteorological data sets.

[48] Figures 25 and 26 show the AOD at $550 \mathrm{~nm}$ in January and July, respectively, calculated with DAO, FVGCM, and GISS fields, along with the satellite retrievals for the year 2000 from the Multiangle Imaging SpectroRadiometer (MISR) and MODIS instruments. The global distribution patterns are similar for the calculated AOD with the three meteorological data sets. However, regional differences are still significant. For example, in January, the AOD in the $\mathrm{NH}$ extratropics is $0.02-0.04$ with FVGCM, much lower than the values of $0.06-0.1$ predicted with the DAO data; this is consistent with the lower aerosol concentrations due to the weakest poleward transport with the FVGCM fields. In the SH storm track regions the AOD is generally higher with FVGCM than with DAO in both January and July, due to the efficient uplifting of sea salt by the FVGCM convective updrafts. Comparing with the MISR AOD over land, the model reproduces the maxima in the industrialized regions. However, the AOD in North America is underestimated in January with FVGCM. The model captures the maxima in central Africa in January due to biomass burning aerosol and in Northern Africa and Saudi Arabia in July due to mineral dust. Comparing with the MODIS AOD over the ocean, the model underpredicts the AOD over the central Pacific between $10^{\circ} \mathrm{S}$ and $30^{\circ} \mathrm{S}$ and most of the Indian Ocean in January, over the central Pacific between $10^{\circ} \mathrm{S}$ and $10^{\circ} \mathrm{N}$ in July due to the weak transport of aerosols from the South America especially in the DAO and GISS simulations. GISS has weak westerly transport by advection from African continents in the tropics (see Figure 2) as compared 

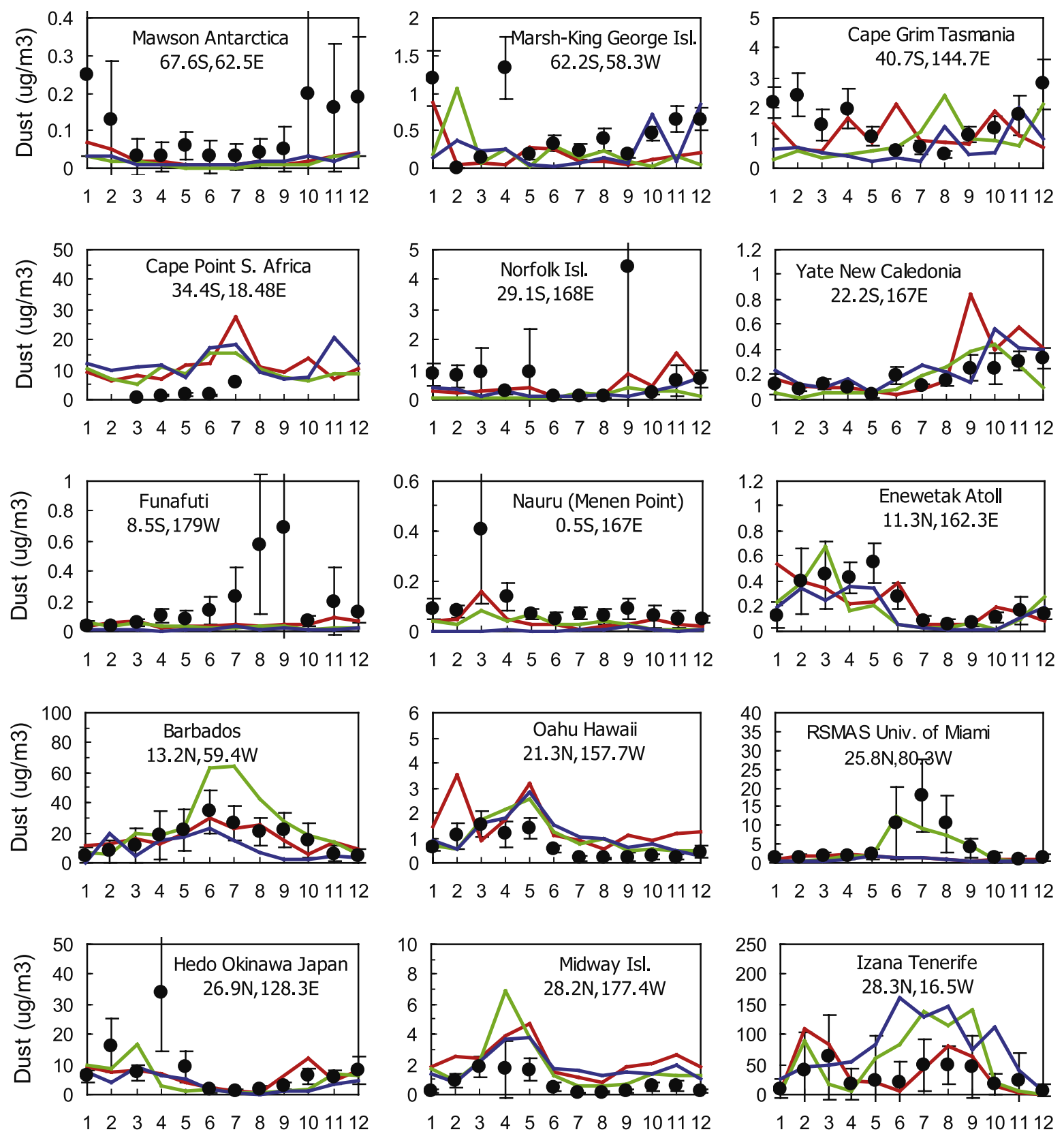

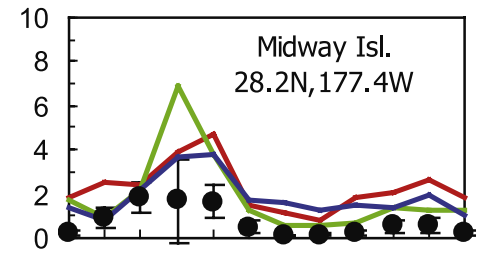

$\begin{array}{llllllllll}1 & 2 & 3 & 4 & 5 & 6 & 7 & 8 & 9 & 101112\end{array}$

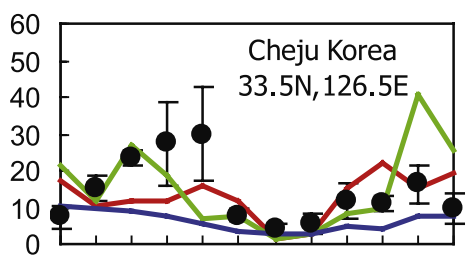

$\begin{array}{llllllllll}1 & 2 & 3 & 4 & 5 & 6 & 7 & 8 & 9 & 101112\end{array}$

month

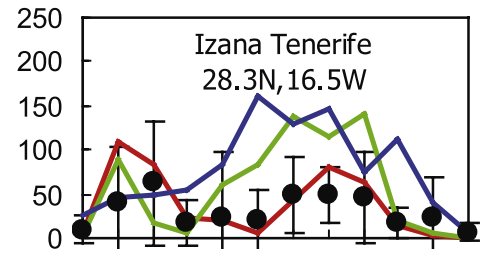

$\begin{array}{llllllllll}1 & 2 & 3 & 4 & 5 & 6 & 7 & 8 & 9 & 101112\end{array}$

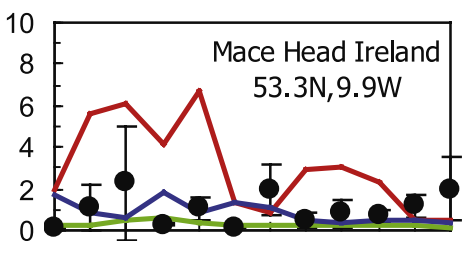

$\begin{array}{llllllllll}1 & 2 & 3 & 4 & 5 & 6 & 7 & 8 & 9 & 101112\end{array}$

month

Figure 19. Same as Figure 12 but for mineral dust at 18 sites in the $\mathrm{SH}$ and $\mathrm{NH}$.

to the MODIS data, which is also evident in the underestimation of dust concentrations in the summer at Barbados. It should be noted that there are still large uncertainties in the AOD among different satellite retrievals [Myhre et al., 2004] and MODIS is biased high over land and MISR data biased high over the ocean [Kinne et al., 2006]. Table 9 gives the model calculated annual and global mean AOD with DAO, FVGCM, and GISS fields. The total AOD $(0.120-0.131)$ is similar among these meteorological data sets and falls in the range suggested by other global models 


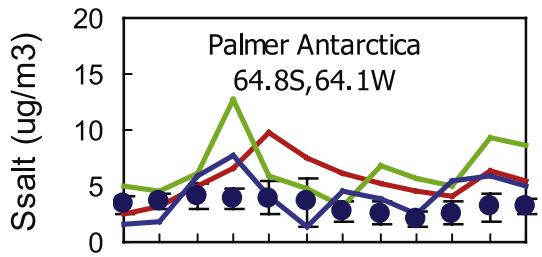

$\begin{array}{lllllllllll}1 & 2 & 3 & 4 & 5 & 6 & 7 & 8 & 9 & 10 & 1112\end{array}$
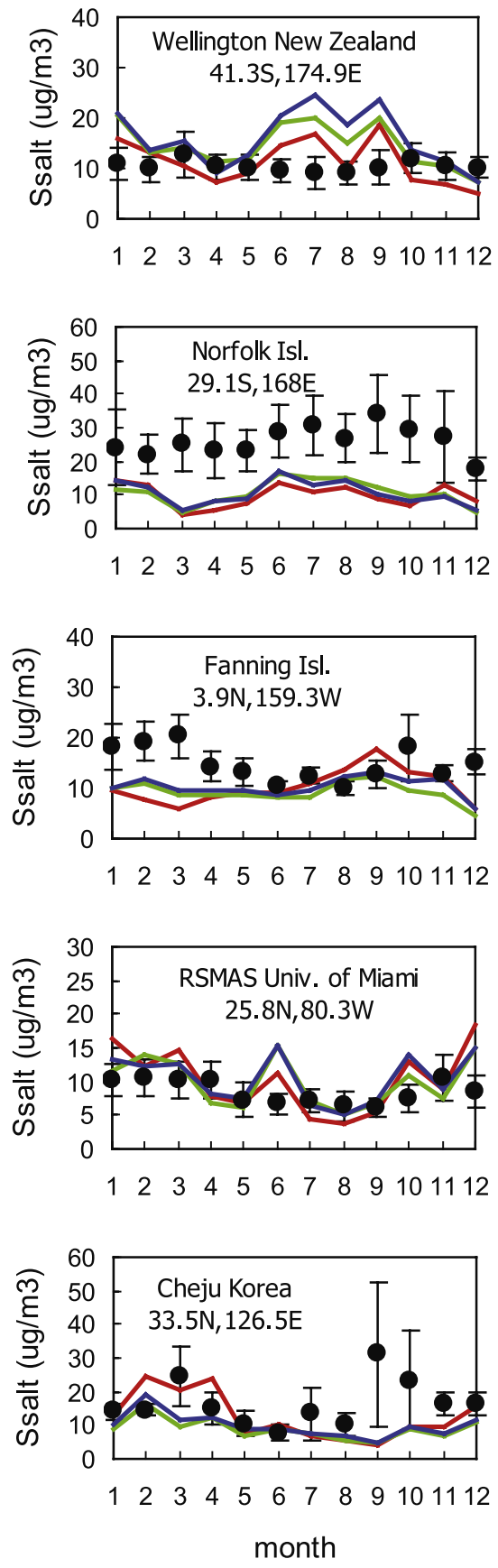

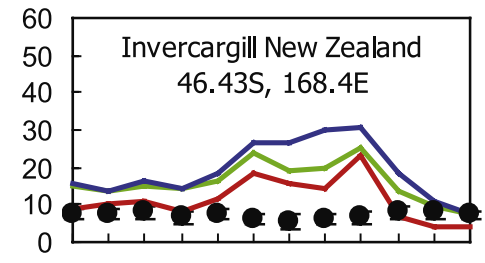

$\begin{array}{llllllllll}1 & 2 & 3 & 4 & 5 & 6 & 7 & 8 & 9 & 101112\end{array}$
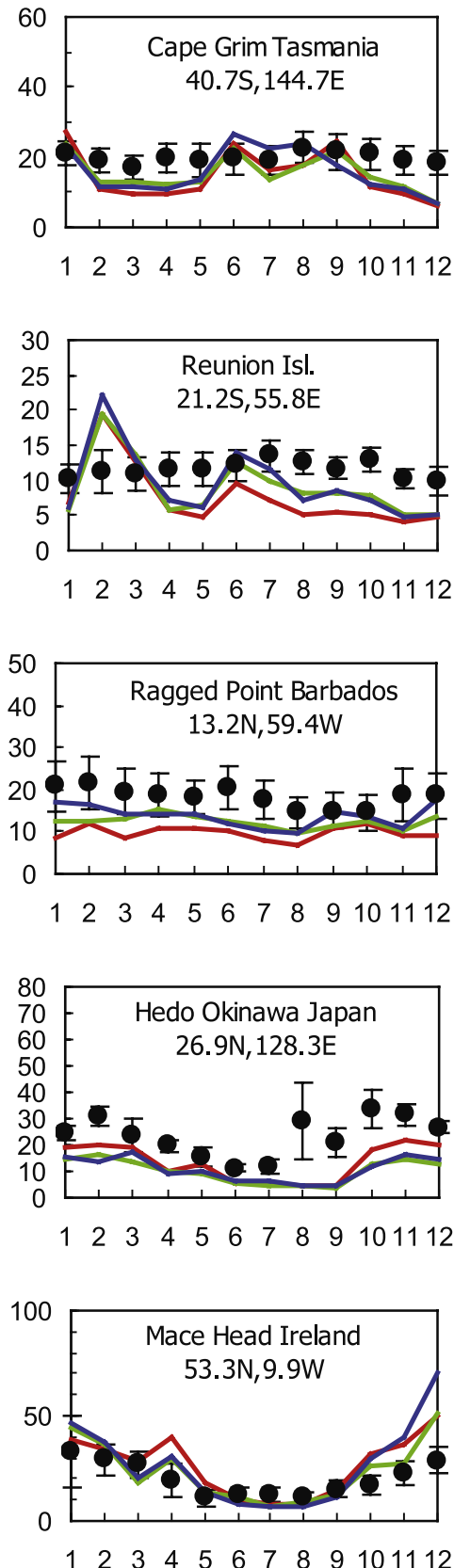

month
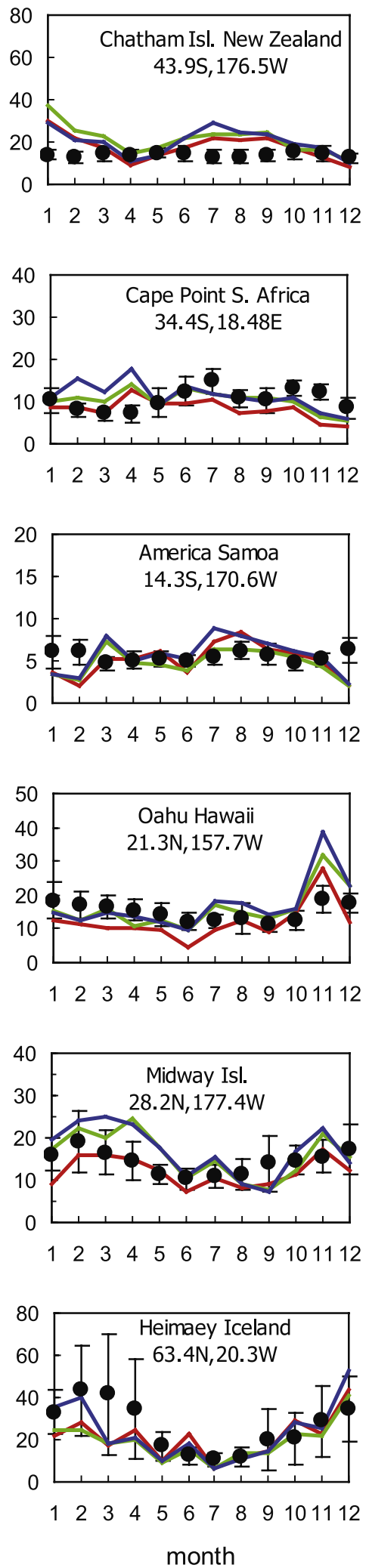

Figure 20. Same as Figure 12 but for sea salt at 18 sites in the SH and NH.

participating in the AEROCOM model intercomparison (i.e., 0.116-0.155) [Kinne et al., 2006]. Our AOD is also similar to the global annual mean AOD of 0.135 based on the AERONET measurements but lower than the satellite composite of 0.151 [Kinne et al., 2006]. The contributions from different aerosol components, however, differ significantly for sulfate and sea salt with different meteorological data. FVGCM has the lowest contributions from sulfate and 
Table 7. Global Burdens, $\mathrm{Tg}^{\mathrm{a}}$

\begin{tabular}{lclcc}
\hline & DAO (GEOS-1) & \multicolumn{1}{c}{ GEOS-4 } & FVGCM & FVGCM 94-98 \\
\hline $\mathrm{SO}_{2}$ & 0.75 & $0.68 \pm 0.006$ & 0.55 & $0.55 \pm 0.007$ \\
$\mathrm{SO}_{4}$ & 0.93 & $0.73 \pm 0.01$ & 0.65 & $0.66 \pm 0.007$ \\
$\mathrm{OM}$ & 1.43 & $1.56 \pm 0.07$ & 1.41 & $1.44 \pm 0.01$ \\
$\mathrm{BC}$ & 0.18 & $0.19 \pm 0.01$ & 0.17 & $0.17 \pm 0.001$ \\
Dust & 27.3 & $20.8 \pm 0.22$ & 19.4 & $19.4 \pm 0.34$ \\
Sea salt & 3.4 & $5.4 \pm 0.08$ & 5.3 & $5.4 \pm 0.02$ \\
\hline
\end{tabular}

${ }^{\mathrm{a}}$ For GEOS-4 and FVGCM 94-98 fields, averaged burden and standard deviation over the simulation years are listed. dust to the total AOD but these low values are compensated for by the even higher AOD contributed from sea salt.

[49] Figure 27 shows annual mean all-sky aerosol radiative effect due to all present-day aerosols at the surface and at the top-of-the-atmosphere (TOA) calculated with the DAO, FVGCM, and GISS fields. The radiative effect of aerosols is negative at the surface at all locations. The distribution patterns are similar between DAO, FVGCM, and GISS with large negative effect (over $15 \mathrm{~W} \mathrm{~m}^{-2}$ ) in the industrial regions, mineral dust and biomass burning source regions. However, regional differences are quite large: DAO
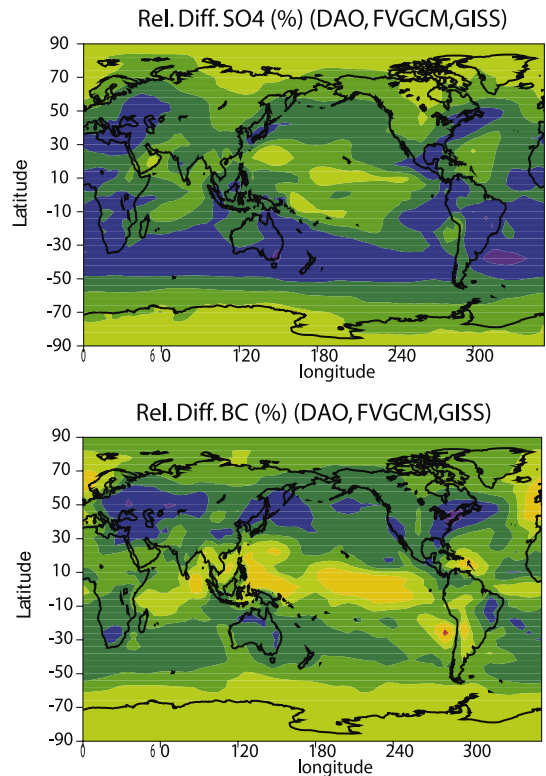

Rel. Diff. Dust (\%) (DAO, FVGCM,GISS)
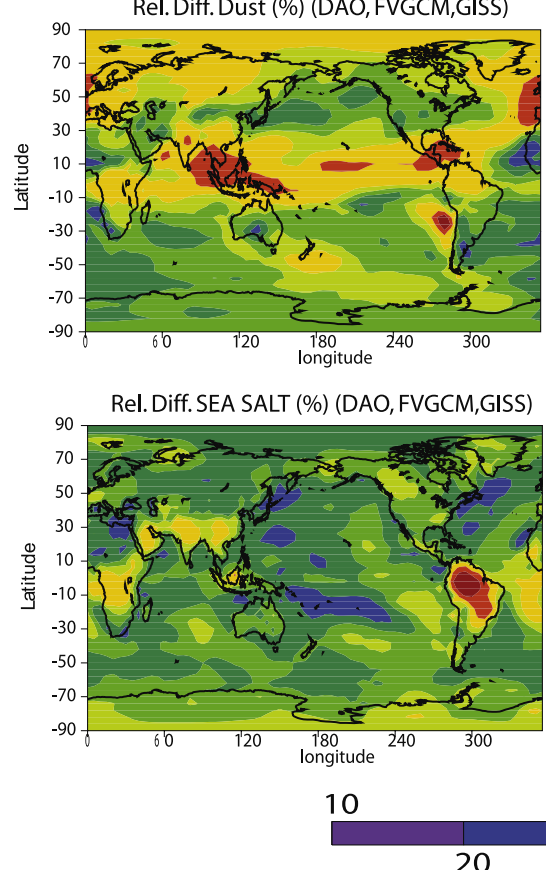

Rel.Diff.SO4 (\%) (FVGCM 94_98)

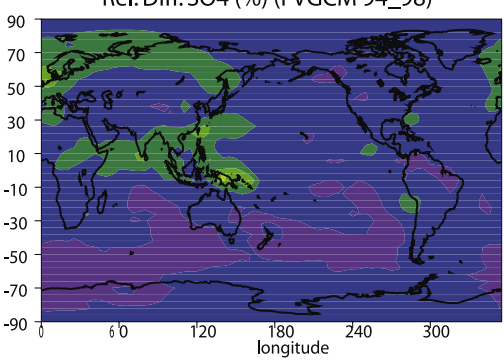

Rel.Diff. BC (\%) (FVGCM 94_98)

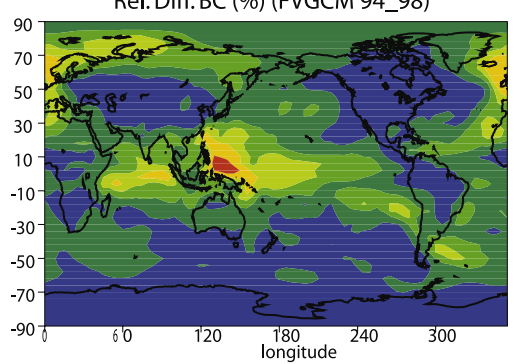

Rel. Diff.Dust (\%) (FVGCM 94_98)
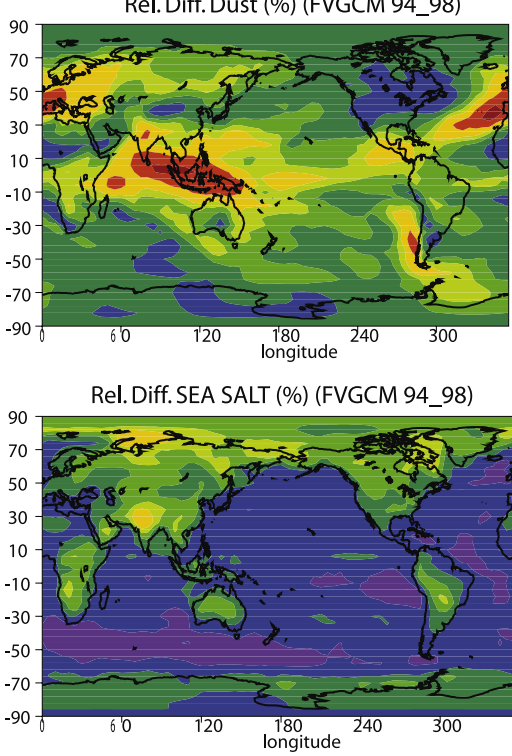
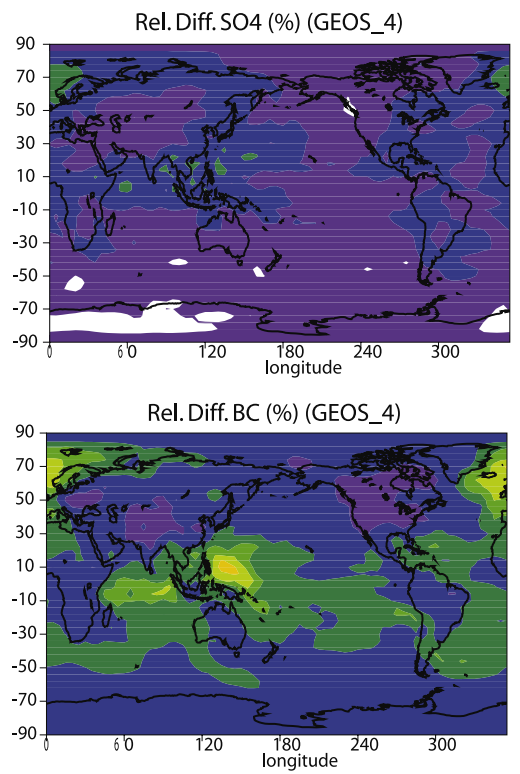

Rel.Diff.Dust (\%) (GEOS_4)

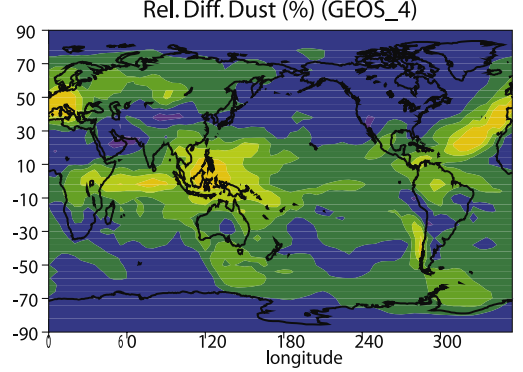

Rel.Diff. SEA SALT (\%) (GEOS_4)

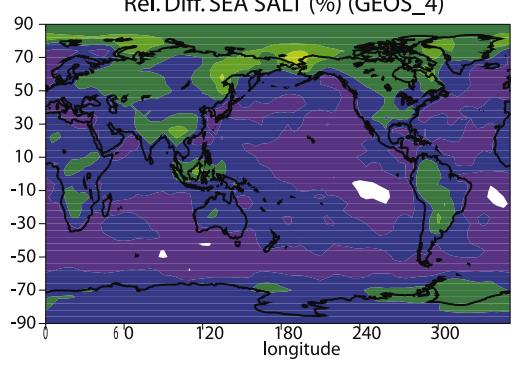

230

Figure 21. Annual averaged relative difference (max-min divided by the mean in \%) of vertically integrated sulfate, $\mathrm{BC}$, dust, and sea salt concentrations (left) between the DAO, FVGCM and GISS fields, (middle) between the 5 years of FVGCM 94-98 fields, and (right) between the 3 years of GEOS-4 fields. 

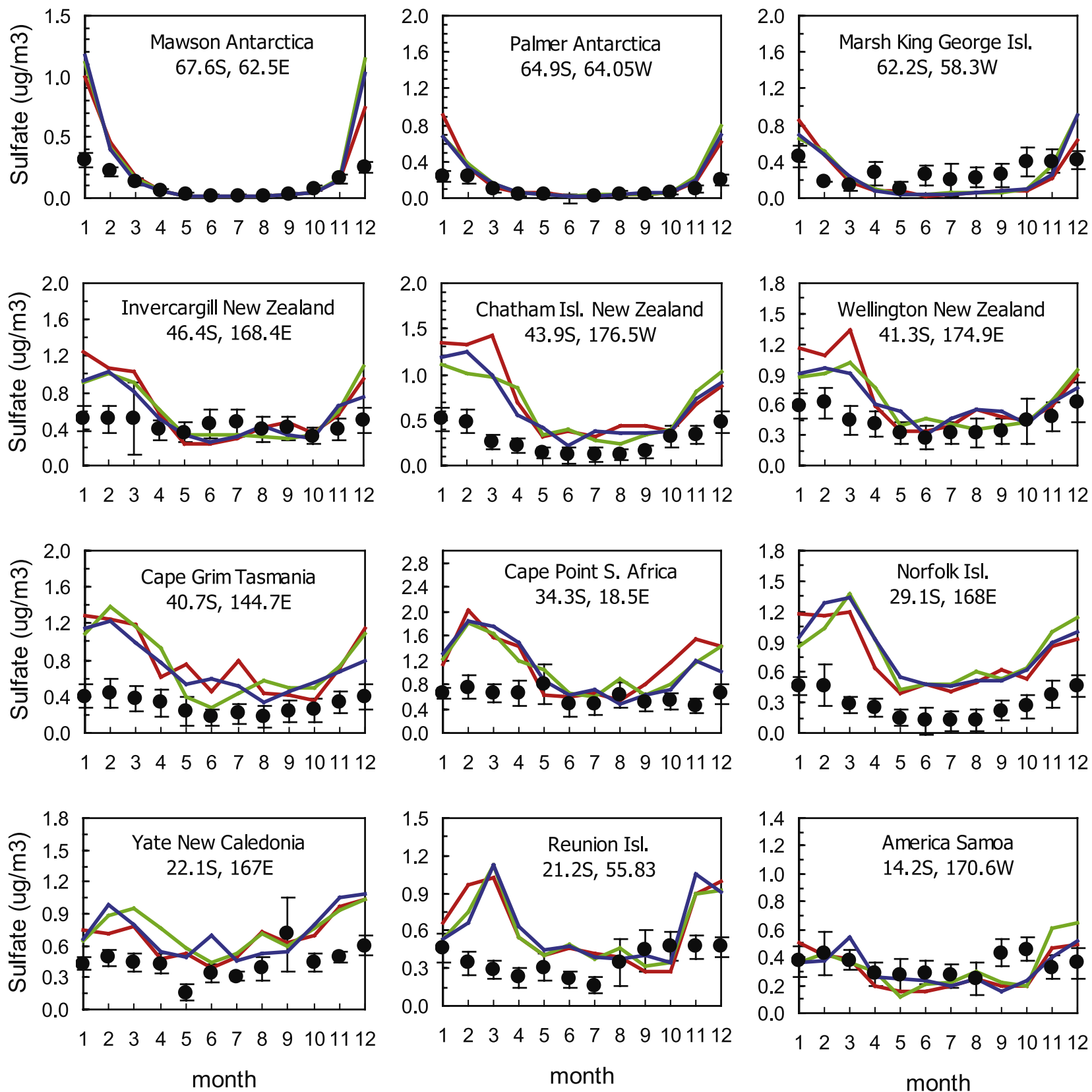

Figure 22. Same as Figure 12 but for model results with the GEOS-4 fields (year 2001: in red; year 2004: in green; year 2005: in blue).

predicts a larger negative effect in the continental outflows over the Pacific and Atlantic in the NH midlatitudes, consistent with its higher sulfate burden. Looking at the clear-sky forcing at the surface, the difference is smaller. Thus the different cloud fields associated with the three meteorological data sets (see Figure 6) also contribute to the all-sky radiative differences. A larger negative effect is also predicted with the DAO fields around Saudi Arabia and the Arabian Sea. FVGCM predicts a smaller negative effect in the $\mathrm{NH}$ extratropics because of the less efficient transport of pollutants. There is larger negative effect with the FVGCM fields from $50^{\circ} \mathrm{S}$ to $70^{\circ} \mathrm{S}$ than that with the DAO fields due to the higher sea salt burdens with FVGCM. The radiative differences at the surface between different meteorological data sets also appear for the effects at the TOA. The positive TOA effects predicted with the three meteorological data sets around the North Pole and in a region over the Asian Gobi desert is due to high surface albedos there. Table 10 gives the annual global mean present-day aerosol radiative effect at the TOA and at surface. The negative aerosol radiative effect estimates at surface and at the TOA are much smaller in the all-sky case than those in the clear-sky case due to the effect of clouds. The difference in the clear-sky radiative effect is small between the three meteorological data sets. It is larger for the all-sky case (i.e., up to $0.6 \mathrm{~W} \mathrm{~m}^{-2}$ ), while DAO has the largest negative effect.

[50] Anthropogenic aerosol forcing was also calculated with the different meteorological data sets. For this estimate, 

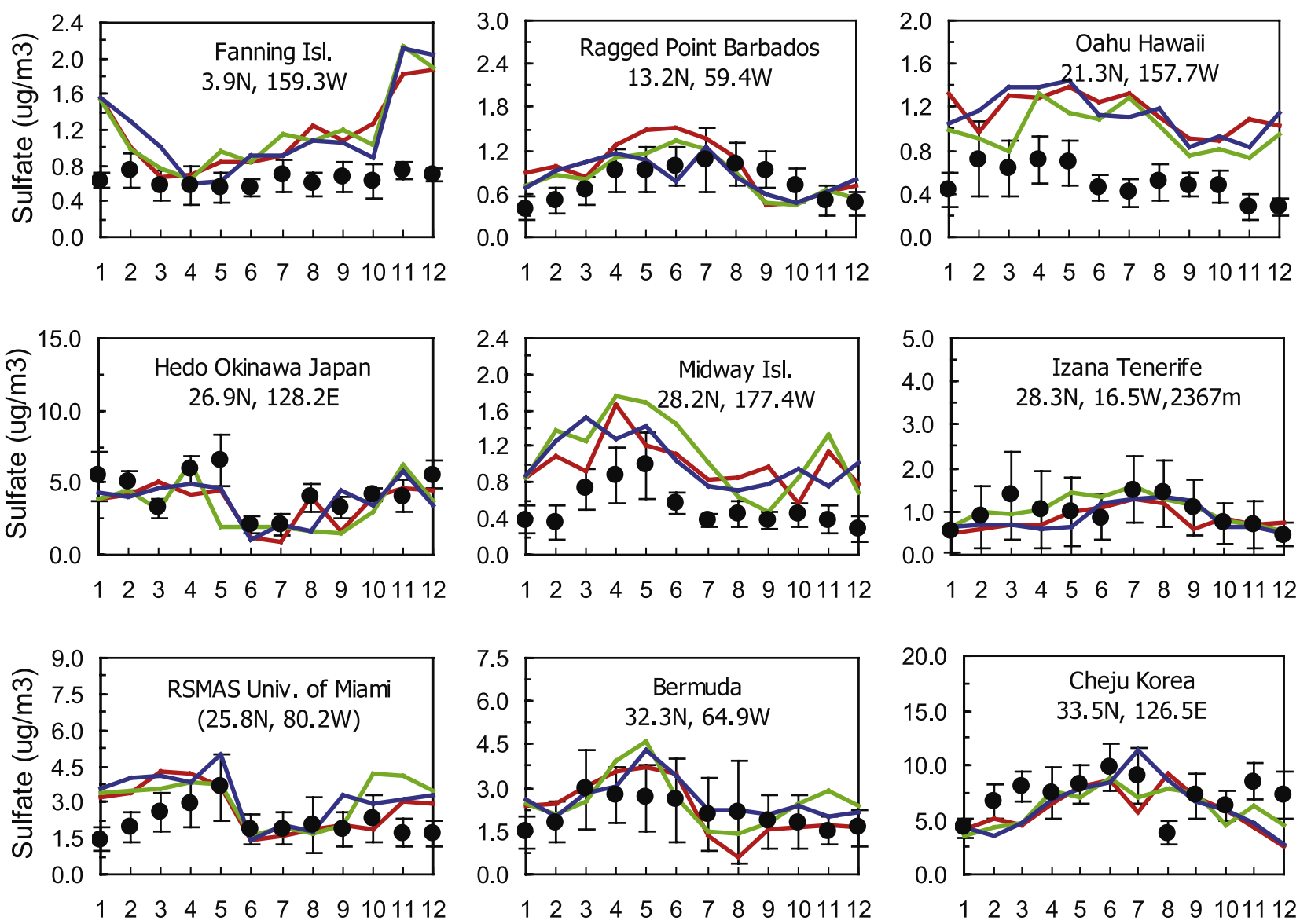

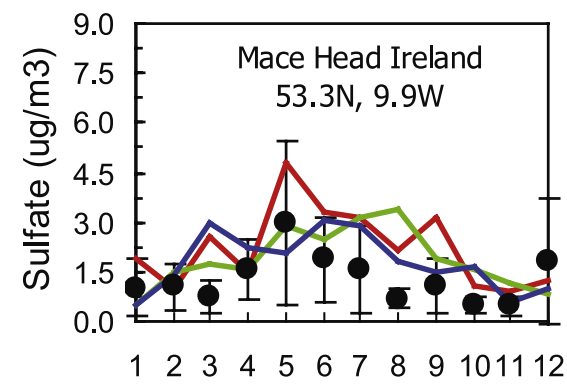

month

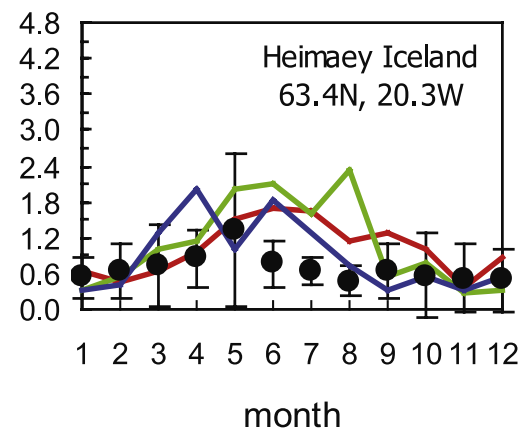

Figure 23. Same as Figure 22 but for 11 sites in the NH.

we calculated the preindustrial aerosol concentrations and subtracted the present-day and preindustrial aerosol radiative effects. The GMI aerosol model was run with the three meteorological data sets but using preindustrial emissions and preindustrial oxidant fields $\left(\mathrm{OH}, \mathrm{HO}_{2}\right.$, and $\left.\mathrm{O}_{3}\right)$. For preindustrial emissions, we set fossil fuel $\mathrm{SO}_{2}$ and carbonaceous aerosol (OM and $\mathrm{BC}$ ) emissions to zero, and used the present-day emissions for the natural DMS, volcanic $\mathrm{SO}_{2}$, natural OM, mineral dust, and sea salt. The biomass burning $\mathrm{OM}$ and $\mathrm{BC}$ emissions from Ito and Penner [2005] for year 1870 were used and we assumed that there was no significant change in biomass burning emissions from the preindustrial times to the year 1870 . The total biomass burning emissions in 1870 are $27 \%$ and $30 \%$ of the present-day values for OM and $\mathrm{BC}$, respectively. In order to calculate preindustrial oxidant fields, the GMI tropospheric chemistry model was run with the respective meteorological data using the preindustrial emissions of chemical species (B. Duncan, private communication, 2005). Tropospheric $\mathrm{O}_{3}$ concentrations increase by $50-100 \%$ from the preindustrial atmosphere to present, and similar increases take place for the $\mathrm{HO}_{2}$ radical. The $\mathrm{OH}$ concentration maxima in the tropics, however, are slightly reduced (by $\sim 10 \%$ ) in the present-day simulations compared to the preindustrial values. These results are generally consistent with the findings from Wang and Jacob [1998]. Figure 28 is the same as Figure 27 except for the anthropogenic aerosol forcing. The positive TOA forcing predicted with the three meteorological data sets in the polar regions and in regions over the Asian Gobi and Sahara deserts is again due to the high surface albedos there, whereas that 

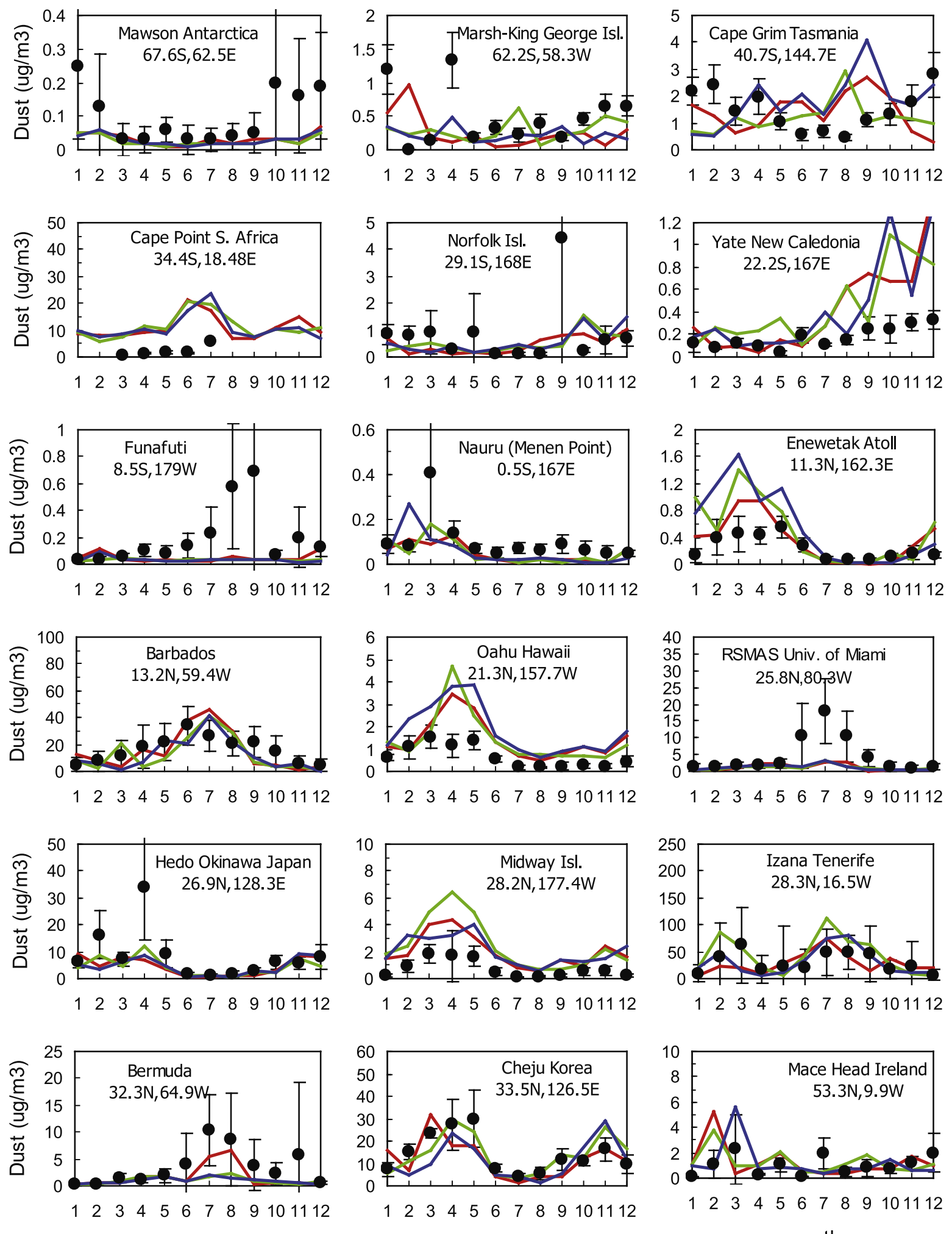

month

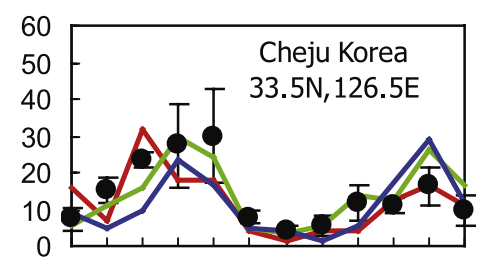

$\begin{array}{llllllllll}1 & 2 & 3 & 4 & 5 & 6 & 7 & 8 & 9 & 101112\end{array}$ month

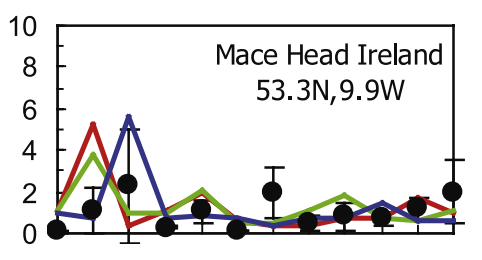

$\begin{array}{llllllllll}1 & 2 & 3 & 4 & 5 & 6 & 7 & 8 & 9 & 101112\end{array}$

month

Figure 24. Same as Figure 22 but for mineral dust at 18 sites in the $\mathrm{SH}$ and $\mathrm{NH}$.

in the tropics over the ocean is due to the presence of cloud and $\mathrm{BC}$ above the clouds [Penner et al., 1998], as the clear sky forcing there is negative. Large absolute differences in the anthropogenic aerosol forcing at the surface in the $\mathrm{NH}$ extratropics and both at surface and at the TOA in the continental outflows over the NH oceans are evident. For example, over the North Atlantic the all-sky anthropogenic aerosol forcing (negative) at surface is $2-5 \mathrm{~W} \mathrm{~m}^{-2}$ for DAO, compared to values between 0.5 and $1.0 \mathrm{~W} \mathrm{~m}^{-2}$ for FVGCM. Figure 29 shows the relative difference (maximum minus 
Table 8. Aerosol Physical and Optical Properties at $550 \mathrm{~nm}^{\mathrm{a}}$

\begin{tabular}{|c|c|c|c|c|c|c|c|}
\hline Aerosol Type & $r_{0}, \mu \mathrm{m}$ & $\sigma_{\mathrm{g}}$ & $\rho, \mathrm{g} \mathrm{cm}^{-3}$ & $k_{\mathrm{e}}, \mathrm{m}^{2} \mathrm{~g}^{-1}$ & $\omega$ & $g$ & Refractive Index ${ }^{\mathrm{c}}$ \\
\hline Sulfate & 0.05 & 1.9 & 1.769 & $3.508(11.490)$ & $1.000(1.000)$ & $0.6278(0.744)$ & $1.53-10^{-7} i$ \\
\hline Fossil Fuel $\mathrm{SO}_{4} / \mathrm{BC}^{-\mathrm{OM}^{\mathrm{b}}}$ & 0.05 & 1.9 & $\begin{array}{l}1.5(\mathrm{BC}) \\
1.2(\mathrm{OM})\end{array}$ & & & & $\begin{array}{l}1.80-0.50 i(\mathrm{BC}) \\
1.53-10^{-7} i(\mathrm{OM})\end{array}$ \\
\hline $\begin{array}{l}f_{\mathrm{BC}}=4 \% \\
f_{\mathrm{BC}}=10 \%\end{array}$ & & & & $\begin{array}{l}3.967(9.810) \\
4.807(7.526)\end{array}$ & $\begin{array}{l}0.896(0.957) \\
0.780(0.853)\end{array}$ & $\begin{array}{l}0.634(0.731) \\
0.639(0.698)\end{array}$ & \\
\hline Biomass burning $\mathrm{BC} / \mathrm{OM}^{\mathrm{b}}$ & 0.08 & 1.65 & $\begin{array}{l}1.5(\mathrm{BC}) \\
1.2(\mathrm{OM})\end{array}$ & & & & $\begin{array}{l}1.80-0.50 i(\mathrm{BC}) \\
1.53-10^{-7} i(\mathrm{OM})\end{array}$ \\
\hline $\begin{array}{l}f_{\mathrm{BC}}=8 \% \\
\text { Dust }\end{array}$ & $0.01,0.045,0.275$ & $1.4,1.6,1.5$ & & $5.877(8.399)$ & $0.824(0.875)$ & $0.637(0.689)$ & \\
\hline$(0.05-0.63 \mu \mathrm{m})$ & & & 2.6 & 2.460 & 0.990 & 0.710 & $1.53-0.0014 i$ \\
\hline$(0.63-1.25 \mu \mathrm{m})$ & & & 2.6 & 0.786 & 0.967 & 0.704 & $1.53-0.0014 i$ \\
\hline$(1.25-2.5 \mu \mathrm{m})$ & & & 2.6 & 0.381 & 0.942 & 0.785 & $1.53-0.0014 i$ \\
\hline$(2.5-10.0 \mu \mathrm{m})$ & & & 2.6 & 0.118 & 0.865 & 0.841 & $1.53-0.0014 i$ \\
\hline Sea Salt & $0.04,0.41$ & $1.92,1.7$ & & & & & \\
\hline$(0.05-0.63 \mu \mathrm{m})$ & & & 2.2 & $2.500(10.354)$ & $1.000(1.000)$ & $0.788(0.761)$ & $1.38-5.8 \times 10^{-7}$ \\
\hline$(0.63-1.25 \mu \mathrm{m})$ & & & 2.2 & $0.903(4.012)$ & $1.000(1.000)$ & $0.692(0.820)$ & $1.38-5.8 \times 10^{-7}$ \\
\hline$(1.25-2.5 \mu \mathrm{m})$ & & & 2.2 & $0.501(2.060)$ & $1.000(1.000)$ & $0.802(0.840)$ & $1.38-5.8 \times 10^{-7}$ \\
\hline$(2.5-10.0 \mu \mathrm{m})$ & & & 2.2 & $0.254(1.064)$ & $1.000(1.000)$ & $0.834(0.857)$ & $1.38-5.8 \times 10^{-7}$ \\
\hline
\end{tabular}

${ }^{\mathrm{a}} \mathrm{Here}, r_{0}$ is modal radius; $\sigma_{\mathrm{g}}$ is geometric standard deviation; $\rho$ is density; $k_{\mathrm{e}}$ is extinction coefficient; $\omega$ is single scattering albedo; $g$ is asymmetry factor. For $k_{\mathrm{e}}, \omega, g$, the values in the parenthesis are given at $80 \%$ relative humidity for hydrophilic or soluble aerosol, and all other values are given at dry conditions.

${ }^{\mathrm{b}} \mathrm{Here}, f_{\mathrm{BC}}$ is dry volume fraction of $\mathrm{BC}$ in the internal mixture.

${ }^{\circ}$ References for refractive indices: Toon et al. [1976] for sulfate, Twitty and Weinman [1971] for BC, Toon et al. [1976] for OM, Myhre et al. [2003] for dust, and d'Almeida et al. [1991] for sea salt.

minimum divided by the mean in percent) in the all-sky anthropogenic aerosol forcing at surface and at the TOA along with the averaged forcing from the three data sets. The relative difference at the surface is smaller (less than $40 \%$ ) in the continental source regions where the forcing is larger. Away from sources over the oceans (especially near the tropics) and in the polar regions the difference reaches more than a factor of 2 . The same is true for aerosol forcing at the TOA where regional differences can be even larger (by a factor of 4-5). Table 10 gives the global annual mean difference between present-day and preindustrial aerosol radiative effects (i.e., the anthropogenic aerosol forcing) at the TOA and at surface. The all-sky anthropogenic aerosol forcing at the TOA is $-0.75,-0.35$, and $-0.40 \mathrm{~W} \mathrm{~m}^{-2}$, respectively, for the DAO, FVGCM, and GISS fields, which may be compared to the AEROCOM derived forcing of +0.04 to $-0.41 \mathrm{~W} \mathrm{~m}^{-2}$ [Schulz et al., 2006]. Our clearsky anthropogenic aerosol forcing at the TOA ranges from -1.0 to $-1.3 \mathrm{~W} \mathrm{~m}^{-2}$, which may be compared to the AEROCOM derived clear-sky forcing of -0.29 to $-0.94 \mathrm{~W} \mathrm{~m}^{-2}$. The clear-sky forcing based on observational studies driven by satellite retrievals is larger and more negative (e.g., $-1.9 \mathrm{~W} \mathrm{~m}^{-2}$ from Bellouin et al. [2005] and $-1.10 \mathrm{~W} \mathrm{~m}^{-2}$ (over ocean) and $-1.80 \mathrm{~W} \mathrm{~m}^{-2}$ (over land) from $\mathrm{Yu}$ et al. [2006]).

[51] We have run sensitivity tests using the same gasphase oxidant fields for $\mathrm{OH}, \mathrm{HO}_{2}$, and $\mathrm{O}_{3}$ concentrations in both the present-day and preindustrial simulations for all three meteorological data sets. These oxidants had prescribed concentrations taken from monthly averages in a present-day simulation of photochemically active compounds by the GRANTOUR model [Penner et al., 1994]. The general distribution patterns of $\mathrm{SO}_{2}$ and sulfate are not changed much with the common oxidant fields for all the three meteorological data sets, although regional concentration differences can be large $(\sim 50 \%)$. Global sulfate burden is reduced in the sensitivity tests by $9 \%$, $5 \%$, and $8 \%$ for the DAO, FVGCM, and GISS data sets, respectively. The global distributions of aerosol optical depth, the present-day and the anthropogenic aerosol forcing are also not changed much. The global annual average all-sky present-day aerosol forcing at the TOA is changed from $-2.6 \mathrm{~W} \mathrm{~m}^{-2}$ in the standard run for the DAO data set to $-2.4 \mathrm{~W} \mathrm{~m}^{-2}$ in the sensitivity run, and the all-sky anthropogenic aerosol forcing at the TOA changes from -0.75 to $-0.67 \mathrm{~W} \mathrm{~m}^{-2}$. The differences for the FVGCM and GISS data sets are very small. Thus most of the differences in sulfate aerosol concentrations are due to the different meteorological data sets, not due to the different $\mathrm{OH}, \mathrm{HO}_{2}$, and $\mathrm{O}_{3}$ fields.

\section{Summary and Conclusions}

[52] Current available aerosol model intercomparisons are often constrained by difficulties in the interpretation of model differences, as participating models have different added complexities, different physical and chemical schemes and related parameters, different meteorological fields, and often different emission sources. In this study, under the NASA GMI framework, the differences and uncertainties of aerosol simulations for sulfate, organic carbon, black carbon, dust, and sea salt solely due to the meteorology are analyzed and quantified. Three meteorological data sets available from the NASA DAO GCM, GISS-II' GCM, and NASA FVGCM are used to drive the same aerosol model. It is suggested that the differences in the precipitation, convective mass flux, and horizontal advection from the three meteorological data sets are the three key fields accounting for the large differences in the model-calculated aerosol concentrations.

[53] The differences for sulfate and carbonaceous aerosol in the source regions (e.g., North America and Europe) near the surface are small for the three meteorological data sets, 
DAO
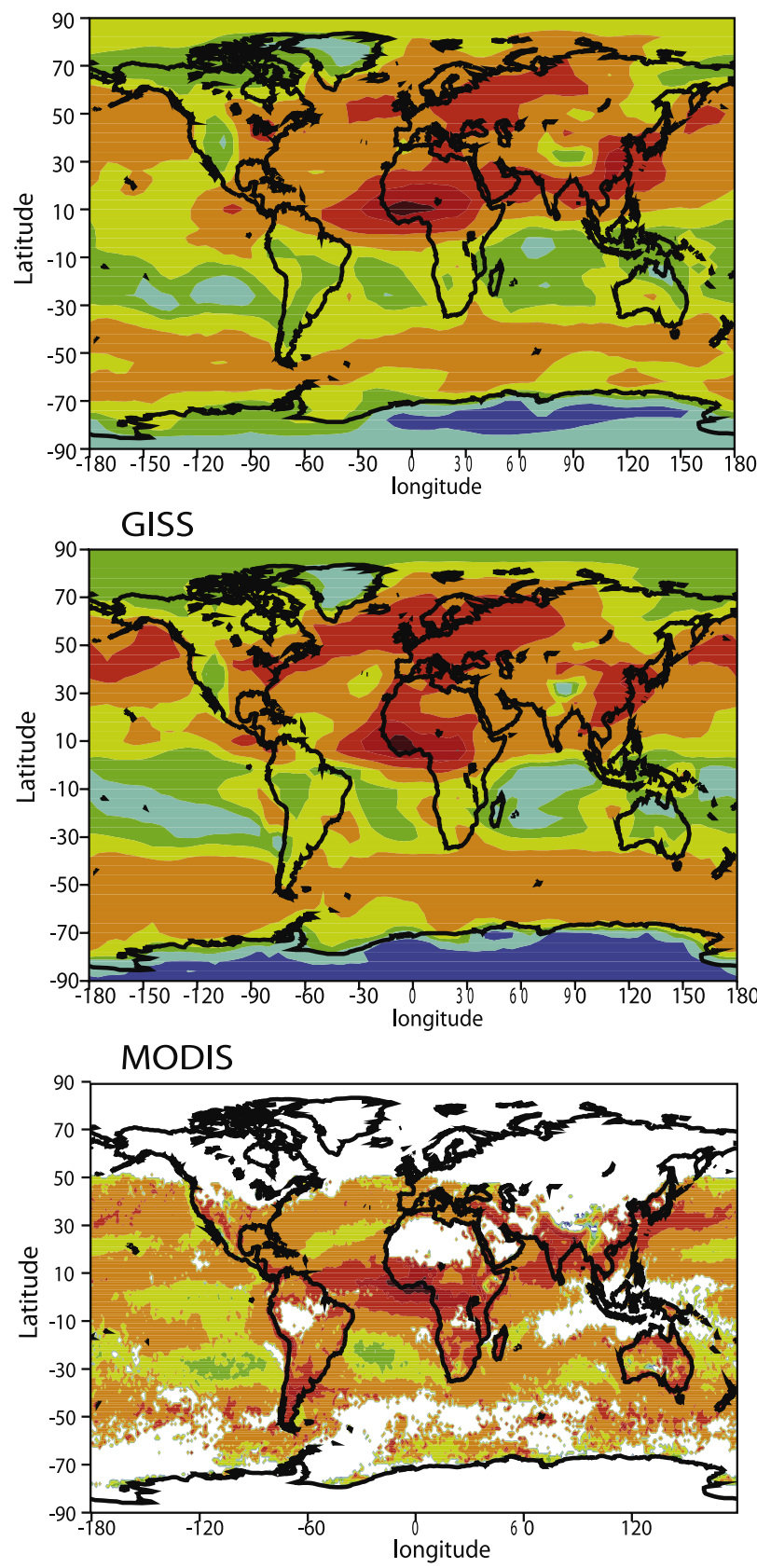

FVGCM
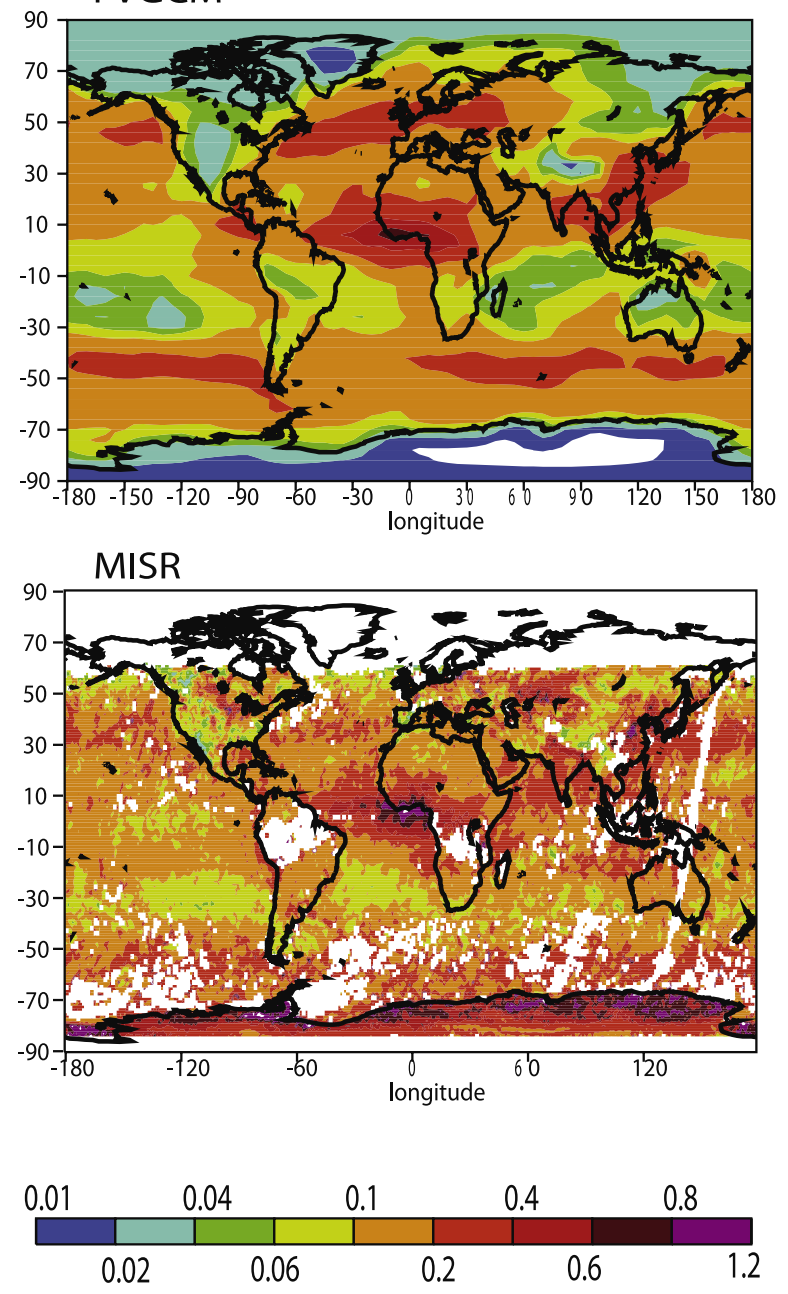

Figure 25. Aerosol optical depth at $550 \mathrm{~nm}$ in January from model calculations and from satellite measurements.

although FVGCM generally has larger underpredictions. Away from the source regions, however, the results from DAO, FVGCM, and GISS differ greatly. Sulfate concentrations at the surface in the $\mathrm{NH}$ extratropics and at $\sim 500 \mathrm{hPa}$ in the $\mathrm{NH}$ are a factor of 3 higher with DAO than those with FVGCM due to the stronger poleward transport from the $\mathrm{NH}$ midlatitudes with $\mathrm{DAO}$ and to more efficient scavenging with FVGCM. Also, the sea salt simulated with FVGCM over the ocean is more widely dispersed vertically than that with DAO and GISS due to the stronger cloud convection from FVGCM, although the difference is small at the surface. Global sulfate and mineral dust burdens with FVGCM fields are $40 \%$ and $20 \%$ less than those with the DAO and GISS fields, respectively, whereas the sea salt burden predicted with FVGCM fields is $56 \%$ and $43 \%$ higher than those with DAO and GISS, respectively.

[54] There are also large differences in the horizontal dispersal of aerosols associated with the circulation strength and wind speeds from the three meteorological data sets. For example, FVGCM has stronger intercontinental transport than DAO and is especially stronger than GISS, as seen from the sulfate distribution patterns over the ocean in the $\mathrm{NH}$ and dust transport from the Sahara source regions in Northern Africa. GISS has the strongest poleward transport of aerosols toward the South Pole. The agreement with 

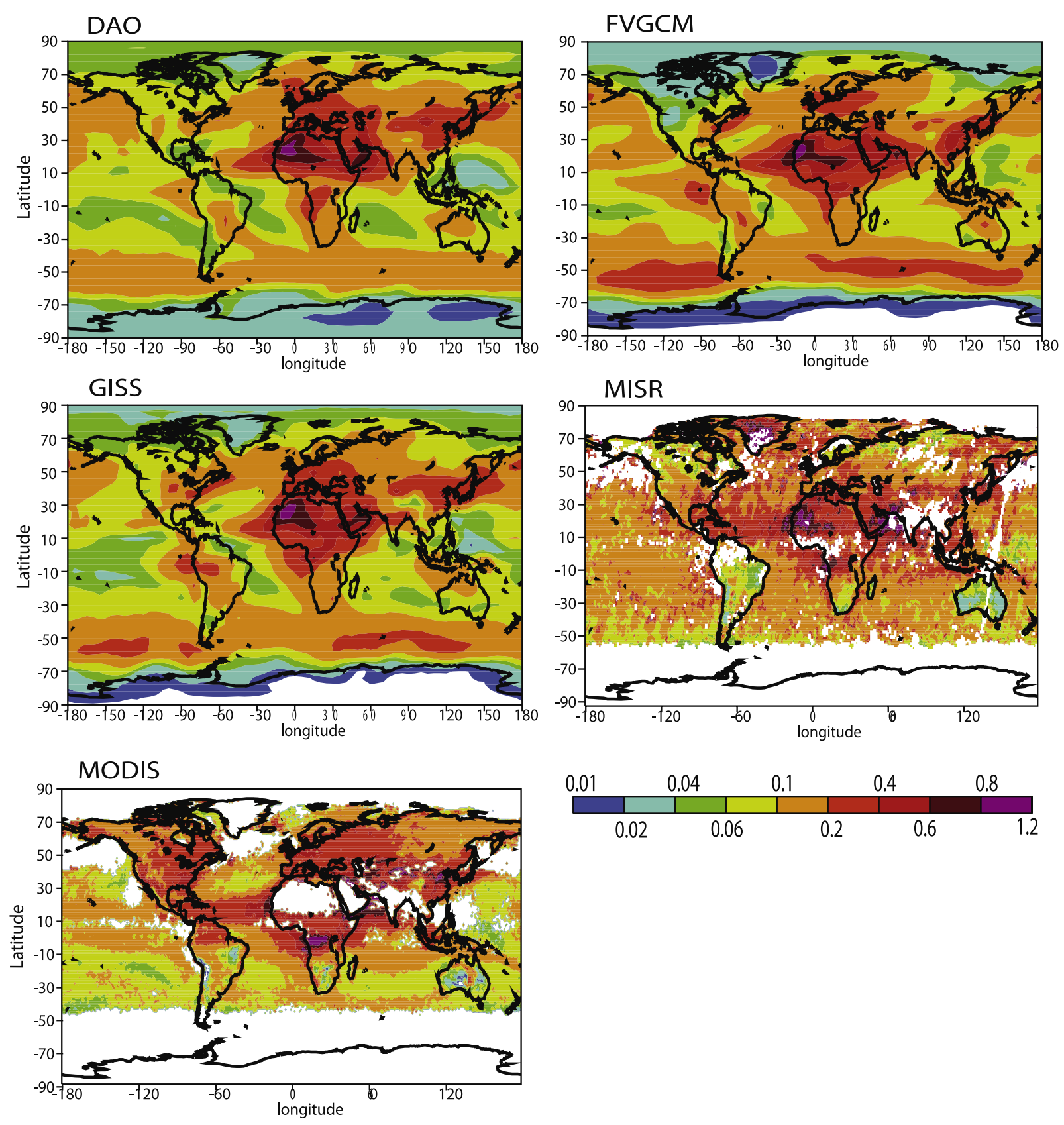

Figure 26. Same as Figure 25, but in July.

surface observation data in the industrial regions (North America and Europe) is generally good for sulfate. However the model severely underestimates the data for BC in North America for all the three data sets. When compared with the data available at the remote oceanic sites, no "best" meteorological data set can be chosen based on the present study, given the fact that the performance of the model using different data sets varies largely depending on the site and the specie.

[55] On the basis of the aerosol calculations, the aerosol optical depth at $550 \mathrm{~nm}$ is calculated for the three meteorological data sets and is also compared with satellite observations. Caclulated AOD captures the regional maxima seen in the observations due to fossil fuel sulfate, biomass burning carbon, and mineral dust extinction. How- ever, over the oceans in the tropics, calculated AODs are lower than observations, especially for GISS with the weakest circulation transport from the continents. The global annual mean AOD is $0.120,0.131$, and 0.122 for DAO, FVGCM, and GISS, respectively. However, the contributions from different aerosol components differ significantly. For example, the contributions from sulfate and dust are highest for DAO whereas the sea salt contribution is much lower than that for FVGCM and GISS.

[56] Aerosol direct radiative effects (both in the clear sky and in the all sky) were calculated for the present-day and preindustrial atmosphere for the three meteorological data sets. The forcing patterns generally follow those of the aerosol optical depth. Cloud coverage differences contribute additional differences to the all-sky forcing. The global 
Table 9. Annual Global Average Aerosol Optical Depth (AOD) at $550 \mathrm{~nm}$ Calculated with DAO, FVGCM and GISS Fields, and Total AOD of Remote Sensing Data from Ground (AERONET) and Space (MISR and MODIS)

\begin{tabular}{|c|c|c|c|c|}
\hline & $\mathrm{DAO}$ & FVGCM & GISS & Observed Total AOD \\
\hline Sulfate & $0.039(33 \%)$ & $0.033(25 \%)$ & $0.035(29 \%)$ & 0.135 (AERONET \\
\hline $\mathrm{OM}$ & $0.021(18 \%)$ & $0.022(17 \%)$ & $0.023(19 \%)$ & [Holben et al., 1998]) \\
\hline $\mathrm{BC}$ & $0.0026(2.2 \%)$ & $0.0026(2.0 \%)$ & $0.0028(2.3 \%)$ & 0.189 (MISR [Kahn et al., 1998]) \\
\hline Dust & $0.022(18 \%)$ & $0.016(12 \%)$ & $0.018(15 \%)$ & 0.182 (MODIS [Tanré et al., 1997; \\
\hline Sea salt & $0.035(29 \%)$ & $0.057(44 \%)$ & $0.043(35 \%)$ & Kaufman et al., 1997]) \\
\hline Total & 0.120 & 0.131 & 0.122 & \\
\hline
\end{tabular}

(a) DAO
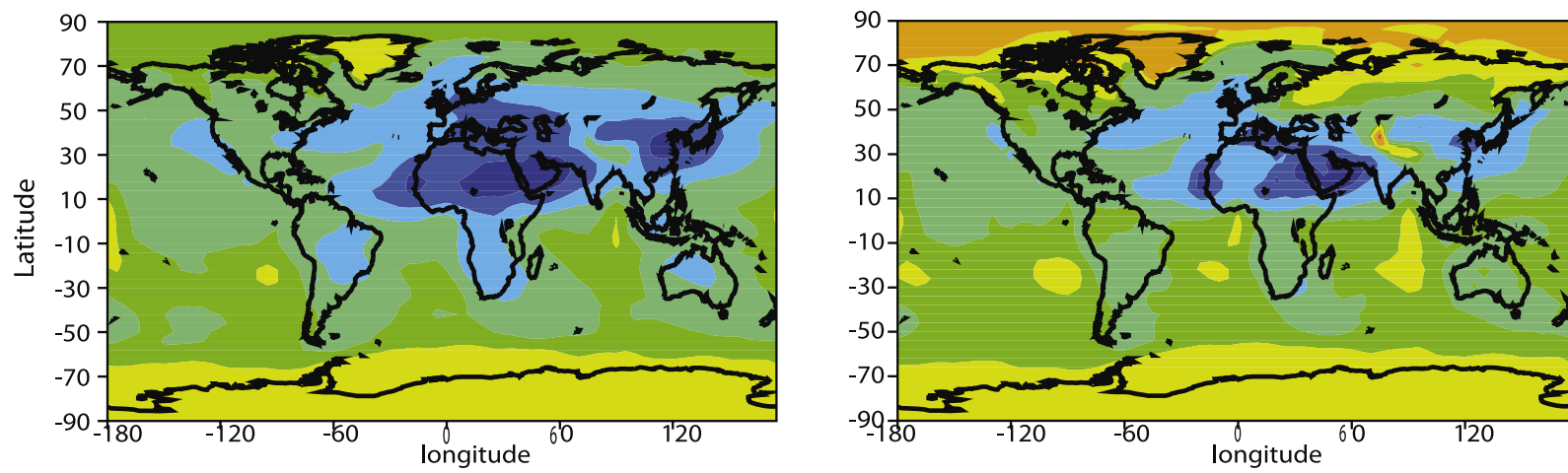

(b) FVGCM
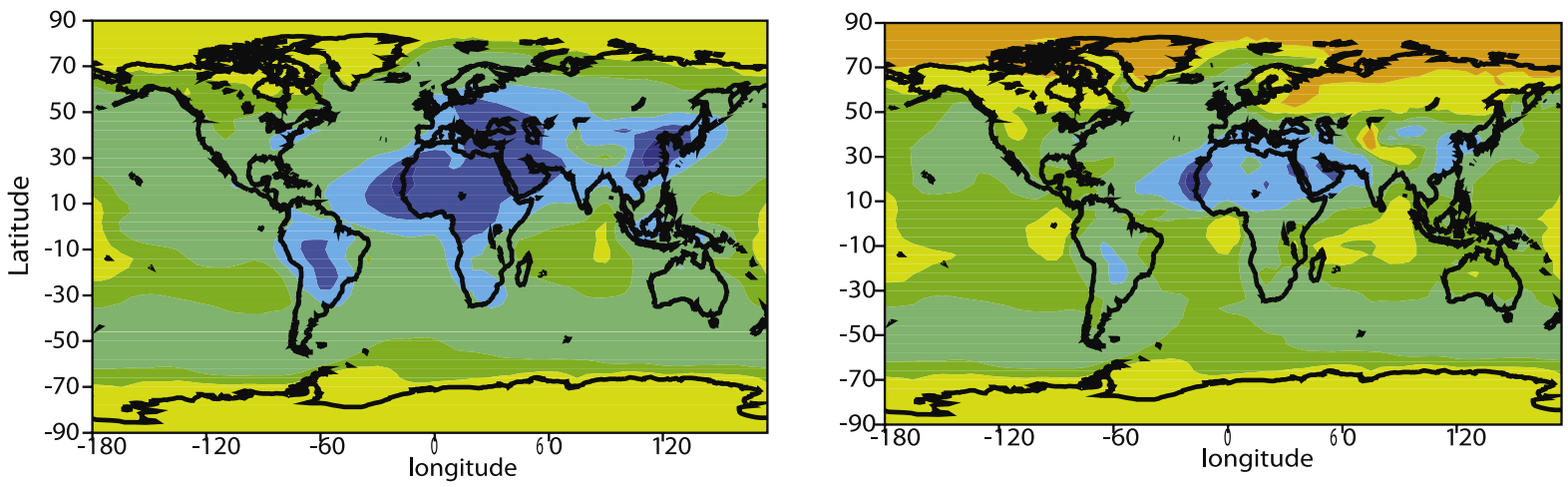

(c) GISS
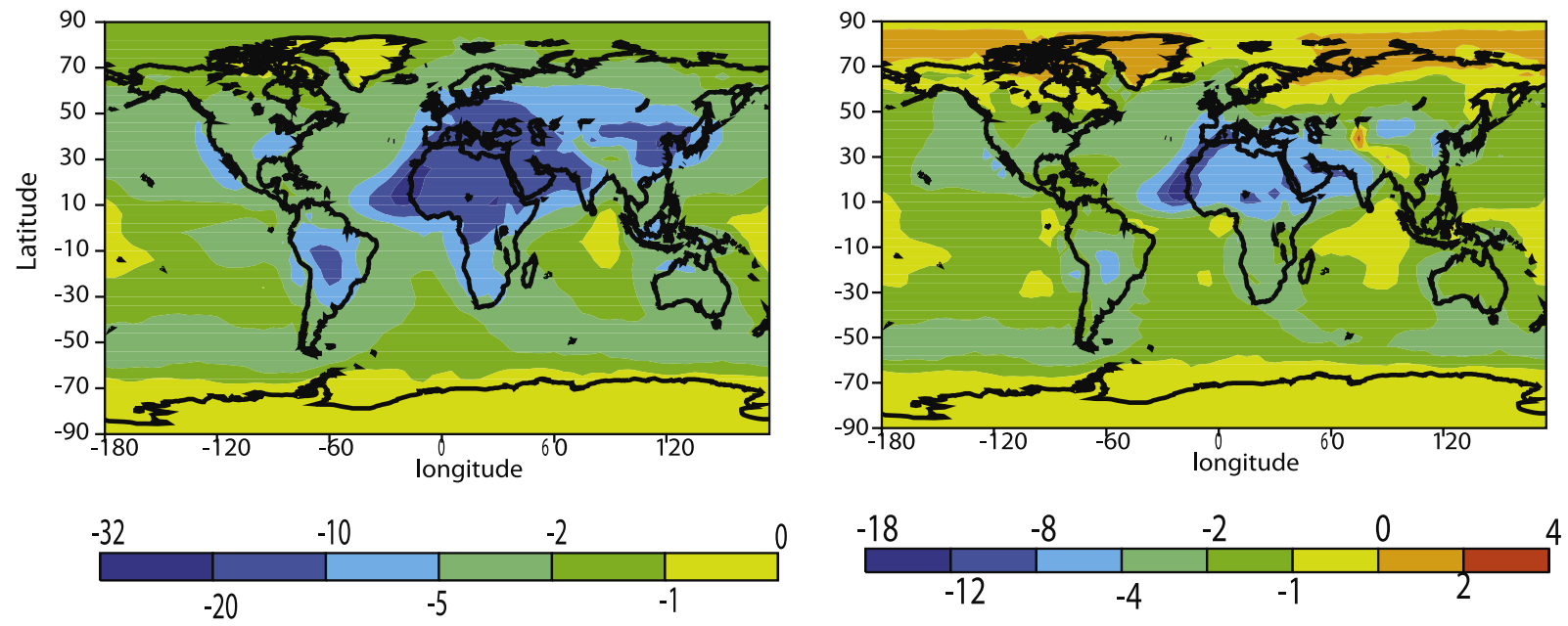

Figure 27. Annual mean all-sky present-day aerosol radiative effects $\left(\mathrm{W} \mathrm{m}^{-2}\right)$ at surface (left) and at the top-of-the-atmosphere (TOA) (right) calculated with DAO, FVGCM, and GISS fields. 
Table 10. Global Annual Mean Present-Day Aerosol Direct Radiative Effects, W $\mathrm{m}^{-2}$, and Anthropogenic Aerosol Forcing (Difference Between Present-Day and Preindustrial Aerosol Radiative Effects, $\mathrm{W} \mathrm{m} \mathrm{m}^{-2}$ ) at the TOA and at the Surface Calculated with DAO, FVGCM, and GISS Fields

\begin{tabular}{lccc}
\hline & DAO & FVGCM & GISS \\
\hline All-Sky (Clear-Sky) & Present-Day Aerosol \\
At TOA & $-2.6(-4.3)$ & $-2.1(-4.0)$ & $-2.0(-4.1)$ \\
At surface & $-4.7(-6.3)$ & $-4.1(-6.0)$ & $-4.1(-6.2)$ \\
& \multicolumn{4}{c}{ All-Sky (Clear-Sky) } & Anthropogenic Aerosol \\
At TOA & $-0.75(-1.3)$ & $-0.35(-1.0)$ & $-0.40(-1.1)$ \\
At surface & $-2.2(-2.7)$ & $-1.8(-2.3)$ & $-1.9(-2.6)$ \\
\hline
\end{tabular}

annual average clear-sky anthropogenic aerosol forcing at the TOA is $-1.3 \mathrm{~W} \mathrm{~m}^{-2}$ with DAO, $-1.0 \mathrm{~W} \mathrm{~m}^{-2}$ with FVGCM, and $-1.1 \mathrm{~W} \mathrm{~m}^{-2}$ with GISS. DAO has the largest negative forcing in the clear-sky case, which indicates a higher forcing efficiency (the ratio between aerosol forcing and AOD) for sulfate and dust than that for sea salt (DAO has the largest sulfate and dust and the smallest sea salt burdens.) The global annual average all-sky anthropogenic aerosol forcing at the TOA is $-0.75,-0.35$, and $-0.40 \mathrm{~W} \mathrm{~m}^{-2}$ for DAO, FVGCM, and GISS, respectively. Thus the all-sky negative forcing at the TOA is even larger with DAO than that with FVGCM and GISS due to the lower cloud amount in DAO (e.g., in the North Pacific and Atlantic). Regional differences

(a) DAO
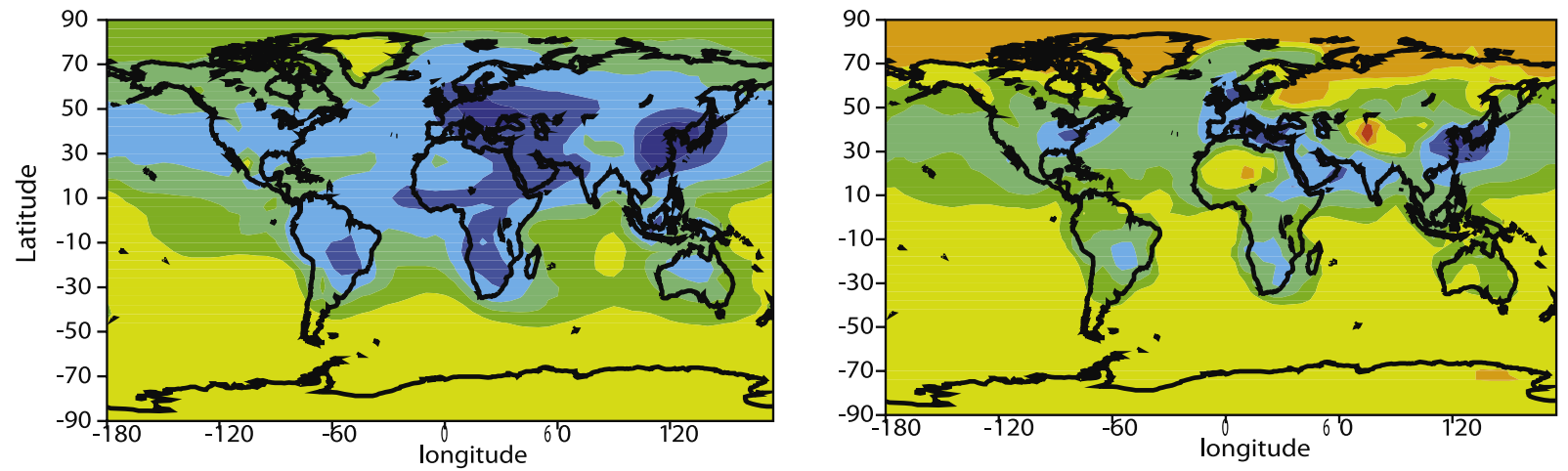

(b) FVGCM
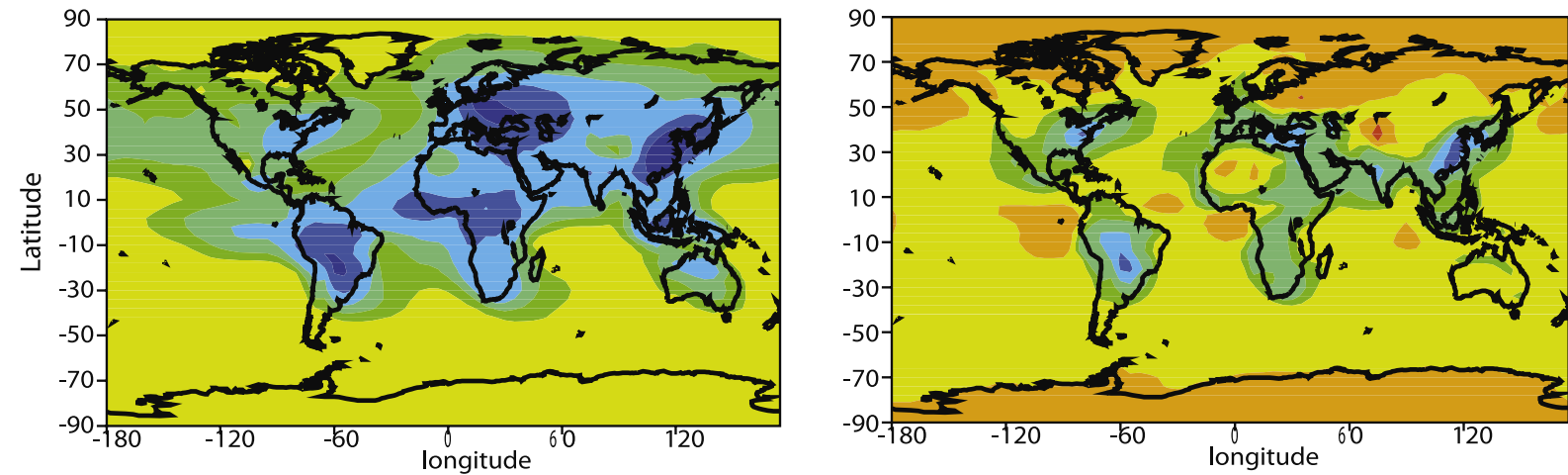

(c) GISS
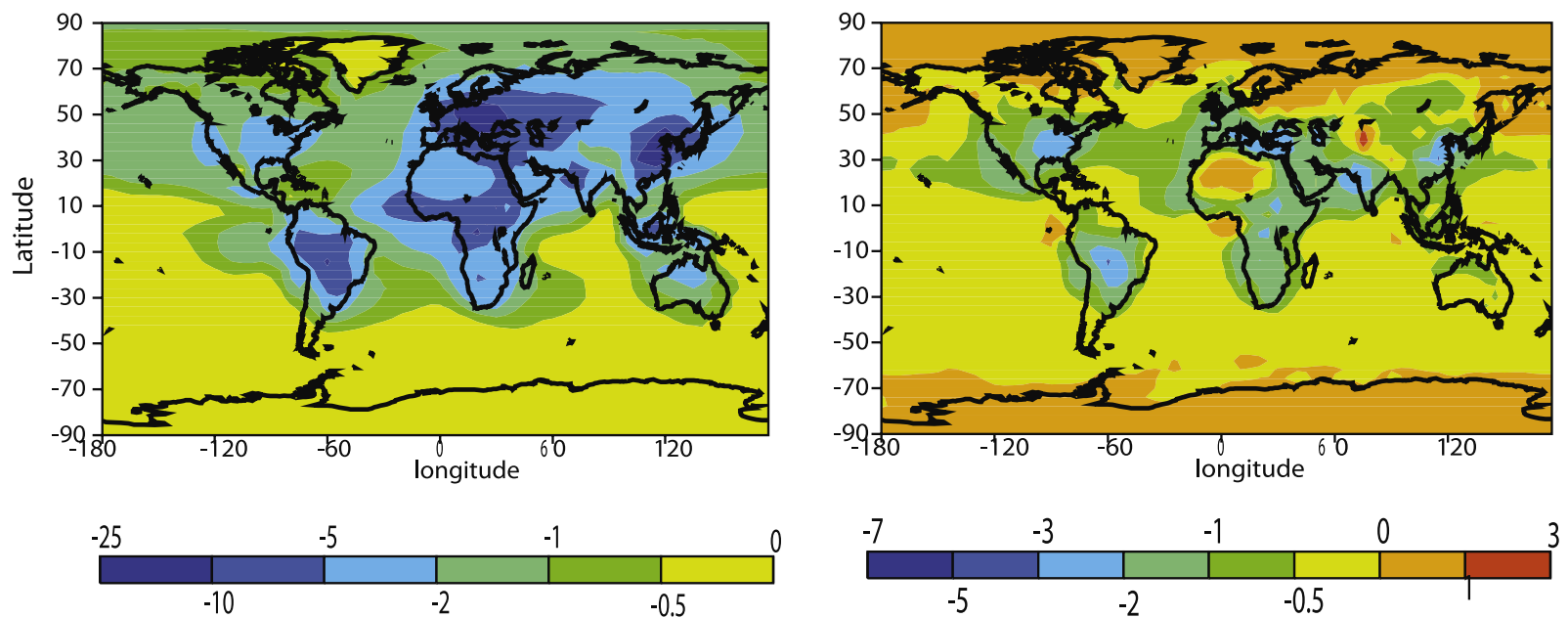

Figure 28. Same as Figure 27, but for anthropogenic aerosol forcing. 
SW forcing at surface, anth., all-sky (W/m2)

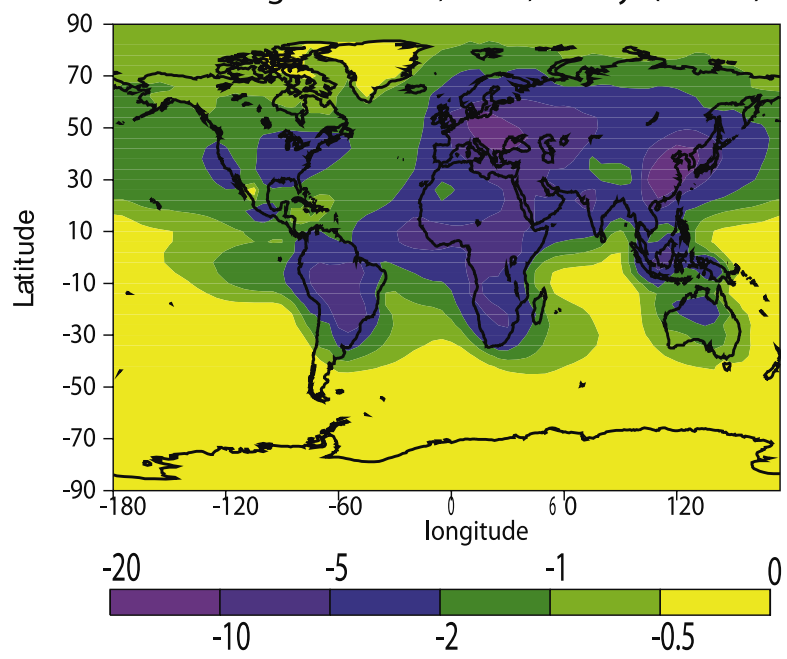

SW forcing at TOA, anth., all-sky (W/m2)

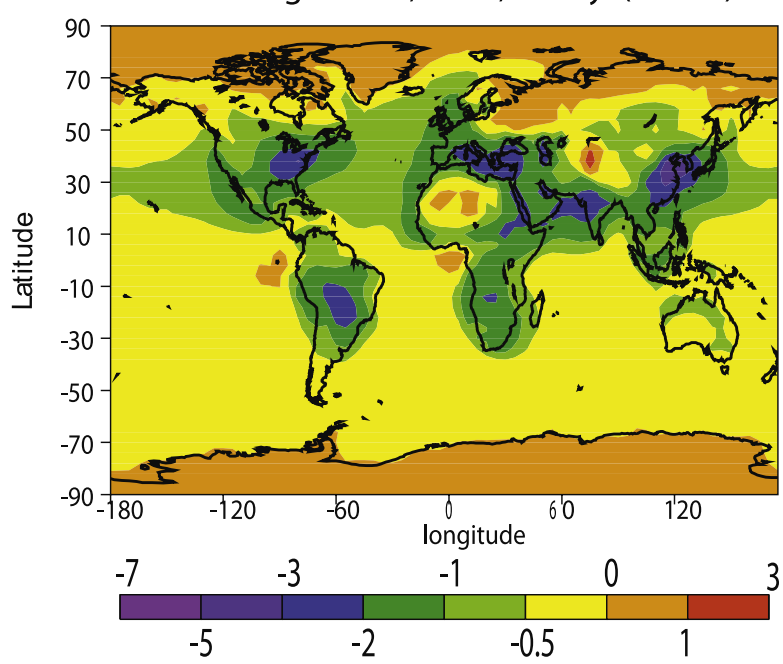

Rel. Diff. SW forcing (\%), sfc., (max-min)/avg.

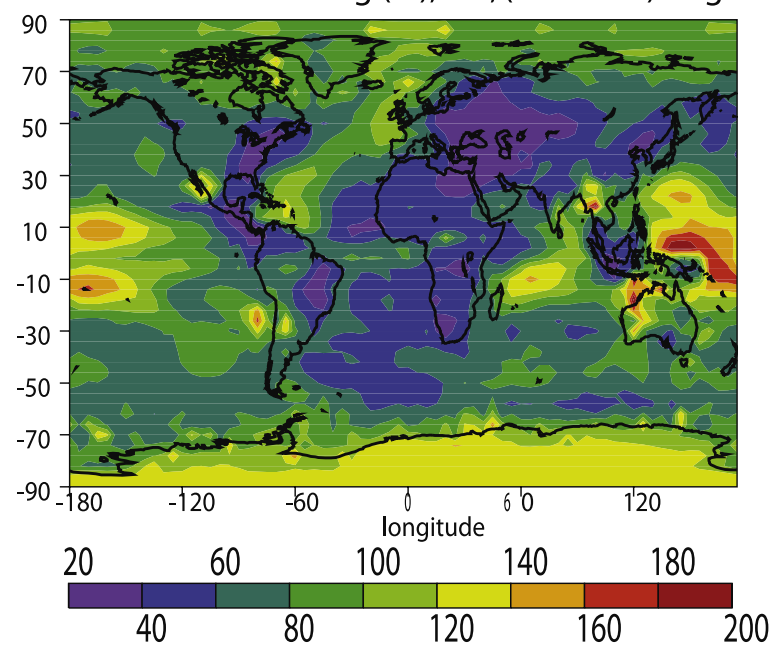

Rel. Diff. SW forcing (\%), TOA (max-min)/avg.

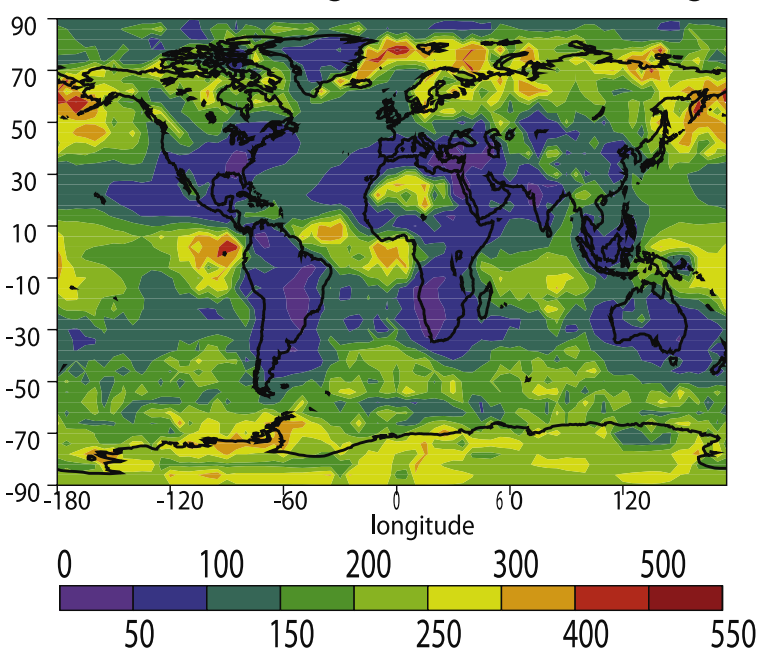

Figure 29. (left) Annual mean all-sky anthropogenic aerosol forcing $\left(\mathrm{W} \mathrm{m}^{-2}\right)$ averaged over the three data sets and (right) the uncertainty in aerosol forcing (max-min divided by the mean in \%) (top) at surface and (bottom) at the TOA.

with the three data sets in the all-sky anthropogenic aerosol forcing at the TOA can be much larger (by a factor of 4-5) near the tropics over the ocean and in the polar regions. This difference is remarkable and points to the large differences associated with meteorological fields (e.g., wind, cloud convective mass flux, cloud fraction, and precipitation rate). Our study points out that difficulties and uncertainties in the representation of cloud and precipitation processes in GCMs also cause large differences in the aerosol simulations and thus in the direct forcing estimates. Therefore better understanding in these processes in GCMs is required to reduce the uncertainties in estimating aerosol effects on climate system.

[57] We examined the impact of interannual variability in aerosol concentrations by performing two additional sets of simulations. One set of simualtions uses 5 years of FVGCM fields using 1994-1998 SSTs. Another set of simulations used the NASA GEOS-4 DAS fields for the years 2001, 2004, and 2005. The interannual variability in aerosol concentrations can be large (a factor of 3 ) in the tropics (e.g., over Indonesia) and in the storm track regions (e.g., over the Atlantic) especially for dust, but are, however, generally smaller than the uncertainty due to the different meteorological data sets. It is noted that in this study the DMS, dust, and sea salt emissions are prescribed, and thus the uncertainty in DMS, dust and sea salt concentrations is due to differences in the chemistry, transport, and deposition of these species. The range of emissions of mineral dust and sea salt can be as large as a factor of 8 in the literature depending on the source parameterization and surface wind speeds [e.g., Luo et al., 2003; Timmreck and Schulz, 2004]. In the future, we hope to include the uncertainty in DMS, mineral dust and sea salt simulations caused by different surface winds by implementing source parameterizations for DMS, dust, and sea salt in the GMI aerosol model. The GMI aerosol model assumes that the production yield of $\mathrm{SO}_{2}$ from DMS oxidation is $100 \%$. The reaction of DMS with $\mathrm{NO}_{3}$ is neglected, which can be important at night and at high latitudes in winter. These reactions will be improved 
in the GMI aerosol model in the future, and the impact of different DMS flux parameterizations [e.g, Liss and Merlivat, 1986; Wanninkhof, 1992] will be examined.

[58] Different aerosol model results are often used to quantify the uncertainty in predicted aerosol concentrations and radiative forcing [Ramaswamy et al., 2001]. However, the ranges of differences in the literature are due to different emissions sources, different parameterizations of wet and dry deposition, as well as different parameterizations of gas to particle formation and radiative properties of the aerosols. Here, we use the variation of results from only the variation of the meteorology fields to quantify the uncertainty due to meteorology alone. The true uncertainty, of course, could be either larger or smaller than we estimate, if a larger suite of meteorological fields is used.

[59] Acknowledgments. This work is supported by the NASA Global Modeling Initiative (GMI) Program. Participation of Dan Bergmann at the Lawrence Livermore National Laboratory was under the auspices of the U.S. Department of Energy contract W-7405-ENG-48. The authors thank Brian Duncan and Steve Steenrod for assistance. Pacific Northwest National Laboratory is operated for the DOE by Battelle Memorial Institute under contract DE-AC06-76RLO 1830.

\section{References}

Adler, R. F. (2003), The Version 2 Global Precipitation Climatology Project (GPCP) monthly precipitation analysis (1979-Present), J. Hydrometeorol., 4, 1147-1167.

Anderson, B. E., Jr., G. W. Sachse, D. R. Bagwell, C. H. Hudgins, D. R. Blake, and N. J. Blake (1996), Aerosols from biomass burning over the tropical South Atlantic region: Distributions and impacts, J. Geophys. Res., 101, 24,117-24,138.

Andreae, M. O., H. Berresheim, T. W. Andreae, M. A. Kritz, T. S. Bates, and J. T. Merrill (1988), Vertical distribution of dimethylsulfide, sulfur dioxide, aerosol ions, and radon over the northeast Pacific Ocean, J. Atmos. Chem., 6, 149-173.

Andreae, M. O., C. D. Jones, and P. M. Cox (2005), Strong present-day aerosol cooling implies a hot future, Nature, 435, 1187-1190.

Andres, R. J., and A. D. Kasgnoc (1998), A time-averaged inventory of sub-aerial volcanic sulfur emissions, J. Geophys. Res., 103, $25,251-25,262$.

Arimoto, R., R. A. Duce, D. L. Savoie, J. M. Prospero, R. Talbot, J. D. Cullen, U. Tomza, N. F. Lewis, and B. J. Ray (1996), Relationships among aerosol constituents from Asia and the North Pacific during PEM-West A, J. Geophys. Res., 101, 2011-2024.

Balkanski, Y. J., D. J. Jacob, G. M. Gardner, W. C. Graustein, and K. K. Turekian (1993), Transport and residence times of tropospheric aerosols inferred from a global three-dimensional simulation of ${ }^{210} \mathrm{~Pb}, J$. Geophys. Res., 98, 20,573-20,586.

Barrie, L., et al. (2001), A comparison of large scale atmospheric sulphate aerosol models (COSAM): Overview and highlights, Tellus, Ser. B, 53, $615-645$.

Barth, M. C., P. J. Rasch, J. T. Kiehl, C. M. Benkovitz, and S. E. Schwartz (2000), Sulfur chemistry in the National Center for Atmospheric Research Community Climate Model: Description, evaluation, features, and sensitivity to aqueous chemistry, J. Geophys. Res., 105, $1387-1416$

Bellouin, N., O. Boucher, J. Haywood, and M. S. Reddy (2005), Global estimate of aerosol direct radiative forcing from satellite measurements, Nature, 438, 1138-1141.

Bloom, S., et al. (2005), Documentation and validation of the Goddard Earth Observing System (GEOS) Data Assimilation System-Version 4, Tech. Rep. Ser. on Global Modeling and Data Assimilation 104606, vol. 26, Natl. Aeronaut. and Space Admin, Silver Spring, Md. (Availble at http://gmao.gsfc.nasa.gov/systems/geos4/)

Bodhaine, B. A. (1995), Aerosol absorption measurements at Barrow, Mauna Loa and the South Pole, J. Geophys. Res., 100, 8967-8975.

Charlson, R. J., S. E. Schwartz, J. M. Hales, R. D. Cess, J. A. Coakley, J. E. Hansen, and D. J. Hofmann (1992), Climate forcing by anthropogenic aerosols, Science, 255, 423-430.

Chen, Y., and J. E. Penner (2005), Uncertainty analysis for estimates of the first indirect aerosol effect, Atmos. Chem. Phys., 5, 2935-2948.

Chin, M., and D. J. Jacob (1996), Anthropogenic and natural contributions to tropospheric sulfate: A global model analysis, J. Geophys. Res., 101, $18,691-18,700$.
Chin, M., R. B. Rood, S.-J. Lin, J. F. Muller, and A. M. Thompson (2000a), Atmospheric sulfur cycle simulated in the global model GOCART: Model description and global properties, J. Geophys. Res., 105, $24,671-24,687$

Chin, M., D. L. Savoie, B. J. Huebert, A. R. Bandy, D. C. Thornton, T. S. Bates, P. K. Quinn, E. S. Saltzman, and W. J. De Bruyn (2000b), Atmospheric sulfur cycle simulated in the global model GOCART: Comparison with field observations and regional budgets, J. Geophys. Res., 105, 24,689-24,712.

Chin, M., P. Ginoux, S. Kinne, O. Torres, B. N. Holben, B. N. Duncan, R. V. Martin, J. A. Logan, A. Higurashi, and T. Nakajima (2002), Tropospheric aerosol optical thickness from the GOCART model and comparisons with satellite and sun photometer measurements, J. Atmos. Sci., 59, 461-483.

Chuang, C. C., J. E. Penner, K. E. Taylor, A. S. Grossman, and J. J. Walton (1997), An assessment of the radiative effects of anthropogenic sulfate, J. Geophys. Res., 102, 3761-3778.

Chuang, C. C., J. E. Penner, J. M. Prospero, K. E. Grant, G. H. Rau, and K. Kawamoto (2002), Cloud susceptibility and the first aerosol indirect forcing: Sensitivity to black carbon and aerosol concentrations, J. Geophys. Res., 107(D21), 4564, doi:10.1029/2000JD000215.

Chung, S. H., and J. H. Seinfeld (2002), Global distribution and climate forcing of carbonaceous aerosols, J. Geophys. Res., 107(D19), 4407, doi:10.1029/2001JD001397.

Considine, D. B., D. J. Bergmann, and H. Liu (2005), Sensitivity of Global Modeling Initiative chemistry and transport model simulations of radon222 and lead-210 to input meteorological data, Atmos. Chem. Phys., 5, 3389-3406.

Cooke, W. F., and J. J. N. Wilson (1996), A global black carbon aerosol model, J. Geophys. Res., 101, 19,395-19,410.

Cooke, W. F., S. G. Jennings, and T. G. Spain (1997), Black carbon measurements at Mace Head, 1989-1996, J. Geophys. Res., 102, 25,339-25,346.

Cooke, W. F., C. Liousse, H. Cachier, and J. Feichter (1999), Construction of a $1^{\circ} \times 1^{\circ}$ fossil fuel emission data set for carbonaceous aerosol and implementation and radiative impact in the ECHAM4 model, J. Geophys. Res., 104, 22,137-22,162.

Cooke, W. F., V. Ramaswamy, and P. Kasibhatla (2002), A general circulation model study of the global carbonaceous aerosol distribution, J. Geophys. Res., 107(D16), 4279, doi:10.1029/2001JD001274.

d'Almeida, G. A., P. Koepke, and E. P. Shettle (1991), Atmospheric Aerosols: Global Climatology and Radiative Characteristics, Deepak, A., Hampton, Va.

Easter, R. C., S. J. Ghan, Y. Zhang, R. D. Saylor, E. G. Chapman, N. S. Laulainen, H. Abdul-Razzak, L. R. Leung, X. Bian, and R. A. Zaveri (2004), MIRAGE: Model description and evaluation of aerosols and trace gases, J. Geophys. Res., 109, D20210, doi:10.1029/2004JD004571.

Erickson, D. J., and R. A. Duce (1988), On the global flux of atmospheric sea salt, J. Geophys. Res., 93, 14,079-14,088.

Feichter, J., E. Kjellstroem, H. Rodhe, F. Dentener, J. Lelieveld, and G.-J. Roelofs (1996), Simulation of the tropospheric sulfur cycle in a global climate model, Atmos. Environ., 30, 1693-1707.

Feng, Y., J. E. Penner, S. Sillman, and X. Liu (2004), Effects of cloud overlap in photochemical models, J. Geophys. Res., 109, D04310, doi:10.1029/2003JD004040.

Gerber, H. (1991), Supersaturation and droplet spectral evolution in fog, J. Atmos. Sci., 48, 2569-2588.

Ginoux, P., M. Chin, I. Tegen, J. M. Prospero, B. Holben, O. Dubovik, and S.-J. Lin (2001), Sources and distributions of dust aerosols simulated with the GOCART model, J. Geophys. Res., 106, 20,255-20,274.

Giorgi, F., and W. L. Chameides (1986), Rainout lifetimes of highly soluble aerosols and gases as inferred from simulations with a general circulation model, J. Geophys. Res., 91, 14,367-14,376.

Gong, S. L., L. A. Barrie, and J.-P. Blanchet (1997), Modeling sea-salt aerosols in the atmosphere: 1. Model development, J. Geophys. Res., $102,3805-3818$.

Grant, K. E., A. S. Grossman, C. C. Chuang, and J. E. Penner (1997), Sensitivity of aerosol radiative forcing calculations to spectral resolution, in Proceedings of the International Radiation Symposium, edited by W. L. Smith and K. Stamnes, pp. 275-278, Deepak, A., Hampton, Va.

Grant, K. E., C. C. Chuang, A. S. Grossman, and J. E. Penner (1999), Modeling the spectral optical properties of ammonium sulfate and biomass burning aerosols: Parameterization of relative humidity effects and model results, Atmos. Environ., 33, 2603-2620.

Greenwald, T. J., G. L. Stephens, T. H. Vonder Haar, and D. L. Jackson (1993), A physical retrieval of cloud liquid water over the global oceans using special sensor microwave/imager (SSM/I) observations, J. Geophys. Res., 98, 18,471-18,488.

Guenther, A., et al. (1995), A global model of natural volatile organic compound emissions, J. Geophys. Res., 100, 8873-8892. 
Hack, J. J. (1994), Parameterization of moist convection in the National Center for Atmospheric Research Community Climate Model (CCM2), J. Geophys. Res., 99, 5551-5568.

Hack, J. J. (1998), Sensitivity of the simulated climate to a diagnostic formulation for cloud liquid water, J. Clim., 11, 1497-1515.

Heintzenberg, J., and E. K. Bigg (1990), Tropospheric transport of trace substances in the Southern Hemisphere, Tellus, Ser. B, 42, 355-363.

Hjellbrekke, A.-G., and J. E. Hanssen (1998), Data report 1996, 1, Annual summaries, EMEP/CCC Rep. 1/98, 85 pp., Norw. Inst. for Air Res., Lillestrom, Norway.

Holben, B., et al. (1998), AERONET, A federated instrument network and data-archive for aerosol characterization, Remote Sens. Environ., $66,1-66$.

Hopper, J. F., D. E. J. Worthy, L. A. Barrie, and N. B. A. Trivett (1994), Atmospheric observations of aerosol black carbon, carbon-dioxide, and methane in the high Arctic, Atmos. Environ., 28, 3047-3054.

Intergovernmental Panel on Climate Change (IPCC) (2001), Climate Change 2001: The Scientific Basis: Contribution of Working Group to the Third Assessment Report of the Intergovernmental Panel on Climate Change, edited by J.T. Houghton et al., 881 pp., Cambridge Univ. Press, New York.

Ito, A., and J. E. Penner (2005), Historical emissions of carbonaceous aerosols from biomass and fossil fuel burning for the period 1870 2000, Global Biogeochem. Cycles, 19, GB2028, doi:10.1029/ 2004GB002374.

Jacob, D. J., and S. C. Wofsy (1990), Budgets of reactive nitrogen, hydrocarbons, and ozone over the Amazon forest during the wet season, J. Geophys. Res., 95, 16,737-16,754.

Kahn, R., P. Banerjee, D. McDonald, and D. J. Diner (1998), Sensitivity of multi-angle imaging to aerosol optical depth and to pure particle size distribution and composition over ocean, J. Geophys. Res., 103, $32,195-32,213$

Kaufman, Y., D. Tanré, L. Remer, E. Vermote, D. Chu, and B. Holben (1997), Operational remote sensing of tropospheric aerosol over the land from EOS-MODIS, J. Geophys. Res., 102, 17,051-17,061.

Kettle, A. J., and M. O. Andreae (2000), Flux of dimethylsulfide from the oceans: A comparison of updated data sets and flux models, J. Geophys. Res., 105, 26,793-26,808.

Kettle, A. J., et al. (1999), A global database of sea surface dimethylsulfide (DMS) measurements and a procedure to predict sea surface DMS as a function of latitude, longitude and month, Global Biogeochem. Cycles, $13,399-444$

Kinne, S., et al. (2003), Monthly averages of aerosol properties: A global comparison among models, satellite data, and AERONET ground data, J. Geophys. Res., 108(D20), 4634, doi:10.1029/2001JD001253.

Kinne, S., et al. (2006), An AeroCom initial assessment-Optical properties in aerosol component modules of global models, Atmos. Chem. Phys., 6 , $1815-1834$

Koch, D. (2001), Transport and direct radiative forcing of carbonaceous and sulfate aerosols in the GISS GCM, J. Geophys. Res., 106 , 20,311-20,332.

Koch, D., and D. Rind (1998), ${ }^{10} \mathrm{Be} /{ }^{7} \mathrm{Be}$ as a tracer of stratospheric transport, J. Geophys. Res., 103, 3907-3917.

Koch, D., D. Jacob, I. Tegen, D. Rind, and M. Chin (1999), Tropospheric sulfur simulation and sulfate direct radiative forcing in the Goddard Institute for Space Studies general circulation model, J. Geophys. Res., 104, 23,799-23,822.

Kreidenweis, S. M., C. J. Walcek, G. Feingold, W. Gong, M. Z. Jacobson, C.-H. Kim, X. Liu, J. E. Penner, A. Nenes, and J. H. Seinfeld (2003), Modification of aerosol mass and size distribution due to aqueous-phase $\mathrm{SO}_{2}$ oxidation in clouds: Comparison of several models, J. Geophys. Res., 108(D7), 4213, doi:10.1029/2002JD002697.

Langner, J., and H. Rodhe (1991), A global three-dimensional model of the tropospheric sulfur cycle, J. Atmos. Chem., 13, 225-263.

Lin, S.-J., and R. B. Rood (1996), Multidimensional flux-form semiLagrangian transport schemes, Mon. Weather Rev., 124, 2046-2070.

Liousse, C., J. E. Penner, C. Chuang, J. J. Walton, H. Eddleman, and H. Cachier (1996), A global three-dimensional model study of carbonaceous aerosols, J. Geophys. Res., 101, 19,411-19,432.

Liss, P. S., and L. Merlivat (1986), Air-sea gas exchange rates: Introduction and synthesis, in The Role of Air-Sea Gas Exchange in Geochemical Cycling, edited by P. B. Menard, pp. 113-127, Springer, New York.

Liu, H., D. J. Jacob, I. Bey, and R. M. Yantosca (2001), Constraints from ${ }^{210} \mathrm{~Pb}$ and ${ }^{7} \mathrm{Be}$ on wet deposition and transport in a global threedimensional chemical tracer model driven by assimilated meteorological fields, J. Geophys. Res., 106(D11), 12,109-12,128.

Liu, X., J. E. Penner, and M. Herzog (2005), Global modeling of aerosol dynamics: Model description, evaluation and interactions between sulfate and non-sulfate aerosols, J. Geophys. Res., 110, D18206, doi:10.1029/ 2004JD005674.
Lohmann, U., and J. Feichter (1997), Impact of sulfate aerosols on albedo and lifetime of clouds: A sensitivity study with the ECHAM4 GCM, J. Geophys. Res., 102, 13,685-13,700.

Lohmann, U., J. Feichter, C. C. Chuang, and J. E. Penner (1999a), Prediction of the number of cloud droplets in the ECHAM GCM, J. Geophys. Res., 104, 9169-9198.

Lohmann, U., K. von Salzen, N. McFarlane, H. G. Leighton, and J. Feichter (1999b), Tropospheric sulfur cycle in the Canadian general circulation model, J. Geophys. Res., 104, 26,833-26,858.

Lohmann, U., et al. (2001), Vertical distributions of sulfur species simulated by large scale atmospheric models in COSAM: Comparison with observations, Tellus, Ser. B, 53, 646-672.

Luo, C., N. M. Mahowald, and J. del Corral (2003), Sensitivity study of meteorological parameters on mineral aerosol mobilization, transport, and distribution, J. Geophys. Res., 108(D15), 4447, doi:10.1029/2003JD003483.

Malm, W. C., M. L. Pitchford, M. Scruggs, J. F. Sisler, R. Ames, S. Copeland, K. A. Gebhart, and D. E. Day (2000), Spational and seasonal patterns and temporal variability of haze and its constituents in the United States, Report III, Coop. Inst. for Res., Colo. State Univ., Fort Collins, Colo.

Mari, C., D. J. Jacob, and P. Bechtold (2000), Transport and scavenging of soluble gases in a deep convective cloud, J. Geophys. Res., 105, $22,255-22,268$

McNaughton, D. J., and R. J. Vet (1996), Eulerian Model Evaluation Field Study (EMEFS): A summary of surface network measurements and data quality, Atmos. Environ., 30, 227-238.

Monahan, E. C., D. E. Spiel, and K. L. Davidson (1986), A model of marine aerosol generation via whitecaps and wave disruption, in Oceanic Whitecaps, edited by E. C. Monahan, and G. Mac Niocaill, pp. 167-174, Reidel, D., Norwell, Mass.

Moorthi, S., and M. J. Suarez (1992), Relaxed Arakawa-Schubert: A parameterization of moist convection for general circulation models, Mon. Weather Rev., 120, 978-1002.

Myhre, G., A. Grini, J. M. Haywood, F. Stordal, B. Chatenet, D. Tanré, J. K. Sundet, and I. S. A. Isaksen (2003), Modeling the radiative impact of mineral dust during the Saharan Dust Experiment (SHADE) campaign, J. Geophys. Res., 108(D18), 8579, doi:10.1029/2002JD002566.

Myhre, G., et al. (2004), Intercomparison of satellite retrieved aerosol optical depth over the ocean, J. Atmos. Sci., 61, 499-513.

Nakicenovic, N., et al. (2000), Emissions scenarios, in Special Report on Emission Scenarios, edited by N. Nakicenovic et al., 599 pp., Cambridge Univ. Press, New York.

Nightingale, P. D., G. Malin, C. S. Law, A. J. Watson, P. S. Liss, M. I. Liddicoat, J. Boutin, and R. C. Upstill-Goddard (2000), In situ evaluation of air-sea gas exchange parameterizations using novel conservative and volatile tracers, Global Biogeochem. Cycles, 14, 373-388.

Nyeki, S., U. Baltensperger, I. Colbeck, D. T. Jost, E. Weingartner, and H. W. Gäggeler (1998), The Jungfraujoch high-alpine research station $(3454 \mathrm{~m})$ as a background clean continental site for the measurement of aerosol parameters, J. Geophys. Res., 103, 6097-6107.

Penner, J. E. (2004), Climate change-The cloud conundrum, Nature, 432, $962-963$

Penner, J. E., H. Eddleman, and T. Novakov (1993), Towards the development of a global inventory of black carbon emissions, Atmos. Environ., Part A, 27, 1277-1295.

Penner, J. E., C. A. Atherton, and T. E. Graedel (1994), Global emissions and models of photochemically active compounds, in Global Atmospheric-Biospheric Chemistry, edited by R. Prinn, pp. 223-248, Springer, New York.

Penner, J. E., C. C. Chuang, and K. Grant (1998), Climate forcing by carbonaceous and sulfate aerosols, Clim. Dyn., 14, 839-851.

Penner, J. E., et al. (2002), A comparison of model- and satellite-derived aerosol optical depth and reflectivity, J. Atmos. Sci., 59, 441-460.

Pham, M., J.-F. Müller, G. P. Brasseur, C. Granier, and G. Mégie (1995), A three-dimensional study of the tropospheric sulfur cycle, J. Geophys. Res., 100, 26,061-26,092.

Prospero, J. M., M. Uematsu, and D. L. Savoie (1989), Mineral aerosol transport to the Pacific Ocean, in Chemical Oceanography, edited by J. P. Ridley et al., vol. 10, pp. 188-218, Elsevier, New York.

Quinn, P. K., and D. J. Coffman (1998), Local closure during the First Aerosol Characterization Experiment (ACE 1): Aerosol mass concentration and scattering and backscattering coefficients, J. Geophys. Res., 103, $16,575-16,596$

Radke, L. F., D. A. Hegg, J. H. Lyons, C. A. Brock, P. V. Hobbs, R. Weiss, and R. Rasmussen (1988), Airborne measurements on smokes from biomass burning, in Aerosols and Climate, edited by P. V. Hobbs, and M. P. McCormick, pp. 411-422, Deepak, A., Hampton, Va.

Ramaswamy, V., O. Boucher, J. D. Haigh, D. A. Hauglustaine, J. M. Haywood, G. Myhre, T. Nakajima, ,G. Y. Shi, and S. Solomon (2001), Radiative forcing of climate change, in Climate Change 2001: The Scientific Basis: Contribution of Working Group I to the Third Assessment 
Report of the Intergovernmental Panel on Climate Change, edited by J. T. Houghton et al., pp. 349-416, Cambridge Univ. Press, New York.

Rasch, P. J., N. M. Mahowald, and B. E. Eaton (1997), Representation of transport, convection, and the hydrological cycle in chemical transport models: Implication for the modeling of short-lived and soluble species, J. Geophys. Res., 102, 28,127-28,138.

Rasch, P. J., et al. (2000a), A comparison of scavenging and deposition processes in global models: Results from the WCRP Cambridge Workshop of 1995, Tellus, Ser. B, 52, 1025-1056.

Rasch, P. J., M. C. Barth, J. T. Kiehl, S. E. Schwartz, and C. M. Benkovitz (2000b), A description of the global sulfur cycle and its controlling processes in the National Center for Atmospheric Research Community Climate Model, Version 3, J. Geophys. Res., 105, 1367-1386.

Reynolds, R. W., N. A. Rayner, T. M. Smith, D. C. Stokes, and W. Q. Wang (2002), An improved in situ and satellite SST analysis for climate, J. Clim., 15, 1609-1625.

Rind, D., and J. Lerner (1996), Use of on-line tracers as a diagnostic tool in general circulation model development: 1 . Horizontal and vertical transport in the troposphere, J. Geophys. Res., 101, 12,667-12,683.

Rodriguez, J. M. (2003), et al. Activities of NASA's Global Modeling Initiative (GMI) in the assessment of subsonic aircraft impact, in European Conference on Aviation, Atmosphere and Climate, Eur. Com. Air Pollut. Res. Rep. 83, edited by R. Sausen et al., pp. 134-139, European Commission, Friedrichshafen, Germany, July. (Available at http:// www.pa.op.dlr.de/aac/proceedings/AAC-proceedings-contents.pdf)

Roelofs, G.-J., J. Lelieveld, and L. Ganzeveld (1998), Simulation of global sulfate distribution and the influence on effective cloud radil with a coupled photochemistry-sulfur cycle model, Tellus, Ser. B, 50, $224-242$.

Roelofs, G.-J., et al. (2001), Analysis of regional budgets of sulfur species modeled for the COSAM exercise, Tellus, Ser. B, 53, 673-694.

Rotman, D. A., et al. (2004), IMPACT, the LLNL 3-D global atmospheric chemical transport model for the combined troposphere and stratosphere: Model description and analysis of ozone and other trace gases, J. Geophys. Res., 109, D04303, doi:10.1029/2002JD003155.

Rotstayn, L. D., and U. Lohmann (2002), Simulation of the tropospheric sulfur cycle in a global model with a physically based cloud scheme, J. Geophys. Res., 107(D21), 4592, doi:10.1029/2002JD002128.

Rotstayn, L. D., and J. E. Penner (2001), Indirect aerosol forcing, quasi forcing, and climate response, J. Clim., 14, 2960-2975.

Savoie, D. L., and J. M. Prospero (1989), Comparison of oceanic and continental sources of non-sea-salt sulfate over the Pacific Ocean, Nature, $339,685-687$.

Savoie, D. L., J. M. Prospero, and E. S. Saltzman (1989), Nitrate, non-seasalt sulfate and methanesulfonate over the Pacific Ocean, in Chemical Oceanography, edited by J. P. Ridley et al., vol. 10, pp. 219-250, Elsevier, New York.

Savoie, D. L., J. M. Prospero, R. J. Larson, F. Huang, M. Izaguirre, T. Huang, and T. H. Snowdon (1993), Nitrogen and sulfur species in Antarctic aerosols at Mawson, Palmer Station, and Marsh (King George Island), J. Atmos. Chem., 17, 95-122.

Schulz, M., et al. (2006), Radiative forcing by aerosols as derived from the AeroCom present-day and pre-industrial simulations, Atmos. Chem. Phys., 6, 5225-5246.

Seinfeld, J. H., and S. N. Pandis (1998), Atmospheric Chemistry and Physics: From Air Pollution to Climate Change, John Wiley, Hoboken, N. J.

Stevenson, D. S., et al. (2006), Multimodel ensemble simulations of present-day and near-future tropospheric ozone, J. Geophys. Res., 111, D08301, doi:10.1029/2005JD006338.

Sundqvist, H., E. Berge, and J. E. Kristiansson (1989), Condensation and cloud parameterization studies with a mesoscale numerical weather prediction model, Mon. Weather Rev., 117, 1641-1657.

Tanré, D., et al. (1997), Remote sensing of aerosol properties over ocean using the MODIS/EOS spectral radiances, J. Geophys. Res., 102, $16,971-16,988$

Tegen, I., and I. Fung (1994), Modeling of mineral dust in the atmosphere: Sources, transport, and optical thickness, J. Geophys. Res., 99, 22,89722,914 .

Tegen, I., and A. A. Lacis (1996), Modeling of particle size distribution and its influence on the radiative properties of mineral dust aerosol, J. Geophys. Res., 101, 19,237-19,244.

Tegen, I., P. Hollrig, M. Chin, I. Fung, D. Jacob, and J. E. Penner (1997), Contribution of different aerosol species to the global aerosol extinction optical thickness: Estimates from model results, J. Geophys. Res., 102, $23,895-23,916$
Tegen, I., S. P. Harrison, K. Kohfeld, I. C. Prentice, M. Coe, and M. Heimann (2002), Impact of vegetation and preferential source areas on global dust aerosol: Results from a model study, J. Geophys. Res., 107(D21), 4576, doi:10.1029/2001JD000963.

Textor, C., et al. (2006), Analysis and quantification of the diversities of aerosol life cycles within AeroCom, Atmos. Chem. Phys., 6, 1777-1813. Timmreck, C., and M. Schulz (2004), Significant dust simulation differences in nudged and climatological operation mode of the AGCM ECHAM, J. Geophys. Res., 109, D13202, doi:10.1029/2003JD004381.

Twomey, S. A. (1977), Atmospheric Aerosols, Elsevier, New York.

Twomey, S. A. (1991), Aerosols, clouds and radiation, Atmos. Environ, Part A, 25, 2435-2442.

Walcek, C. J., R. A. Brost, J. S. Chang, and M. L. Wesely (1986), $\mathrm{SO}_{2}$, sulfate, and $\mathrm{HNO}_{3}$ deposition velocities computed using regional landuse and meteorological data, Atmos. Environ., 20, 949-964.

Walton, J. J., M. C. MacCracken, and S. J. Ghan (1988), A global-scale Lagrangian trace species model of transport, transformation, and removal processes, J. Geophys. Res., 93, 8339-8354.

Wang, C. (2004), A modeling study on the climate impacts of black carbon aerosols, J. Geophys. Res., 109, D03106, doi:10.1029/2003JD004084.

Wang, Y., and D. J. Jacob (1998), Anthropogenic forcing on tropospheric ozone and $\mathrm{OH}$ since preindustrial times, J. Geophys. Res., 103, 31,12331,135 .

Wanninkhof, R. (1992), Relationship between wind speed and gas exchange over the ocean, J. Geophys. Res., 97, 7373-7382.

Weng, F., and N. C. Grody (1994), Retrieval of cloud liquid water using the special sensor microwave imager (SSM/I), J. Geophys. Res., 99, 25,53525,551 .

Werner, M., I. Tegen, S. P. Harrison, K. E. Kohfeld, I. C. Prentice, Y. Balkanski, H. Rodhe, and C. Roelandt (2002), Seasonal and interannual variability of the mineral dust cycle under present and glacial climate conditions, J. Geophys. Res., 107(D24), 4744, doi:10.1029/ 2002JD002365.

Wesely, M. L. (1989), Parameterization of surface resistances to gaseous dry deposition in regional-scale numerical models, Atmos. Environ., 23, $1293-1304$

Wolff, E. W., and H. Cachier (1998), Concentrations and seasonal cycle of black carbon in aerosol at a coastal Antarctic station, J. Geophys. Res., 103, 11,033-11,042.

Xu, K. M., and S. K. Krueger (1991), Evaluation of cloudiness parameterizations using a cumulus ensemble model, Mon. Weather Rev., 119, 342367.

Yu, H., et al. (2006), A review of measurement-based assessments of the aerosol direct radiative effect and forcing, Atmos. Chem. Phys., 6, 613666.

Zender, C. S., H. Bian, and D. Newman (2003), Mineral Dust Entrainment and Deposition (DEAD) model: Description and 1990s dust climatology, J. Geophys. Res., 108(D14), 4416, doi:10.1029/2002JD002775.

Zhang, G. J., and N. A. McFarlane (1995), Sensitivity of climate simulations to the parameterization of cumulus convection in the Canadian Climate Centre general circulation model, Atmos. Ocean., 33, 407-446.

Zhang, L., S. L. Gong, J. Padro, and L. Barrie (2001), A size-segregated particle dry deposition scheme for an atmospheric aerosol module, Atmos. Environ., 35, 549-560.

Zhang, S. Y., J. E. Penner, and O. Torres (2005), Inverse modeling of biomass burning emissions using Total Ozone Mapping Spectrometer aerosol index for 1997, J. Geophys. Res., 110, D21306, doi:10.1029/ 2004JD005738.

D. Bergmann, Lawrence Livermore National Laboratory, 7000 East Avenue, Livermore, CA 94550, USA.

B. Das and S. Strahan, Goddard Earth Science and Technology Center (GEST), University of Maryland Baltimore County, NASA Goddard Space Flight Center, Code 613.3, Greenbelt, MD 20771, USA.

Y. Feng, Scripps Institution of Oceanography, University of California, San Diego, 9500 Gilman Drive, La Jolla, CA 92093, USA.

X. Liu, Atmospheric Science and Global Change Division, Pacific Northwest National Laboratory, 3200 Q Avenue, MSIN K9-24, Richland, WA 99352, USA. (xiaohong.liu@pnl.gov)

J. E. Penner and M. Wang, Department of Atmospheric, Oceanic and Space Sciences, University of Michigan, Ann Arbor, MI 48109, USA

J. M. Rodriguez, NASA Goddard Space Flight Center, Greenbelt, MD 20771, USA. 